Perez et al. Resubmission

\title{
A novel, ataxic mouse model of Ataxia Telangiectasia caused by a clinically relevant nonsense mutation
}

Perez, Harvey ${ }^{¥ 1}$; Abdallah, May, F. ${ }^{¥ 1}$; Chavira, Jose, I. ${ }^{¥ 1}$; Egeland, Martin, T. ' ; Vo, Karen, L. ${ }^{1}$;

Buechsenschuetz, Callan, L. '; Sanghez, Valentina ${ }^{1}$; Kim, Jeannie, L. ' ; Pind, Molly ${ }^{2}$, Nakamura, Kotoka $^{3}$, Hicks, Geoffrey, G. ${ }^{2}$; Gatti, Richard, A. ${ }^{3}$; Madrenas, Joaquin ${ }^{1,5}$; lacovino, Michelina ${ }^{1,4}$; McKinnon, Peter, J. ${ }^{6}$; Mathews, Paul, J. *1,7

1. The Lundquist Institute for Biomedical Innovation, Harbor-UCLA Medical Center, Torrance, CA

2. Department of Biochemistry \& Medical Genetics, Max Rady College of Medicine, University of Manitoba

3. Department of Pathology \& Laboratory Medicine, David Geffen School of Medicine, University of California, Los Angeles, CA

4. Department of Pediatrics, Harbor-UCLA Medical Center, Torrance, CA

5. Department of Medicine, Harbor-UCLA Medical Center, Torrance, CA

6. Center for Pediatric Neurological Disease Research, St. Jude Translational Neuroscience, St. Jude Children's Research Hospital, Memphis, TN, USA

7. Department of Neurology, Harbor-UCLA Medical Center, Torrance, CA

${ }^{¥}$ Contributed equally

${ }^{*}$ Corresponding Author

\section{Abstract}

Ataxia Telangiectasia (A-T) and ataxia with ocular apraxia type 1 (AOA1) are devastating neurological disorders caused by null mutations in the genome stability genes, A-T mutated (ATM) and aprataxin $(A P T X)$, respectively. Our mechanistic understanding and therapeutic repertoire for treating these disorders is severely lacking, in large part due to the failure of prior animal models with similar null mutations recapitulating the characteristic loss of motor coordination (i.e., ataxia) and associated cerebellar defects. By increasing genotoxic stress, through the insertion of null mutations in both the Atm (nonsense) and Aptx (knockout) genes in the same animal, we have generated a novel mouse model that for the first time progressively develops a severe ataxic phenotype associated with atrophy of the cerebellar molecular layer. We find biophysical properties of cerebellar Purkinje neurons are significantly perturbed (e.g., reduced membrane capacitance, lower action potential thresholds, etc.), while properties of synaptic inputs remain largely unchanged. These perturbations significantly alter 
Perez et al. Resubmission

31 Purkinje neuron neural activity, including a progressive reduction in spontaneous action potential firing

32 frequency that correlates with both cerebellar atrophy and ataxia over the animal's first year of life.

33 Double mutant mice also exhibit a high predisposition to developing cancer (thymomas) and immune

34 abnormalities (impaired early thymocyte development and T-cell maturation), symptoms characteristic

35 of the disorder A-T. Lastly, by inserting a clinically relevant nonsense type null mutation in Atm, we

36 demonstrate that small molecule readthrough (SMRT) compounds can restore ATM production,

37 indicating their potential as a future A-T therapeutic.

38

\subsection{Introduction}

Ataxia Telangiectasia $(A-T)$ is a rare $(1$ in $~ 100,000)$ (Swift et al. 1986), autosomal recessive genetic disorder characterized by cancer predisposition, immune deficiency, and a highly penetrant progressive and severe ataxia linked to cerebellar atrophy (Rothblum-Oviatt et al. 2016; Boder and Sedgwick 1958; Levy and Lang 2018). A-T patients typically die in their second and third decade of life (Crawford et al. 2006) from lymphatic cancers, respiratory infections, or debilitating ataxia—unfortunately, survivability has not dramatically changed since the 1950s (Micol et al. 2011; Rothblum-Oviatt et al. 2016). While disease progression and cause of death vary widely across patients, the highly penetrant progressive decline in motor coordination is reported as having the greatest negative impact on a patient's quality of life (Jackson et al. 2016). Care is generally palliative, directed at reducing, limiting, or eliminating cancers or infections. No long-term therapies are available for treating the ataxia and associated cerebellar dysfunction and atrophy.

A-T is caused by deficiency or dysfunction of the ATM (A-T mutated) protein (Savitsky et al. 1995). Premature termination codon (PTC) causing nonsense mutations account for up to a half of known cases with missense and deletions also contributing (Concannon and Gatti 1997; Sandoval et al. 1999). ATM is a serine/threonine PIKK family kinase that plays a key role in the DNA damage response (DDR), protecting cells from the tens of thousands of DNA lesions incurred each day (Lindahl and Barnes 2000; Kastan and Bartek 2004; Shiloh and Ziv 2013). In the active monomeric form, ATM phosphorylates several key proteins halting the production of new DNA (cell cycle arrest) (Ando et al. 
Perez et al. Resubmission

57 2012), and then, depending on severity of the damage, initiating DNA repair or programmed cell death

58 (i.e., apoptosis) (Ando et al. 2012; Rashi-Elkeles et al. 2006). Several downstream DDR pathway

59 targets of ATM have been identified, including p53, CHK2, BRCA1, SMC1, and NBS1 (Matsuoka et al.

60 2007). ATM's role in DNA repair is also implicated in normal immune system development, where it is

61 proposed to contribute to the recombination of natural DNA splicing that occurs during gene

62 rearrangement in T- and B-lymphocyte maturation (Chao, Yang, and Xu 2000; Matei, Guidos, and

63 Danska 2006; Vacchio et al. 2007; Schubert, Reichenbach, and Zielen 2002). Although its roles are still

64 emerging, ATM has also been implicated in oxidative stress homeostasis (Guo et al. 2010) and

65 mitophagy (Valentin-Vega and Kastan 2012; Pizzamiglio, Focchi, and Antonucci 2020).

66 A mechanistic understanding of why ATM deficiency causes ataxia is still under debate, but it is far

67 from the only DDR protein linked to ataxia, as aprataxin (APTX) (Aicardi et al. 1988), meiotic

68 recombination 11 homolog 1 (MRE11) (Sedghi et al. 2018), nibrin (NBS1) (van der Burgt et al. 1996),

69 senataxin (SETX) (Moreira et al. 2004), and tyrosyl-DNA phosphodiesterase 1 (TDP1) (Takashima et

70 al. 2002) when absent or dysfunctional can cause cerebellar-related ataxia. This suggests that the

71 neurological features of genome instability syndromes have a common underlying cause, although this

72 idea is still to be mechanistically demonstrated (McKinnon 2009; Rass, Ahel, and West 2007).

73 A major factor limiting our ability to define why loss of DDR proteins, like ATM, selectively impacts the

74 cerebellum and causes progressive ataxia is the lack of an animal model that recapitulates these

75 neurological symptoms (Lavin 2013). Several A-T rodent models have been created over the past

76 several years by inserting gene mutations that cause protein dysfunction (lack kinase activity) or

77 complete deficiency (Herzog et al. 1998; Xu and Baltimore 1996; Elson et al. 1996; Spring et al. 2001;

78 Campbell et al. 2015; Quek et al. 2016; Tal et al. 2018; Lavin 2013); a minipig was also recently

79 reported (Beraldi et al. 2017). Unfortunately, none acquire an overt, progressive ataxia with cerebellar

80 dysfunction and atrophy that recapitulates the human disease, even though other aspects of the

81 disorder like thyroid cancers, infertility, and immune abnormalities do develop. It remains unclear why

82 these prior animal models fail to display the progressive ataxic phenotype (Lavin 2013). It is possible 
Perez et al. Resubmission

83 that species specific molecular compensations in mice provide redundancies or alternative pathways

84 minimizing the effects of ATM deficiency in the brain (El-Brolosy and Stainier 2017). It is also possible

85 that the shortened lifespan of prior models (Barlow et al. 1996) is too brief for the stochastic

86 mechanisms driving cerebellar dysfunction and atrophy to accumulate and impact motor behavior.

87 Other challenges include potentially leaky genetic manipulations that result in low levels of ATM protein

88 or active fragments with residual kinase activity, thus limiting neuropathology (Li et al. 2011). The

89 impact of missing such a crucial animal model has been significant, severely limiting not only

90 experimental studies from identifying the cellular and molecular mechanisms but hampering pre-clinical

91 development and testing of much needed therapeutics.

92 We test here whether increasing genotoxic stress, by placing null mutations in not just the Atm gene,

93 but also the related Aptx gene, leads to a more representative mouse model that displays cerebellar

94 dysfunction, atrophy, and the development of progressive ataxia. We chose to additionally knock-out

95 Aptx because its deficiency causes an A-T like disorder in humans called ataxia with ocular apraxia

96 type 1 (AOA1), but without A-T's other system defects that could increase the potential for prenatal

97 lethality or early death (e.g., immunodeficiency and cancer predisposition) (Coutinho P 2002).

98 Moreover, APTX is a phosphodiesterase involved in DNA reassembly after double and single stranded

99 repair, having a function downstream of, but not directly regulated or related to ATM (Gueven et al.

100 2004; Schellenberg, Tumbale, and Williams 2015; Ahel et al. 2006). We therefore reasoned that

101 deficiency of both proteins would have an additive effect on genotoxic stress capable of inducing a

102 detectable neurological dysfunction. Our results indeed demonstrate that mice deficient in ATM and

103 APTX develop cerebellar dysfunction, atrophy, and a progressive and profound ataxia, while deficiency

104 in either protein alone do not. Additionally, double mutants acquired several additional characteristic

105 symptoms of A-T, including defects in immune maturation and a high incidence of cancer (thymomas),

106 making it the most representative model, from a phenotypic standpoint, to date.

107 Finally, to improve the clinical and translational relevance of this new mouse model, we inserted a point 108 mutation $(103 \mathrm{C}>\mathrm{T})$ in the Atm gene common to a large family North African A-T patients. This mutation 
Perez et al. Resubmission

109 results in a premature termination codon (PTC) at what would normally be amino acid 35 resulting in 110 loss of ATM production. As a result of this genotypic mutation, we were then able to conduct proof-of111 principle experiments demonstrating the ability of so-called PTC readthrough therapeutics to restore 112 production of the ATM protein. This includes the Small Molecule Readthrough (SMRT) compound, 113 GJ103 we are currently developing (Du et al. 2013).

\subsection{Results}

\subsection{Creation of a new A-T mutant mouse model expressing a clinically relevant nonsense} mutation

117 To create a more clinically relevant mouse model of A-T we used a gateway recombination cloning and 118 site-directed mutagenesis method to recapitulate a c.103C>T (p.R35X) mutation in the ATM gene 119 found in a large population of North African A-T patients (Fig. 1A and Methods) (Gilad et al. 1996). 120 The insertion of thymine in place of cytosine at this site in exon 3 results in a premature termination 121 codon (PTC) causing nonsense mutation in the ATM gene. Since the c.103C>T mutation results in different PTCs in the human compared to the mouse Atm gene, TGA vs. TAG respectively, we created two different mice by exchanging the mouse Atm exon 3 with either a human or mouse exon 3 variant with the c.103C>T mutation (Fig. 1B). In the human variant, a 103C>T mutation of the mouse codon, where the arginine $(R)$ encoding codon (CGA) becomes a TGA stop codon, results in a mouse we denote as Atm $^{R 35 X}$ (officially $A_{t m}^{T m 1.1(103 C A G) T G A) M f g c}$ ). In the mouse variant, the $\mathrm{c.103C}>\mathrm{T}$ mutation transforms a glutamine $(\mathrm{Q})$ encoding CAG codon into a TAG stop codon and is denoted Atm $^{\text {Q35X }}$ (officially Atm $^{T m 1.1(103 C) T \text { Mfgq }}$ ). The presence of the PTC results in a loss of ATM expression, either reduced by about half in the heterozygote expressing one normal mouse copy of the Atm gene $\left(A t m^{R 35 X /+}\right.$ or $\left.A t m^{Q 35 X /+}\right)$, or completely in the homozygote $\left(A t m^{R 35 X / R 35 X}\right.$ or $\left.A^{2 t m^{Q 35 X / Q 35 X}}\right)($ Fig. 1C).

$A t m^{R 35 X / R 35 X} ; A^{-1-}$ mice were created by first crossing single mutant $A^{-m^{R 35 X / R 35 X}}$ (congenic on the

C57BL/6J background) and Aptx ${ }^{-/-}$(mixed C57BL/6J and 129 background) mice to generate double mutant heterozygote $\mathrm{Atm}^{R 35 \mathrm{X}+}$; $\mathrm{Aptx}^{+/-}$mice. F1-5 littermate $\mathrm{Atm}^{R 35 \mathrm{X} /+^{*}} ; \mathrm{Aptx}^{+/-}$mice were then crossed within litters to create sufficient numbers of the desired experimental and control genotypes to 
Perez et al. Resubmission

determine how loss of different amounts of ATM and APTX affect the animal's phenotype (Fig. 1D).

Like prior ATM deficient A-T mouse models, ATM or APTX deficiency alone did not result in mice with

137 ataxia (Video 1 and 2). However, deficiency in both proteins (Atm ${ }^{\left.R 35 X / R 35 X ; A p t x^{-/}\right)}$results in the 138 development of a severe and progressively ataxic phenotype (Fig. 1E, Video 3 and 4).

\subsection{ATM deficient mice have lowered survivability and a high incidence of thymomas}

We assessed the general health and development of control and experimental mice expressing different levels of ATM and APTX (Fig. 2). We found that Atm ${ }^{\text {R35X/R35X }}$; Aptx ${ }^{-/}$mice grew $\sim 55 \%$ slower and reached estimated plateau weights that were $\sim 35 \%$ less than control genotypes (log-rank, $\mathrm{n}=21$ to weight differences were detected just after birth (P8) across all genotypes (1-way ANOVA, $\mathrm{n}=5$ to 23 , $\mathrm{p}>0.23$ ). Adolescent double mutant mice at postnatal day 45 (P45) weighed on average $30 \%$ less in males double mutant: $14.4 \pm 1.0 \mathrm{~g}(\mathrm{n}=13)$ vs. wildtype: $20.2 \pm 0.5 \mathrm{~g}(\mathrm{n}=16), t$-test, $\mathrm{p}<0.0001]$ and $25 \%$

less in females [double mutant: $12.7 \pm 0.6 \mathrm{~g}(\mathrm{n}=17)$ vs. wildtype: $17.0 \pm 0.2 \mathrm{~g}(\mathrm{n}=15), t$-test, $\mathrm{p}<0.0001$;

Fig. 1A]. Differences across the control genotypes were observed, but they were small and not consistent across time points or sex and therefore judged to not be physiologically relevant (Fig. 2A).

Survivability of the Atm ${ }^{R 35 X / R 35 X} ; A p t x^{--}$mice was significantly reduced compared to $A_{t m^{+/+}}$Aptx ${ }^{+/+}$mice, with $53 \%$ of mice still alive at 400 days of age, compared to $97 \%$ of $\mathrm{Atm}^{+/+} ; \mathrm{Aptr}^{+/+}$mice at the same time point (Fig. 2B). ATM deficiency alone was sufficient to reduce survivability, as compared to $\mathrm{Atm}^{+/+t}$; $A p t X^{+/+}$mice, both $A t m^{R 35 X / R 35 X} ; A p t x^{+/+}$and $A t m^{R 35 X / R 35 X} ; A p t x^{+/-}$mice had significantly reduced survivability rates $\left[42 \%\right.$, log-rank, $\chi_{(1,56)}^{2}=13.49, \mathrm{p}=0.0002$ and $52 \%$, log-rank, $\chi_{(1,53)}^{2}=19.54, \mathrm{p}<0.0001$, respectively]. No significant difference between ATM deficient mice with partial or complete APTX deficiency was detected [log-rank, $\left.\chi_{(2,85)}^{2}=1.01, \mathrm{p}=0.6\right]$. Conversely, mice harboring at least one functional copy of the Atm gene had normal survivability rates, regardless of whether they expressed APTX or not [log-rank, $\left.\chi_{(3,131)}^{2}=3.08, \mathrm{p}=0.4\right]$. No significant difference between male and female mice was observed and thus data were pooled [log-rank, p>0.4 for all pairwise comparisons; Fig. 2-fig. S1B]. Generally, a third of mice with ATM deficiency died from complications related to large thymic cancers 
Perez et al. Resubmission

161 (thymoma) found in the thoracic cavity (Fig. 2C). The presence or absence of APTX did not impact 162 cancer prevalence, and mice with at least one Atm transcript were cancer free up until at least P400. 163 Overall, ATM, but not APTX deficiency had severe effects on the health and survivability of mice.

\subsection{Both ATM and APTX deficiency are necessary to produce progressive motor dysfunction}

165 The progressive development of severe ataxia is a hallmark characteristic of A-T that is recapitulated in 166 the Atm ${ }^{\text {R3X/R35X }} ;$ Aptx ${ }^{-/}$mice but none of the other control genotypes we tested. Overall, we find motor coordination deficits emerge between 210 and 400 days after birth in Atm $^{R 35 X / R 35 X}$; Aptx ${ }^{-/-}$mice and find no evidence of ataxia in mice with at least one copy of the Atm or Aptx gene (Fig. 3A, B). For the vertical pole test, Atm $^{R 35 X / R 35 X} ;$ Aptx ${ }^{-/-}$mice took twice as long to descend at P400 compared to Atm $^{+/}$;

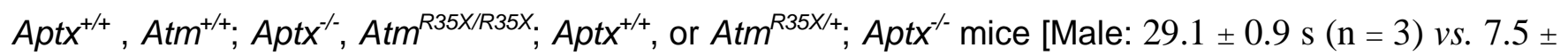
$0.4 \mathrm{~s}(\mathrm{n}=12), 12.5 \pm 2.5 \mathrm{~s}(\mathrm{n}=9), 9.2 \pm 0.9 \mathrm{~s}(\mathrm{n}=10), 8.6 \pm 0.9 \mathrm{~s}(\mathrm{n}=11), 1$-way ANOVA, $\mathrm{F}_{(4,40)}=19.9$ $\mathrm{p}<0.0001$; Female: $19.0 \pm 4.0 \mathrm{~s}(\mathrm{n}=4)$ vs. $7.5 \pm 0.4 \mathrm{~s}(\mathrm{n}=12), 7.8 \pm 0.4 \mathrm{~s}(\mathrm{n}=10), 10.5 \pm 1.2 \mathrm{~s}(\mathrm{n}=6)$, $8.2 \pm 0.5 \mathrm{~s}(\mathrm{n}=8), 1$-way ANOVA, $\left.\mathrm{F}_{(4,35)}=13.9, \mathrm{p}<0.0001\right]$. An examination of gait indicated that Atm ${ }^{\text {R35X/R35X }} ;$ Aptx/- mice at P400, but not P210 need additional stabilization during ambulation, as they spend twice as much time with 3 paws, rather than the normal 2 in contact with the ground as they walk across the gait analysis platform [Male: 56.2 vs. 26.4 to $32.2 \%$, 1-way ANOVA, $\mathrm{F}_{(4,54)}=14.3$, p<0.0001;

Female: 58.4 vs. 18.9 to $28.8 \%$, 1-way ANOVA, $\mathrm{F}_{(3,178)}=95.5, \mathrm{p}<0.0001$; Fig. 3B]. Atm ${ }^{\text {R35x/R35X }}$; Aptx also display a slower cadence and average speed across the platform compared to all other genotypes at P400 [cadence, Male: 9.5 vs. 13.3 to 15.9 steps/s, 1-way ANOVA, $\mathrm{F}_{(3,204)}=36.8, \mathrm{p}<0.0001$; Female:

9.1 vs. 14.2 to 15.9 steps/s, 1 -way ANOVA, $\mathrm{F}_{(3,204)}=39.7, \mathrm{p}<0.0001$; speed, Male: 8.8 vs. 22 to $26 \mathrm{~cm} / \mathrm{s}$, 1-way ANOVA, $\mathrm{F}_{(4,50)}=28.3$, p<0.0001; Female: 58.4 vs. 18.9 to $28.8 \mathrm{~cm} / \mathrm{s}, 1$-way ANOVA, $\mathrm{F}_{(3,178)}=$ 39.7, p<0.0001; Fig. 3B; Fig. 3-fig. S1]. This difference in speed and cadence is unlikely due to animal size, as there are no significant differences in these parameters at earlier time points when the difference in size is significant (Fig. 2A). These observations across the two behavioral tests were found in both male and female mice at each of their respective time points, consistent with the lack of sex differences observed in A-T patients. 
Perez et al. Resubmission

187 We further examined behavioral differences between the Atm $^{\text {R35X/R35X; }}$ Aptx ${ }^{-/}$and Atm $^{+/+} ;$Aptx $^{+/+}$mice $^{2}$ 188 using a standardized set of experimental procedures used to phenotype genetically modified mice (i.e., 189 SHIRPA; Fig. 3C; Fig. 3-fig. S1) (Rogers et al. 1997). We first detected differences in motor function at 190 P8, where Atm ${ }^{R 35 X / R 35 X} ; A p t x^{-/}$mice took 3-4 times longer on average to right themselves compared to $191 \mathrm{Atm}^{+/+} ;$Aptx $^{+/+}$mice [Male: $6.4 \pm 1.1 \mathrm{~s}(\mathrm{n}=24)$ vs. $1.5 \pm 0.1 \mathrm{~s}(\mathrm{n}=23), t$-test, $\mathrm{p}<0.0002$; Female: $11.1 \pm$ $1921.9 \mathrm{~s}(\mathrm{n}=21)$ vs. $2.4 \pm 0.3 \mathrm{~s}(\mathrm{n}=17)$, $t$-test, $\mathrm{p}<0.0002$; Fig. 3 C bottom]. At 30-days of age, we detected 193 significant differences between Atm $^{R 35 X / R 35 X} ; A p t x^{-/-}$and $A^{+m^{+/+}} ; A_{p t X^{+/+}}$mice in behavioral tests that 194 qualitatively measure body position and spontaneous activity (Fig. 3C). Striking differences in $195 A t$ At $^{R 5 X / R 35 X} ;$ Aptx $^{-/}$compared to $\mathrm{Atm}^{+/+} ; \mathrm{Aptx}^{+/+}$mice were observed at P400, especially for behaviors 196 related to movement, including locomotor activity, body position, and gait (Fig. 3C). The results from 197 this battery of tests demonstrates that $A t m^{R 35 X / R 35 X} ; A p t x^{-/}$mice develop a severe change in behavior by 198 P400, consistent with purely visual observations of significant motor coordination deficits in the mice up 199 to this time point. Importantly, we do not find any significant differences between the other control 200 genotypes, including $\mathrm{Atm}^{R 35 \mathrm{X}+} ; \mathrm{Aptx}^{-/-}$mice that express at least some ATM but no APTX protein (Fig. 201 3-fig. S1).

2.4 The membrane and synaptic properties are perturbed in ATM and APTX deficient neurons of the cerebellum

204 Purkinje neurons (PN) are a key neuronal subtype located in the cerebellar cortex. They display 205 considerable intrinsic excitability, firing action potentials spontaneously at rates significantly higher than 206 most other neurons in the brain (50 to $100 \mathrm{~Hz}$ more in many cases). Their activity shapes cerebellar 207 output via tonic inhibition of neurons of the cerebellar nuclei, which project to motor coordination 208 centers in the forebrain, brainstem, and spinal cord. Dysfunction of cerebellar PNs is associated with 209 several forms of ataxia and implicated in A-T (Hoxha et al. 2018; Cook, Fields, and Watt 2020; Shiloh 210 2020). We therefore examined if the electrophysiological properties of PNs in the Atm $^{R 35 X / R 35 X} ; A p t x^{-/-}$ 211 cerebellum were abnormal. 
Perez et al. Resubmission

212 Since PN baseline activity and responsivity to input is mediated by a baseline set of passive and active 213 membrane properties (Fig. 4), we directly recorded from and compared the membrane properties of $214 \mathrm{PNs}$ in acute cerebellar slices harvested from $\mathrm{Atm}^{\mathrm{R35X/R35X}} ; \mathrm{Aptx}^{-/-}$and $\mathrm{Atm}^{+/+} ; \mathrm{Aptx}^{+/+}$mice (P350 to 215 400). PNs recorded from $A t m^{R 35 X / R 35 X} ; A p t x^{-/}$mice had significantly "tighter" membranes, displaying 216 higher membrane input resistances $\left(\mathrm{R}_{\mathrm{m}}\right)$ than those from Atm $^{+/+} ; A p t x^{+/+}$mice $[47.7 \pm 5.6(\mathrm{n}=15) \mathrm{vs}$. $21730.2 \pm 1.47(\mathrm{n}=23) \mathrm{M} \Omega, t$-test, $\mathrm{p}=0.008 ;$ Fig. 4B]. They also displayed a faster membrane time 218 constant $(\tau)[3.6 \pm 0.4(\mathrm{n}=15)$ vs. $5.1 \pm 0.3(\mathrm{n}=23) \mathrm{ms}$, $\mathrm{t}$-test, $\mathrm{p}=0.009 ; \mathbf{F i g} .4 \mathrm{~B}]$. These results indicate 219 that the total membrane capacitance $\left(\mathrm{C}_{\mathrm{m}}=\tau / \mathrm{R}_{\mathrm{m}}\right)$ of the $A t m^{R 35 X / R 35 X} ; A p t x^{-/} \mathrm{PNs}$ is significantly reduced $[98.25 \pm 19.23(\mathrm{n}=15)$ vs. $175.6 \pm 12.67(\mathrm{n}=23) \mathrm{pF}$, $t$-test, $\mathrm{p}=0.0025$; Fig. 4B]. At the cellular level, this suggests that the ATM and APTX deficient PNs have less (i.e., smaller in size) or thinner membranes than that of wildtype PNs; a result suggestive of a developmental deficit or neurodegenerative process (Dell'Orco et al. 2015). We next assessed the intrinsic excitability of PNs in Atm ${ }^{R 35 X / R 35 X}$; Aptx $X^{-/}$and $\mathrm{Atm}^{+/+} ; \mathrm{Aptx}^{+/+}$mice by examining PN action potential (AP) generation and dynamics. Significant deficits in the ability of PNs to fire continuously in response to current injection were observed in Atm $^{\text {R35X/R35X; }}$ Apt ${ }^{-/}$mice (Fig. 4C). These deficits were associated with significant perturbations to the amplitude, threshold, and area of evoked action potentials [amplitude: $66.2 \pm 0.7(\mathrm{n}=14)$ vs. $72.1 \pm 1.4(\mathrm{n}=13)$ $\Delta \mathrm{mV}$, $t$-test, $\mathrm{p}=0.003$; threshold: $-55.2 \pm 1.5$ vs. $-48.61 \pm 1.9 \mathrm{mV}, t$-test, $\mathrm{p}=0.0196$; area: $17.96 \pm 0.6$ vs. $20.63 \pm 1.0 \mathrm{mV}^{*} \mathrm{~ms}$, $t$-test, $\mathrm{p}=0.048$; Fig. 4C]. Together, these experiments demonstrate significant perturbations of PN physiological properties that likely perturb their ability to function normally in the cerebellum of $A t m^{R 35 X / R 35 X} ; A p t X^{-/}$mice.

We next tested whether extrinsic and/or synaptic PN properties were also impacted in Atm $^{\text {R35X/R35X; }}$ $A p t x^{-/}$mice. We first examined spontaneous mini excitatory post synaptic currents (mEPSC) generated by granule cell-to-PN synapses (i.e., parallel fiber inputs). No difference in mEPSC size was detected, indicating the function of granule cell axon terminals (i.e. parallel fibers) was relatively normal in the Atm $^{\text {R35X/R35X }} ;$ Aptx ${ }^{-/-}$cerebellum [18.92 $\pm 1.3(\mathrm{n}=11)$ vs. $23.4 \pm 3.3(\mathrm{n}=11)$ pA, $t$-test, $\mathrm{p}=0.477 ;$ Fig. 4D] 
Perez et al. Resubmission

increased, a phenomenon that could be attributed to either an increase in the total number of synapses,

an increase in the size of the readily releasable pool of synaptic vesicles, or an increase in the probability of neurotransmitter release in PNs of $A_{t m}^{R 35 X / R 35 X} ; A p t x^{-/-}$mice $[18.75 \pm 2.8 \mathrm{~Hz}(\mathrm{n}=11) v s$.

$241 \quad 11.4 \pm 1.0 \mathrm{~Hz}(\mathrm{n}=11), t$-test, $\mathrm{p}=0.047$; Fig. 4D]. We next explored evoked synaptic release and short242 term plasticity by simultaneously recording from PNs and electrically stimulating either granule cell (i.e., 243 parallel fibers) or inferior olivary (i.e., climbing fiber) axons with a paired-pulse burst (2-pulses, $50 \mathrm{~ms}$ 244 apart). The synaptic properties of parallel fibers were found to be normal, displaying no significant 245 differences in the expected short-term facilitation (Atluri and Regehr 1996) or halfwidth and decay time 246 constant of the evoked EPSC [PPR: $1.3 \pm 0.03(\mathrm{n}=10) v s .1 .4 \pm 0.05(\mathrm{n}=13), t$-test, $\mathrm{p}=0.162$; halfwidth: $2473.9 \pm 0.6 v s .4 .9 \pm 0.4 \mathrm{~ms}, t$-test, $\mathrm{p}=0.175 ;$ time constant: $3.5 \pm 0.5$ vs. $4.7 \pm 0.4 \mathrm{~ms}, t$-test, $\mathrm{p}=0.054 ;$ Fig 248 4E]. In comparison, we found climbing fiber-to-PN synaptic responses, which normally displays pair249 pulse depression (Hansel and Linden 2000), to depress at significantly greater magnitudes in Atm ${ }^{R 35 X / R 35 X} ;$ Aptx ${ }^{-/-}$mice [PPR: $0.6 \pm 0.03(\mathrm{n}=6)$ vs. $0.7 \pm 0.02(\mathrm{n}=9), t$-test, $\mathrm{p}=0.03$; Fig. 4F]. The overall width and decay time constant of the evoked currents were also smaller [halfwidth: $2.3 \pm 0.6$ ( $\mathrm{n}=$ 6) vs. $3.0 \pm 0.2(\mathrm{n}=9) \mathrm{ms}, t$-test, $\mathrm{p}=0.004$; time constant (fast): $1.1 \pm 0.14$ vs. $2.9 \pm 0.4 \mathrm{~ms}$, t-test, $\mathrm{p}=0.001]$. While these results could be caused by a presynaptic deficit, such as reduced vesicle stores in the climbing fiber axon terminal, the fact that the initial magnitude of the EPSC is unaffected $[23.5 \pm$ $3.6(\mathrm{n}=6) v s .19 .1 \pm 1.9(\mathrm{n}=9), t$-test, $\mathrm{p}=0.3]$, points to a more intrinsic deficit, such as a reduced $\mathrm{Ca}^{2+}$ influx from the endoplasmic reticulum, which could significantly impact long term synaptic plasticity critical to cerebellar function (Hoxha et al. 2018; Kano and Watanabe 2017). Overall, the perturbations we observed here to the passive and active PN properties likely give rise to significant cerebellar dysfunction in the Atm ${ }^{R 35 X / R 35 X} ;$ Aptx $x^{-/}$mice.

2.5 ATM and APTX deficiency causes a progressive perturbation of PN neural activity that is associated with dendritic shrinking and overall cerebellar atrophy.

Decreased rates of spontaneous PN action potential firing, which can be indicative of PN dysfunction, have been observed in several mouse models of ataxia, including spinocerebellar ataxia (SCA) 2, 3, 5, 
Perez et al. Resubmission

264 6, 13, 27, several models of episodic ataxia (e.g., leaner, ducky, and tottering), and autosomal265 recessive spastic ataxia of the Charlevoix-Saguenay ((Hourez et al. 2011; Hansen et al. 2013; 266 Dell'Orco, Pulst, and Shakkottai 2017; Kasumu and Bezprozvanny 2012; Liu et al. 2009; Perkins et al. 267 2010; Shakkottai et al. 2011a; Jayabal et al. 2016; Stoyas et al. 2020; Hurlock, McMahon, and Joho 268 2008; Shakkottai et al. 2009; Bosch et al. 2015; Walter et al. 2006; Alviña and Khodakhah 2010; Ady et 269 al. 2018; Larivière et al. 2019; Cook, Fields, and Watt 2020). We therefore used this biomarker to 270 characterize the progression of PN perturbation in Atm ${ }^{R 35 X / R 35 X} ;$ Aptx $^{-/}$mice and assess whether deficits 271 were restricted to ATM and APTX deficient mice, consistent with the behavioral results (Fig. 2,3). We 272 additionally examined whether decreased PN activity differed across the cerebellum, as anecdotal 273 clinical pathology reports suggest degeneration may occur asymmetrically across the cerebellum, with 274 the anterior and posterior vermis and middle cerebellar hemispheres affected the most, although no 275 systematic analysis has been performed and the consistency of results across patients is highly 276 variable (Verhagen et al. 2012; De Leon, Grover, and Huff 1976; Amromin, Boder, and Teplitz 1979; 277 Monaco et al. 1988; Terplan and Krauss 1969; Strich 1966; Solitare 1968; Solitare and Lopez 1967; 278 Aguilar et al. 1968a; Paula-Barbosa et al. 1983).

279 Using extracellular recording methods in the acute slice, we recorded spontaneous action potentials

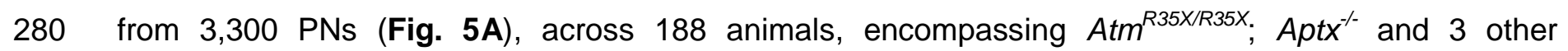
281 genotypes at 4 different time points (P45, 120, 210, and 400). We visually selected "healthy" cells (see 282 Methods), deeper in the slice, that consistently fired during the extent of the 60 second recording 283 period. Qualitatively, tissue and cell quality did not visually differ across genotypes under DIC 284 microscopy. Cells were sampled in a distributed fashion across the lateral, intermediate, and medial 285 (vermis) cerebellum of each mouse to assess whether changes in PN firing activity was ubiquitous or 286 anatomically restricted. Regions were segregated based on gross anatomical domains in the mouse 287 defined by natural anatomical boundaries (e.g., foliation) and their general connectivity with different 288 regions of the nervous system (e.g., forebrain, brainstem, etc.) (Voogd and Glickstein 1998). 
Perez et al. Resubmission

289 We found that complete deficiency of both ATM and APTX, consistent with the behavioral results, was 290 necessary to produce a significantly reduced spontaneous PN firing frequency (Fig. 5A, B). Although 291 the trend of slower PN firing rates was observed across most regions of the cerebellum, some 292 subregions appeared to be less or minimally impacted, including several areas of the lateral 293 cerebellum, including the paraflocculus, paramedian, and crus I and II (Fig. 5-fig. S1). Significant age 294 dependent changes in firing frequency were also only observed in Atm $^{R 35 X / R 35 X}$; Aptx ${ }^{-/-}$mice (Fig. 5B). 295 The most significant decline occurring between P120 and 210 [medial: $50.3 \pm 2.4 \mathrm{~Hz}(\mathrm{n}=61) v s .36 .9 \pm$ $2962.2 \mathrm{~Hz}(\mathrm{n}=31)$, $t$-test, $\mathrm{p}=0.0006]$. No significant difference in PN firing frequency was detected between 297 male and female mice within each genotype, thus the data were pooled (2-way ANOVA, p>0.3 across

298 all pairwise comparisons; Fig. 5-fig. S2). Previous studies across several mouse models of heritable 299 ataxia, including episodic ataxia and several variants of spinocerebellar ataxia find that physiological 300 disruption in PN firing not only changes its frequency, but also its regularity (Kasumu and 301 Bezprozvanny 2012; Jayabal et al. 2016; Stoyas et al. 2020; Cook, Fields, and Watt 2020). We 302 compared both the coefficient of variation (CV) and variability in adjacent intervals (CV2) between 303 Atm ${ }^{R 35 X / R 35 X} ;$ Aptx ${ }^{-/-}$and control mice (Fig. 5-figs. S3, S4). No difference in these parameters across 304 sex, age, or genotype was detected. Consistent with the behavioral results, cerebellar dysfunction was 305 found only in the $A t m^{R 35 X / R 35 X} ; A p t x^{-/-}$mice that developed ataxia and not in mice with at least some 306 expression of ATM or APTX.

\subsection{ATM and APTX deficiency induces cerebellar atrophy}

308 Ataxia in A-T patients is usually detected between 1 to 2-years of age and is associated with mild to no 309 cerebellar atrophy (Tavani et al. 2003; Taylor et al. 2015). Significant structural changes are usually 310 apparent via neuroimaging between 5 to 10-years of age (Demaerel, Kendall, and Kingsley 1992;

311 Tavani et al. 2003). Comprehensive characterization of the progression of cerebellar atrophy is 312 however severely lacking in large part due challenges in imaging young patients (<2-years) and the 313 rarity of the disorder. We therefore assessed the gross developmental progression of cerebellar size 314 and pathohistology in mice deficient in both ATM and APTX that progressively develop a severe ataxia 
Perez et al. Resubmission

315 and perturbations in cerebellar function. Structural changes in the overall size of the cerebellum were 316 examined in $A t m^{R 35 X / R 35 X} ;$ Aptx ${ }^{-/}$and several different control mice over 5 time points (P45, 120, 210, 317 400, 460; Fig. 5C). Cerebellar size was defined within each animal by the ratio of 2-dimensional 318 surface area of the dorsal cerebellum to the forebrain (i.e., cerebellum area divided by forebrain area).

319 The cerebellar size of control mice slightly increased during adolescence and early adulthood (P45320 P210), was generally stable through adulthood (P210-400), and then declined slightly in older age 321 (P400-460). In stark contrast, relative cerebellar size in Atm ${ }^{R 35 X / R 35 X} ;$ Aptx $^{-/}$mice progressively declined 322 after P120. No cerebellar atrophy was observed in mice with at least one copy of the Atm gene [i.e., 323 Atm ${ }^{R 35 X /+} ;$ Aptx $^{-/} ; 1$-way ANOVA, $\mathrm{F}_{(3,44)}=1.2, \mathrm{p}=0.32 ;$ Fig. 5C]. To rule out the possibility that reduced 324 cerebellar size was related to the smaller stature of $A_{t m}^{R 35 X / R 35 X} ; A p t x^{-/-}$mice, we examined, but did not 325 find a correlation between animal weight and actual cerebellar size [Pearson's correlation, $p>0.3$ for all 3264 genotypes at $\mathrm{P} 460, \mathrm{n}=10$ to 20 ]. Furthermore, we found that cerebellar size did not differ between male and the on average $22 \%$ smaller female mice across genotypes at this age [2-way ANOVA, $\mathrm{F}_{(2,}$ $153)=1.9, \mathrm{p}=0.2]$. Therefore, cerebellar neurodegeneration in the $\operatorname{Atm}^{R 35 X / R 35 X} ; A p t X^{-/}$mice, which begins after P120, is correlated with ATM and APTX deficiency.

In humans, cerebellar atrophy is associated with a variety of changes in the macro-structure of the cerebellar cortex and post mortem examination has identified abnormalities in the density and distribution of granule cells (GC) and PNs (Verhagen et al. 2012; De Leon, Grover, and Huff 1976; Amromin, Boder, and Teplitz 1979; Monaco et al. 1988; Terplan and Krauss 1969; Strich 1966; Solitare 1968; Solitare and Lopez 1967; Aguilar et al. 1968a; Paula-Barbosa et al. 1983; Gatti and Vinters 1985). In the Atm ${ }^{R 35 x / R 35 x} ; A p t x^{-/-}$mice we do not qualitatively observe severe pathological changes in the anatomy of their cerebellum (Fig. 5-fig. S5B). To then understand the anatomical basis of the gross atrophy, we measured the width of the cortical layer of the cerebellum that contains the massive dendritic arbors of PNs called the molecular layer (ML). Consistent with the temporal changes in gross cerebellar size, PN firing frequency, and behavior, ML width in Atm ${ }^{R 35 X / R 35 X} ; A^{-/-}$mice was reduced 
Perez et al. Resubmission

341 test, $\mathrm{p}=0.0004$; Fig. 5D]. In contrast, the width of the GC layer did not change with age or differ 342 significantly between Atm $^{R 35 X / R 35 X} ; A$ Apt ${ }^{-/-}$and $A t m^{+/+} ; A p t x^{+/+}$mice $[\mathrm{P} 400: 135.5 \pm 2.4 \mu \mathrm{m}(\mathrm{n}=6) \mathrm{vs}$.

$343127.5 \pm 4.3 \mu \mathrm{m}(\mathrm{n}=5)$, Sidak test, $\mathrm{p}=0.5$; Fig. 5D]. These results, along with the finding that PN density 344 did not significantly differ between Atm $^{\text {R35X/R35X }} ; A$ Aptx ${ }^{-/-}$and Atm $^{+/+} ; A p t x^{+/+}$mice $[\mathrm{P} 400: 3.9 \pm 0.3(\mathrm{n}=4)$ 345 vs. $4.4 \pm 0.3(\mathrm{n}=5) \mathrm{PNs} / 4000 \mu \mathrm{m}^{2}$, Welch's test, $\mathrm{p}=0.3$; Fig. 5-fig. S5B] indicate that cerebellar atrophy 346 is largely due to a reduction in the extent of PN dendrites. At the anatomical level, we were able to 347 qualitatively observe a few other PN abnormalities. This includes abnormally large diameter primary 348 dendrites and axonal swellings in the Atm ${ }^{R 35 X / R 35 X} ;$ Aptx $X^{-/}$mice (Fig. 5-fig. S5C). Overall, we find a good 349 correlation between the abnormal structural and electrophysiological properties and the progression of 350 motor behavioral deficits.

2.6 Differential disruption of thymocyte development in ATM-deficient vs. APTX-deficient mice

Chronic sinopulmonary infections associated with immunodeficiency are one of the leading causes of death in A-T patients (Morrell, Cromartie, and Swift 1986; Bhatt and Bush 2014). Immunodeficiency is linked to deficits in the generation of B- and T-lymphocytes that have been linked to defects in the antigen receptor gene rearrangement processes during the generation of these cells in bone marrow and thymus, respectively (Staples et al. 2008). The resulting defects in mature lymphocyte numbers include decreases in $\mathrm{CD}^{+}$helper T-cells and killer CD8 ${ }^{+}$T-cells (Schubert, Reichenbach, and Zielen 2002). We therefore examined the percentages of T-cells in peripheral blood and of different subpopulations in the thymus of Atm ${ }^{\mathrm{R} 35 \mathrm{X} / \mathrm{R} 35 \mathrm{X}} ; \mathrm{Aptx}^{-/-}$mice using T-cell antigen receptor (TCR) and CD4/CD8 co-receptor expression.

In the peripheral blood, we observed a significant reduction in the total fraction of $\mathrm{CD}^{+} \mathrm{T}$-cells in mice with reduced or absent ATM expression compared to wildtype mice (Fig. 6). This reduction was further compounded by concomitant deficiency of APTX. ATM and APTX deficiencies reduced T-cells in peripheral blood by over $65 \%$ decrease compared to wild type controls. The effect of APTX deficiency was additive to that of ATM deficiency suggesting a different mechanism of action for each of these two 
Perez et al. Resubmission

367 associated with reduction in the CD4+ helper T-cell population (Fig. 6B). Of interest, the proportion of 368 CD8+ T-cells was increased only in Atm ${ }^{\text {R35X/R35X; Aptx }}{ }^{-/-}$mice (Fig. 6B). Again, we observed a 369 differential effect of ATM and APTX deficiencies as seen for the effects of these mutations on the total 370 T-cell fraction.

371 Given the reduction in T-cell populations in the blood, we next assessed T-cell development in the 372 thymus. In this organ, bone marrow-derived T-cell progenitors undergo TCR gene rearrangement 373 followed by positive selection for MHC restriction and negative selection of autoreactive clones. The 374 phases of thymocyte development can be followed by monitoring expression of CD4 and CD8 375 expression in thymocytes. The progression of this developmental program goes from double negative 376 (CD4 $4^{-}$D8 $)$thymocytes, to double positive $\left(C D 4^{+} \mathrm{CD} 8^{+}\right)$thymocytes and then to single positive $\left(C D 4^{+}\right.$or $377 \mathrm{CD}^{+}$) thymocytes. In addition, within the double negative stage, four different subpopulations can be 378 identified, based on expression of CD25 and CD44, known as DN1 (CD44 CD25), DN2 $379\left(\mathrm{CD}_{4} 4^{+} \mathrm{CD} 25^{+}\right)$, DN3 (CD25+CD44) and DN4 (CD44-CD25) (Germain 2002).

380 Gene rearrangement during thymocyte development occurs twice, once at the double negative 381 thymocyte stage in the CD25 ${ }^{+}$CD44 stage (Krangel 2009) and then again in double positive thymocyte 382 stage before progressing into separate $\mathrm{CD} 4^{+}$and $\mathrm{CD} 8^{+}$single positive populations (Livák et al. 1999). 383 ATM deficiency has been linked to defects in both bouts of rearrangement in mice (Vachio 2007, 384 Hathcock 2013). Therefore, we compared the proportion of cells in the thymus expressing these 385 different developmental cell surface markers in our ATM deficient and control mice (Fig. 7). $386 A A^{R 35 X / R 35 X} ;$ Aptx $^{-/-}$and Atm $^{R 35 X /+} ;$ Aptx $^{-/}$, but not Atm $^{R 35 X / R 35 X} ;$ Aptx $^{+/+}$mice had significantly elevated 387 proportions of $\mathrm{CD}_{4} 4^{+} \mathrm{CD} 25^{-}, \mathrm{CD} 44^{+} \mathrm{CD} 25^{+}$, and $\mathrm{CD} 44^{-} \mathrm{CD} 25^{+}$cells compared to wildtype (Fig. 7A). 388 These increased proportions appear to be due in part to an impediment of CD44CD25 ${ }^{+}$cells maturing 389 into CD44 CD25 double negative cells, as the fraction of cells from Atm $^{R 35 X / R 35 X} ;$ Aptx $^{-/-}$and Atm $^{R 35 X /+}$; 390 Aptx ${ }^{-/}$mice is significantly lower than wildtype (Fig. 7A). Of interest, APTX deficiency by itself had the 391 greatest effect on the loss of DN4 cells suggesting that APTX deficiency, rather than ATM deficiency, is 
Perez et al. Resubmission

392 responsible for this effect. To our knowledge, this finding implicates for the first time APTX in gene 393 rearrangement during the process of TCR $\beta$ recombination.

394 Next, we looked at the proportions of $\mathrm{CD}^{+} \mathrm{CD} 8^{+}$thymocytes compared to $\mathrm{CD} 4^{+} \mathrm{CD} 8^{-}$and $\mathrm{CD}^{-} \mathrm{CD} 8^{+}$ 395 single positive thymocytes in these four different strains. In agreement with our results in the blood and 396 prior studies, we found that ATM-deficient mice but not control mice displayed decreased expression of $397 \mathrm{CD}^{+} \mathrm{CD}^{-}$and $\mathrm{CD} 4^{-} \mathrm{CD}^{+}$single positive thymocytes (Fig. 7B). These results support the role of ATM 398 in TCR $\alpha / \delta$ gene rearrangement during thymocyte development (Bredemeyer et al. 2006), a role that is 399 independent of the role played by APTX in early thymocyte maturation.

\subsection{Readthrough molecules overcome PTC to restore ATM expression}

401 Our primary rationale for inserting a clinically relevant nonsense mutation in the Atm gene was to 402 generate a mouse amenable to critical pre-clinical testing of a novel set of small molecule readthrough 403 (SMRT) compounds. We previously demonstrated SMRT compounds recover production of ATM 404 protein in A-T patient derived lymphoblastoid cell lines by overcoming premature termination codons 405 (PTC) caused by nonsense mutations (Du et al. 2013). To demonstrate suitability of this new A-T 406 animal model for SMRT compound testing we chose to directly examine their ability to restore ATM 407 expression using an explant approach that circumvents challenges related to in vivo delivery (e.g., 408 bioavailability, route of delivery, etc.). ATM expression was measured in samples from the spleen, 409 where ATM is normally expressed at high levels, and the cerebellum, a key target tissue for the 410 disorder. We exposed these explant tissues, harvested from homozygous $A_{t m}^{R 35 X}$ and $A^{2 t m^{Q 35 X}}$ mice 411 with either a candidate SMRT compound (GJ103), or an aminoglycoside previously known to have 412 readthrough properties (G418) for $72 \mathrm{hrs}$. and then measured ATM expression by immunoblot to 413 assess restoration. In both types of ATM deficient mice, ATM expression was consistently restored in 414 the spleen and cerebellum by both G418, GJ103 (Fig. 8). These results demonstrate that our SMRT 415 compounds can enable readthrough of at least 2 of the 3 possible nonsense mutation causing PTCs and provide the rationale for in vivo efficacy testing in follow-on studies. 
Perez et al. Resubmission

\section{$417 \quad 3.0$ Discussion}

418 By increasing genotoxic stress through the addition of a secondary hit to the DDR pathway, we 419 generated a novel mouse model that displays the most comprehensive set of A-T symptoms of any 420 model to date. This includes a severe and progressive ataxia associated with cerebellar atrophy and 421 perturbations of PN properties along with a high incidence of cancer and defects in immune cell 422 development. Together, these comorbidities encompass the three leading causes of premature death in 423 A-T - each contributing to roughly a third. Of these, the incapacitating effect of ataxia is the most 424 penetrant and is reported by patients and caregivers as having the greatest impact on their quality of 425 life. For this reason, the presence of ataxia and cerebellar atrophy in this new mouse model is of great 426 significance as it provides for the very first time a resource to not only elucidate the mechanisms of 427 neurological dysfunction, but also a critically needed in vivo model to test severely needed A-T therapeutics like the readthrough compounds we describe here.

429 We found several similarities between the overall progression of ataxia in the $A t m^{R 35 X / R 35 X} ; A p t x^{-/-}$mice 430 and A-T patients. In clinical A-T, motor deficits are observable by roughly 2-years of age, when parents 431 and doctors detect a lowered ability to transition from toddling to a smooth, reflexively coordinated 432 gate-unfortunately, little is known about motor defects at earlier stages due to the diseases low 433 prevalence and current lack of early diagnostic testing (Rothblum-Oviatt et al. 2016). Patients usually 434 learn to walk without assistance and neurological symptoms tend to remain stable through the first 4 to 4355 years of life (Rothblum-Oviatt et al. 2016). We found a similar early progression of motor deficits in $436 A A^{R 35 X / R 35 X} ; A p t x^{-/}$mice, detecting mild motor deficits early at P8 (righting reflex deficit), followed by a 437 period of relative stability, prior to onset of a progressive and severe ataxia developing after p210 that 438 included changes in gait, startle reflex, tremor, and locomotor activity. Several important questions arise 439 out of these findings, including whether ATM and/or APTX have a neurodevelopmental role in the 440 cerebellum. Future studies focused on the early phase of the disorder will be critical in understanding if 441 the cerebellum develops normally prior to dysfunction or whether developmental defects are an initial 442 cause. We also found, similar to A-T patients, that the severity of the late developing ataxia was 
Perez et al. Resubmission

443 variable with some mice ambulating with a clumsy, high stepping rear gate (Video 3) and others 444 moving almost entirely via contortion of the rear trunk (Fig. 1E and Video 4) (Rothblum-Oviatt et al. 445 2016; Levy and Lang 2018; Boder and Sedgwick 1958). Overall, we found that Atm $^{\text {R35X/R35X }}$; Aptx ${ }^{-/-}$mice 446 developed a visually profound and measurable progressive loss in motor coordination that was similar 447 to that observed in A-T patients and that was rescued by expression of at least one copy of the Atm or 448 Aptx gene.

449 The loss of motor coordination in A-T has been attributed to cerebellar degeneration due to its relatively 450 selective neuropathology across the brain and its causal role in several different forms of ataxia (Hoche 451 et al. 2012). Consistent with A-T patient neuroimaging studies (Wallis et al. 2007; Sahama et al. 2015; 452 Sahama et al. 2014; Dineen et al. 2020; Tavani et al. 2003; Quarantelli et al. 2013), we find that 453 cerebellar size in $A t m^{R 35 X / R 35 X} ; A p t x^{-/-}$mice is initially normal, but progressively atrophies in line with 454 changes in neurological function. While loss of cerebellar tissue has been considered a main cause of 455 ataxia in humans, it is unclear from clinical data if ataxia severity is a good predictor of the extent of 456 cerebellar degeneration found postmortem (Aguilar et al. 1968b; Crawford et al. 2006; Dineen et al. 457 2020). In the $A t m^{R 35 X / R 35 X} ; A p t x^{-/}$mice, we find clear atrophy associated with thinning of the Purkinje 458 neuron dendrite layer that precedes the late, severe behavioral deficits. However, since the 459 neuropathology observed in the Atm ${ }^{R 35 X / R 35 X} ;$ Aptx ${ }^{-/-}$mice is not severe, our findings suggest that like 460 several SCAs (e.g.,1 and 3), changes in cerebellar function itself, rather than profound loss of 461 cerebellar cells, is likely sufficient to cause the ataxic phenotype (Shakkottai et al. 2011b; Lorenzetti et 462 al. 2000; Clark et al. 1997).

463 Why ATM and APTX deficiency is required to generate ataxia in mice, when loss of either is sufficient 464 to cause ataxia in humans, remains unclear. One possibility is that the rodent brain may more flexibly 465 utilize compensatory pathways or redundant proteins while responding to the 10-20k DNA lesions that 466 impact cells each day (Lindahl and Barnes 2000). Several forms of DNA repair exist to potentially meet 467 this challenge, including base excision repair (BER), nucleotide excision repair (NER), as well as 468 homologous and non-homologous end joining (HEJ and NHEJ, respectively), all of which ATM and 
Perez et al. Resubmission

469

470

471

472

APTX have been implicated in (Chou et al. 2015; Çaglayan et al. 2017; Wakasugi et al. 2014; Tumbale et al. 2018; Chatterjee and Walker 2017). Alternatively, it may be the case that deficiency in ATM or APTX alone does not adequately impact cell health during the mouse's comparatively short lifespan, and thus eliminating both proteins is necessary to achieve sufficient accumulation of DNA damage to manifest over this time period. This possibility is strengthened by the fact that ATM and APTX have distinct biochemical properties and functional roles in the DNA damage response, and therefore deficiency in both would be predicted to cause a broader hit to genome stability (i.e., increased genotoxic stress).

Our finding, that two genome stability pathway proteins are required to induce neurological defects in mice strongly suggests that it is the loss of ATM's role in DNA repair, rather than potential functions in oxidative stress signaling, mitophagy, or mitochondrial function that cause the cerebellar defects (Shiloh 2020). Alternatives however, cannot be completely ruled out, as APTX, like ATM has been observed within the mitochondria of brain cells, where it is thought to support the processing of mitochondrial DNA (Meagher and Lightowlers 2014; Sykora et al. 2011). This new mouse model provides a new tool to explore these possibilities and mechanistically define how loss of ATM and APTX ultimately causes cerebellar dysfunction.

The biophysical perturbations observed in PNs recorded from the $A t m^{R 35 X / R 35 X}$; Aptx ${ }^{-/}$mice are similarly found in several other mouse models of ataxia. This includes changes we observed in PN input resistance, membrane capacitance, and AP threshold and width, which have also been described in mouse models of SCA like 1, 3, and 7 (Stoyas et al. 2020; Shakkottai et al. 2011b; Dell'Orco et al. 2015). Moreover, the progressive reduction in PN action potential firing frequency we report, which correlates well with the development of ataxia in the $A t m^{R 35 X / R 35 X}$; Aptx/ mice, is reported in a large number of ataxic mouse models, including SCAs $1,2,3,5,6$, and 13 as well as a few episodic forms (see review (Cook, Fields, and Watt 2020)).

Given the significant overlap in PN perturbations observed across many different ataxias caused by distinct cellular defects, restoring PN AP firing frequencies has been considered as a broad-based 
Perez et al. Resubmission

495 therapeutic approach. However, it remains unclear whether reduced PN firing is an actual causal factor 496 of ataxia. Moreover, experimental evidence suggests changes in PN activity may in fact be a 497 generalized response to maintain homeostasis during ongoing disease-related impairment of PN 498 physiology (Dell'Orco et al. 2015). Thus, continued efforts across all cerebellar ataxias are needed to 499 link the genetic, molecular, and cellular disruptions caused by disease to the specific changes in 500 cerebellar neural signaling that ultimately generates the ataxia. Of significant importance in this effort 501 will be defining whether disease-causing cerebellar defects commonly or differentially cause ataxia 502 through a loss of cerebellar function (e.g., loss of coordinating signals during movement), or from a 503 dominant negative effect (e.g., disrupting downstream neural circuits with abnormal neural output 504 patterns). Ultimately, while a common therapeutic strategy to address cerebellar ataxias would have the 505 greatest impact, a directed approach that addresses the distinct genetic and molecular causes of cellular dysfunction may ultimately be necessary to successfully develop an efficacious therapeutic.

507 The mechanistic link between deficiency in DNA stability proteins like ATM and APTX and PN 508 dysfunction is far less obvious than it is for other types of ataxia, like the loss of voltage gated ion 509 channels that directly shape membrane excitability in SCA6 (i.e., Ca ${ }_{\mathrm{v} 2.1}$ ) (Jayabal et al. 2016). Our 510 results suggest the effects of ATM and APTX loss on PNs is intrinsic, as we don't find changes in the 511 presynaptic properties of granule cells, nor evidence of their cellular loss (no change in GCL thickness).

512 Moreover, while we observed differences in short term plasticity of inferior olivary inputs in ATM and 513 APTX deficient PNs and wildtype, these results likely point to a disruption in $\mathrm{Ca}^{2+}$ homeostasis 514 potentially via reductions in Inositol 1,4,5-triphosphate receptor 1 (Itpr1) expression, similar to those 515 observed in SCAs 1, 2, and 3 mouse models as well as ATM-deficient mice (Kim et al. 2020; Chen et 516 al. 2008; Liu et al. 2009; Shakkottai et al. 2011b). While this provides a promising avenue for future 517 examination and comparison, it is as of yet unclear, even for the SCAs, whether changes in $\mathrm{Ca}^{2+}$ 518 homeostasis is the causal factor or just another symptom or even compensatory response of diseased 519 or disturbed PNs (Dell'Orco et al. 2015). 
Perez et al. Resubmission

520 In the immune system, ATM is implicated in the repair of DNA breaks that naturally occur during gene

521 rearrangement of antigen receptor genes in B- and T-cell precursors, a phenomenon critical for antigen 522 receptor (Ig and TCR) diversity of these cells. Our finding that T-cell proportions in the blood are 523 significantly reduced is consistent with prior studies in humans and A-T knockout mice (Schubert, 524 Reichenbach, and Zielen 2002; Hathcock et al. 2013; Chao, Yang, and Xu 2000; Barlow et al. 1996). 525 This reduction of T-cells in the periphery likely correlates with a defect in both cellular and humoral 526 immunity. Importantly, we found that expression of at least one copy of the ATM gene is enough to 527 restore CD4+ deficits in the blood indicating that therapies able to restore at least some ATM 528 expression would have therapeutic efficacy. Although we have not assessed B-cell development in this 529 paper, it is likely that similar conclusions would apply to that process given their mechanistic similarities 530 (Marshall et al. 2018).

531 As expected, the reduction of T-cells in peripheral blood correlated with defective thymocyte 532 development. In the thymus, we found two main defects. One, induced primarily by APTX deficiency, 533 manifests as a defect in the DN3 to DN4 transition coinciding with early rearrangement of TCR $\beta$ locus.

534 The other defect, primarily caused by ATM deficiency, correlates with decreased progression of double 535 positive $\mathrm{CD}^{+} \mathrm{CD}^{+}$to single positive cells, primarily $\mathrm{CD} 4^{+}$thymocytes. While the APTX finding was 536 surprising, as its deficiency (AOA 1) is not associated with immune deficits, APTX is known to interact 537 with TCR $\beta$ gene rearrangement proteins, including XRCC4 (Clements et al. 2004). Future studies 538 aimed at defining APTX's role in end-joining mechanisms during TCR gene rearrangement will be 539 important, and the possibility that alternative end-joining mechanisms, like the use of microhomologies 540 account for the lack of an immune deficit in its absence need further investigation (Bogue et al. 1997).

541 The survivability of $A t m^{R 35 X / R 35 X} ; A p t x^{-/}$mice is considerably longer than prior A-T mouse models. In 542 comparison, the first A-T KO mouse model reported by Barlow et al. died from thymomas usually within 543 2-4 months after birth (Barlow et al. 1996). The increased severity of cancer survivability in this, and 544 many other knockout A-T mouse models is likely genetic, as the background strain harboring the 545 mutation has been shown to have significant effects on cancer prevalence and survivability, with $\mathrm{A} / \mathrm{J}$ 
Perez et al. Resubmission

546 and C57BL/6 backgrounds having significantly increased survivability over the BALBC and 129S strains

547 (Genik et al. 2014). The fact that our ATM deficient mice were created on a C57BL/6 background likely

548 underlies their comparatively long lifespan. Given that the Atm ${ }^{R 35 X / R 35 X} ; A p t X^{+/+}$mice do not develop

549 ataxia, it is unlikely that the early death in A-T KO mice prevents observation of an ataxic phenotype

550 that would otherwise develop in these mice. On the other hand, it is unknown whether the C57BL/6

551 background confers a resilience to developing ataxia, as it does for cancer. Defining the genetic or

552 possibly epigenetic factors that influence the severity of the disease could provide avenues for future

553 therapeutic development.

554 Given the global nature of the ATM and APTX null mutation in our mouse model, we cannot entirely 555 rule out that extra-cerebellar defects may also contribute to the severe ataxic phenotype, and thus 556 future examination outside the cerebellum, in both the forebrain, brainstem, spinal cord, and even 557 muscle will need to be conducted. Within the cerebellum, while we found some anatomical differences 558 in the PN firing properties within different regions of the cerebellum, we didn't detect regional 559 differences in ML width or PN density. However, there are challenges in using regional anatomy as a 560 grouping factor in the cerebellum, as the physical folds of the tissue do not necessarily correlate with 561 the boundaries of functional, molecular expression, or biophysical property domains that have been 562 described (Apps and Hawkes 2009; Tsutsumi et al. 2015; Gao, van Beugen, and De Zeeuw 2012; Zhou 563 et al. 2014). Experiments focused on examining the extent of cerebellar defects within these domains 564 will be important in future studies and compared to the anecdotal reports of anatomical differences in A565 T patients (Verhagen et al. 2012; De Leon, Grover, and Huff 1976; Amromin, Boder, and Teplitz 1979; 566 Monaco et al. 1988; Terplan and Krauss 1969; Strich 1966; Solitare 1968; Solitare and Lopez 1967; 567 Aguilar et al. 1968a; Paula-Barbosa et al. 1983).

568 While we detect two potential stages in the progression of ataxia in the Atm ${ }^{R 35 X / R 35 X} ; A^{A p t X^{++}}$mice, the 569 later stage of severe ataxia develops in adulthood in mice, as compared to the childhood onset in 570 humans. This may limit its use in some neurodevelopmental based studies. Also, the interpretation of 571 future experiments must carefully factor in the fact that this new model expresses null mutations in two 
Perez et al. Resubmission

572 genome stability genes at the same time, a situation that has not been detected in human patients with

573 either A-T or AOA1.

574 Finally, pinpointing where, when, and how ATM deficiency causes cerebellar pathology and ataxia has

575 been a challenge as prior ATM deficient mice generally lack the characteristic features needed to 576 causally link cellular and molecular deficits to the ataxic phenotype. Multiple promising avenues of 577 investigation have been defined, including those focused at the neuronal level where ATM is implicated 578 in oxidative stress signaling (Chen et al. 2003) and synaptic function (Li et al. 2009; Vail et al. 2016), as 579 well as glial function, where recent evidence suggests glial pathology may be a leading factor in 580 cerebellar pathology (Kaminsky et al. 2016; Campbell et al. 2016; Petersen, Rimkus, and Wassarman 581 2012; Weyemi et al. 2015). This novel animal model provides a new tool to test mechanistic 582 hypotheses regarding how ATM deficiency causes cerebellar pathology and ataxia. Additionally, this 583 model may serve most importantly as a critical preclinical tool for testing both previously proposed 584 therapeutic candidates (Browne et al. 2004; Chen et al. 2003) and our own SMRT compounds (Du et 585 al. 2013). The severe limitations of not having a suitable preclinical model for therapeutic testing, 586 especially for a rare disorder like A-T and AOA1, cannot be overstated.

\subsection{Materials and Methods}

\section{Key Resources Table}

\begin{tabular}{|l|l|l|l|l|}
\hline $\begin{array}{l}\text { Reagent type } \\
\text { (species) or } \\
\text { resource }\end{array}$ & Designation & $\begin{array}{l}\text { Source or } \\
\text { reference }\end{array}$ & Identifiers & $\begin{array}{l}\text { Additional } \\
\text { information }\end{array}$ \\
\hline $\begin{array}{l}\text { Strain, strain } \\
\text { background } \\
\text { (Mus } \\
\text { musculus) }\end{array}$ & $\begin{array}{l}A t m^{R 35 X} \\
\text { Atm } \\
\text { CAG)TGA)Mfgc }\end{array}$ & This paper & $\begin{array}{l}103 \mathrm{C}>\mathrm{T} \\
\text { mutation, } \\
\text { human exon } \\
\text { replacement }\end{array}$ & $\begin{array}{l}\text { Generated } \\
\text { by Hicks } \\
\text { laboratory. } \\
\text { Has been } \\
\text { backcrossed } \\
\text { into C57b/6 } 9 \\
\text { times. } \\
\text { Contact } \\
\text { pmathews@I } \\
\text { undquist.org }\end{array}$ \\
\hline
\end{tabular}


Perez et al. Resubmission

\begin{tabular}{|c|c|c|c|c|}
\hline $\begin{array}{l}\text { Strain, strain } \\
\text { background } \\
\text { (Mus } \\
\text { musculus) }\end{array}$ & $\begin{array}{l}\operatorname{Atm}^{Q 35 X} \\
\underset{\text { Atm Mfgc }}{T m 1.1(103 C)}\end{array}$ & This paper & $\begin{array}{l}103 \mathrm{C}>\mathrm{T} \\
\text { mutation, } \\
\text { targeted } \\
\text { premature } \\
\text { termination } \\
\text { signal in the } \\
\text { mouse codon }\end{array}$ & $\begin{array}{l}\text { Generated } \\
\text { by Hicks } \\
\text { laboratory. } \\
\text { Has been } \\
\text { backcrossed } \\
\text { into C57b/6 } 9 \\
\text { times. } \\
\text { Contact } \\
\text { pmathews@। } \\
\text { undquist.org }\end{array}$ \\
\hline $\begin{array}{l}\text { Strain, strain } \\
\text { background } \\
\text { (Mus } \\
\text { musculus) }\end{array}$ & Aptx ${ }^{-/-}$ & $\begin{array}{l}\text { Ahel et al. } \\
2006\end{array}$ & $\begin{array}{l}\text { MGI Cat\# } \\
\text { 3687171, } \\
\text { RRID:MGI:36 } \\
87171\end{array}$ & $\begin{array}{l}\text { Contact } \\
\text { peter.mckinn } \\
\text { on@stjude.o } \\
\text { rg }\end{array}$ \\
\hline $\begin{array}{l}\text { Gene (Mus } \\
\text { musculus) }\end{array}$ & Atm & MGI & $\begin{array}{l}\text { MGI:107202; } \\
\text { C030026E19 } \\
\text { Rik; } \\
\text { ENSMUSG00 } \\
000034218\end{array}$ & \\
\hline $\begin{array}{l}\text { Gene (Homo } \\
\text { Sapien) }\end{array}$ & ATM & OMIM & $\begin{array}{l}\text { OMIM: } \\
607585 \text { MGI: } \\
107202 \\
\text { HomoloGene: } \\
\text { 30952; } \\
\text { ENSG000001 } \\
49311\end{array}$ & \\
\hline $\begin{array}{l}\text { Sequence- } \\
\text { based reagent }\end{array}$ & Atm gene & Transnetyx & PCR primers & $\begin{array}{c}\text { F-5'- } \\
\text { CCTTTGAG } \\
\text { GCATAAGT } \\
\text { TGCAACTT } \\
\text { G-3' }\end{array}$ \\
\hline $\begin{array}{l}\text { Sequence- } \\
\text { based reagent }\end{array}$ & Atm gene & Transnetyx & PCR primers & $\begin{array}{c}\text { R- 5'- } \\
\text { GTACAGTGT } \\
\text { ATCAGGTTA } \\
\text { GGCATGC-3' }\end{array}$ \\
\hline $\begin{array}{l}\text { Chemical } \\
\text { compound/ } \\
\text { drugs }\end{array}$ & $\begin{array}{l}\text { GJ103 salt } \\
\text { Formula: } \\
\mathrm{C}_{16} \mathrm{H}_{14} \mathrm{~N}_{4} \mathrm{O}_{3} \mathrm{~S}\end{array}$ & TargetMol & $\begin{array}{c}\text { T3448; } \\
\text { CAS No. : } \\
\text { 1459687-96-7 }\end{array}$ & $\begin{array}{l}100 \mu \mathrm{M} \text { in } \\
\text { media }\end{array}$ \\
\hline Antibody & $\begin{array}{l}\text { ATM (D2E2) } \\
\text { (Rabbit- } \\
\text { monoclonal) }\end{array}$ & $\begin{array}{l}\text { Cell Signaling } \\
\text { Technology }\end{array}$ & $\begin{array}{c}\text { Cell Signaling } \\
\text { Technology } \\
\text { Cat\# 2873, } \\
\text { RRID:AB_206 }\end{array}$ & $\begin{array}{l}\text { WB(1:500) } \\
\text { WB(1:1000) }\end{array}$ \\
\hline
\end{tabular}


Perez et al. Resubmission

\begin{tabular}{|c|c|c|c|c|}
\hline & & & 2659 & \\
\hline Antibody & $\begin{array}{c}\text { GAPDH } \\
(14 C 10) \\
\text { (Rabbit- } \\
\text { monoclonal) }\end{array}$ & $\begin{array}{l}\text { Cell Signaling } \\
\text { Technology }\end{array}$ & $\begin{array}{c}\text { Cell Signaling } \\
\text { Technology } \\
\text { Cat\# 2118, } \\
\text { RRID:AB_561 } \\
053\end{array}$ & WB(1:4000) \\
\hline Antibody & $\begin{array}{c}\beta \text {-Actin } \\
\text { (D6A8) } \\
\text { (Rabbit- } \\
\text { monoclonal) }\end{array}$ & $\begin{array}{l}\text { Cell Signaling } \\
\text { Technology }\end{array}$ & $\begin{array}{c}\text { Cell Signaling } \\
\text { Technology } \\
\text { Cat\# 8457, } \\
\text { RRID:AB_109 } \\
50489\end{array}$ & WB(1:5000) \\
\hline Antibody & $\begin{array}{l}\text { Anti-Rabbit } \\
\text { IgG,HRP- } \\
\text { linked } \\
\text { (Goat- } \\
\text { monoclonal- } \\
\text { polyclonal) }\end{array}$ & $\begin{array}{l}\text { Cell Signaling } \\
\text { Technology }\end{array}$ & $\begin{array}{c}\text { Cell Signaling } \\
\text { Technology } \\
\text { Cat\# 7074, } \\
\text { RRID:AB_209 } \\
9233\end{array}$ & WB(1:5000) \\
\hline Antibody & $\begin{array}{l}\text { Calbindin } \\
\text { (D-28k) } \\
\text { (Rabbit, } \\
\text { polyclonal) }\end{array}$ & Swant Inc. & $\begin{array}{c}\text { Swant Cat\# } \\
\text { CB 38, } \\
\text { RRID:AB_100 } \\
00340\end{array}$ & IF (1:1000) \\
\hline Antibody & $\begin{array}{l}\text { Anti-Rabbit } \\
\text { Alexa Fluor } \\
488 \text { (Goat- } \\
\text { polyclonal) }\end{array}$ & $\begin{array}{c}\text { ThermoFisher } \\
\text { Invitrogen }\end{array}$ & $\begin{array}{c}\text { Thermo } \\
\text { Fisher } \\
\text { Scientific } \\
\text { Cat\# A- } \\
\text { 11034, } \\
\text { RRID:AB_257 } \\
6217\end{array}$ & $\mathrm{IF}(1: 1000)$ \\
\hline Antibody & $\begin{array}{c}\text { CD4 } \\
\text { (GK1.5) } \\
\text { (Rat- } \\
\text { monoclonal) }\end{array}$ & $\begin{array}{l}\text { ThermoFisher } \\
\text { Invitrogen }\end{array}$ & $\begin{array}{c}\text { Thermo } \\
\text { Fisher } \\
\text { Scientific } \\
\text { Cat\# 50- } \\
\text { 0041-82, } \\
\text { RRID:AB_106 } \\
0933 \overline{7}\end{array}$ & $\begin{array}{c}\text { FACS } \\
\text { (5 ul per test) }\end{array}$ \\
\hline Antibody & $\begin{array}{c}\text { CD8 } \\
(53-6.7) \\
\text { (Rat- } \\
\text { monoclonal) }\end{array}$ & $\begin{array}{l}\text { ThermoFisher } \\
\text { Invitrogen }\end{array}$ & $\begin{array}{c}\text { Thermo } \\
\text { Fisher } \\
\text { Scientific } \\
\text { Cat\# 53- } \\
\text { 0081-82, } \\
\text { RRID:AB_469 } \\
897\end{array}$ & $\begin{array}{l}\text { FACS } \\
\text { (5 ul per } \\
\text { test) }\end{array}$ \\
\hline
\end{tabular}


Perez et al. Resubmission

\begin{tabular}{|c|c|c|c|c|}
\hline Antibody & $\begin{array}{c}\text { CD3 } \\
(145-2 \mathrm{C} 11) \\
\text { (Hamster- } \\
\text { monoclonal) }\end{array}$ & $\begin{array}{c}\text { ThermoFisher } \\
\text { Invitrogen }\end{array}$ & $\begin{array}{c}\text { Thermo } \\
\text { Fisher } \\
\text { Scientific } \\
\text { Cat\# 12- } \\
\text { 0031-83, } \\
\text { RRID:AB_465 } \\
497\end{array}$ & $\begin{array}{l}\text { FACS } \\
\text { (5 ul per } \\
\text { test) }\end{array}$ \\
\hline Antibody & $\begin{array}{c}\text { CD44 } \\
\text { (IM7) } \\
\text { (Rat- } \\
\text { monoclonal) }\end{array}$ & $\begin{array}{l}\text { ThermoFisher } \\
\text { Invitrogen }\end{array}$ & $\begin{array}{c}\text { Thermo } \\
\text { Fisher } \\
\text { Scientific } \\
\text { Cat\# 25- } \\
\text { 0441-82, } \\
\text { RRID:AB_469 } \\
623\end{array}$ & $\begin{array}{c}\text { FACS } \\
\text { (5 ul per test) }\end{array}$ \\
\hline Antibody & $\begin{array}{c}\text { CD25 } \\
\text { (PC61.5) } \\
\text { (Rat- } \\
\text { monoclonal) }\end{array}$ & $\begin{array}{l}\text { ThermoFisher } \\
\text { Invitrogen }\end{array}$ & $\begin{array}{l}\text { Thermo } \\
\text { Fisher } \\
\text { Scientific } \\
\text { Cat\# 47-- } \\
\text { 0251-82, } \\
\text { RRID:AB_127 } \\
2179\end{array}$ & $\begin{array}{l}\text { FACS } \\
\text { (5 ul per } \\
\text { test) }\end{array}$ \\
\hline Other & $\begin{array}{c}\text { Fluoromount } \\
\text {-G with } \\
\text { DAPI }\end{array}$ & $\begin{array}{l}\text { Southern } \\
\text { Biotech }\end{array}$ & $\begin{array}{l}\text { Cat\# 0100-20, } \\
\text { RRID: } \\
\text { SCR_021261 }\end{array}$ & \\
\hline $\begin{array}{l}\text { Commercial } \\
\text { assay or kit }\end{array}$ & $\begin{array}{c}\text { BCA Protein } \\
\text { Assay Kit }\end{array}$ & $\begin{array}{c}\text { ThermoFisher } \\
\text { Pierce }\end{array}$ & Cat\# 23225 & $\begin{array}{l}\text { Protein } \\
\text { Assay }\end{array}$ \\
\hline $\begin{array}{l}\text { Commercial } \\
\text { assay or kit }\end{array}$ & $\begin{array}{c}\text { SuperSignal } \\
\text { West Pico } \\
\text { Chemilumine } \\
\text { scent } \\
\text { Substrate }\end{array}$ & $\begin{array}{c}\text { ThermoFisher } \\
\text { Pierce }\end{array}$ & Cat\# 34580 & $\begin{array}{c}\text { Chemilumine } \\
\text { scent } \\
\text { Substrate }\end{array}$ \\
\hline $\begin{array}{l}\text { Commercial } \\
\text { assay or kit }\end{array}$ & $\begin{array}{l}\text { Radiance } \\
\text { plus }\end{array}$ & $\begin{array}{c}\text { Azure } \\
\text { Biosystems }\end{array}$ & Cat\# AC2103 & $\begin{array}{c}\text { Chemilumine } \\
\text { scent } \\
\text { Substrate }\end{array}$ \\
\hline $\begin{array}{l}\text { Software, } \\
\text { algorithm }\end{array}$ & FlowJo & $\frac{\underline{\text { https://www.fl }}}{\underline{\text { owjo.com/solu }}}$ & $\begin{array}{l}\text { RRID:SCR_0 } \\
08520\end{array}$ & \\
\hline $\begin{array}{l}\text { Software, } \\
\text { algorithm }\end{array}$ & $\begin{array}{l}\text { ImageJ } \\
\text { software }\end{array}$ & $\begin{array}{l}\text { ImageJ } \\
\text { (http://imagej. } \\
\underline{\text { nih.gov/ij/) }}\end{array}$ & $\begin{array}{l}\text { RRID:SCR } 0 \\
\underline{03070}\end{array}$ & \\
\hline
\end{tabular}


Perez et al. Resubmission

\begin{tabular}{|c|c|c|c|c|}
\hline $\begin{array}{l}\text { Software, } \\
\text { algorithm }\end{array}$ & IgorPro & $\begin{array}{l}\text { http://www.wa } \\
\text { vemetrics.co } \\
\text { m/products/ig } \\
\text { orpro/igorpro. } \\
\text { htm }\end{array}$ & $\begin{array}{l}\text { RRID:SCR } 0 \\
\underline{00325}\end{array}$ & $\begin{array}{l}\text { Version 7; } \\
\text { Tarotools } \\
\text { procedures }\end{array}$ \\
\hline $\begin{array}{l}\text { Software, } \\
\text { algorithm }\end{array}$ & $\begin{array}{l}\text { Neuroexpres } \\
\text { s }\end{array}$ & $\begin{array}{l}\text { https://www.re } \\
\text { searchgate.ne } \\
\text { t/project/Neur } \\
\text { oExpress- } \\
\text { Analysis- } \\
\text { software-for- } \\
\text { whole-cell- } \\
\text { electrophysiol } \\
\text { ogical-data }\end{array}$ & $\begin{array}{l}\text { https://www.re } \\
\text { searchgate.ne } \\
\text { t/project/Neur } \\
\text { oExpress- } \\
\text { Analysis- } \\
\text { software-for- } \\
\text { whole-cell- } \\
\text { electrophysiol } \\
\text { ogical-data }\end{array}$ & $\begin{array}{l}\text { Version } \\
21.1 .13 ; \\
\text { Used for } \\
\text { mEPSC } \\
\text { analyses }\end{array}$ \\
\hline $\begin{array}{l}\text { Software, } \\
\text { algorithm }\end{array}$ & $\begin{array}{l}\text { GraphPad, } \\
\text { Prism }\end{array}$ & $\begin{array}{l}\text { GraphPad } \\
\text { Prism } \\
\text { (https://graph } \\
\text { pad.com) }\end{array}$ & $\begin{array}{l}\text { RRID:SCR } 0 \\
\underline{15807}\end{array}$ & $\begin{array}{l}\text { Versions } 8 \\
\text { and } 9\end{array}$ \\
\hline $\begin{array}{l}\text { Software, } \\
\text { algorithm }\end{array}$ & $\begin{array}{l}\text { MBF, Stereo } \\
\text { investigator }\end{array}$ & $\begin{array}{l}\text { https://www.m } \\
\text { bfbioscience.c } \\
\text { om/stereology }\end{array}$ & $\begin{array}{l}\text { RRID:SCR } 0 \\
17667\end{array}$ & Version 2021 \\
\hline $\begin{array}{l}\text { Software, } \\
\text { algorithm }\end{array}$ & $\begin{array}{l}\text { Microsoft } \\
\text { Excel }\end{array}$ & $\begin{array}{c}\text { https://www.m } \\
\text { icrosoft.com/e } \\
\text { n- } \\
\text { us/microsoft- } \\
\text { 365/excel }\end{array}$ & $\begin{array}{l}\text { RRID:SCR_0 } \\
16137\end{array}$ & Version 365 \\
\hline $\begin{array}{l}\text { Software, } \\
\text { algorithm }\end{array}$ & Catwalk XT & $\begin{array}{c}\text { https://www.n } \\
\text { oldus.com/cat } \\
\text { walk-xt }\end{array}$ & $\begin{array}{l}\text { RRID: } \\
\text { SCR_021262 }\end{array}$ & \\
\hline
\end{tabular}

\subsection{Ethics Statement}

590 This study was performed in strict accordance with the recommendations in the Guide for the Care and

591 Use of Laboratory Animals of the National Institutes of Health. All the animals were handled according 592 to approved institutional animal care and use committee (IACUC) protocols at The Lundquist Institute 593 (31374-03, 31773-02) and UCLA (ARC-2007-082, ARC-2013-068). The protocol was approved by the 594 Committee on the Ethics of Animal Experiments of the Lundquist Institute (Assurance Number: D16595 00213). Every effort was made to minimize pain and suffering by providing support when necessary 596 and choosing ethical endpoints. 
Perez et al. Resubmission

\subsection{Mice}

All mice were group housed and kept under a 12-h day/night cycle with food and water available ad libitum. Animals were housed within the general mouse house population, and not in specialized pathogen free rooms. Older animals were made available wetted food or food gel packs on the ground of the cages as ataxia developed. $A^{R t m^{R 35 X}}$ and $A t m^{Q 35 X}$ mice were created and provided by Dr. Hicks and colleagues at the University of Manitoba.

These mice were created to contain the c.103C $>$ T mutation found in a large population of North African AT patients, using recombineering Gateway technology and site-directed mutagenesis. A C>T mutation at this position in the mouse Atm gene creates a TAG G stop codon. The same mutation in the human ATM gene produces a TGA G stop codon. In consideration of the use of these models for therapeutic interventions, we chose to create a mouse model for each of the two PTC codons (Fig. 1A).

A modified Gateway R3-R4-destination vector was used to pull out the desired region of the mouse Atm gene from a Bacterial Artificial Chromosome (BAC) and subsequently mutated to create either a TAG G stop codon at codon 35 (M00001, position 103 (C>T)) or a TGA G stop codon (M00002, position 103 (CAG>TGA), replicating the human AT PTC). The genomic alleles were then cloned into a modified version of the NorCOMM mammalian targeting vector using a 3-way Gateway Reaction (Bradley et al. 2012). The resulting targeting vectors were electroporated into C2 ES cells $(C 57 \mathrm{BI} / 6 \mathrm{~N}$, derived in $\mathrm{A}$. Nagy lab, Toronto, Canada) and successfully targeted clones were identified by selection with G418 (Gertsenstein et al. 2010). Integration of the mutated targeting cassette into the Atm gene locus was confirmed by Southern blot, and by sequencing of PCR products to confirm the presence of the Atm PTC mutation, error free targeting into the Atm locus and error free functional components of the vector (data not shown). Positive ES clones were used for blastocyst injection to obtain the transgenic lines. The transgenic allele contained a floxed human beta actin promoter - delta TK1- Neo cassette in the intron upstream of the region containing the mutated exon. This floxed cassette was subsequently excised by crossing with a Cre driver mouse (B6.C-Tg(CMV-cre)1Cgn/J) to generate $\mathrm{Atm}^{R 35 \mathrm{X}_{+}}$and Atm $^{Q 35 X++}$ (MGI nomenclature: $\operatorname{Atm}^{\text {TM1(103CAG>TGA)MFGC }}$ and Atm $^{\text {TM1(103C>T)MFGC }}$, respectively) mouse lines 
Perez et al. Resubmission

623 (Fig. 1A). Genotyping of the two Atm lines was performed by using the following primers at $\mathrm{Tm} 62^{\circ} \mathrm{C}$ :

624 Atm gene forward (F) primer: 5'-CCTTTGAGGCATAAGTTGCAACTTG-3'; and Atm gene reverse (R) 625 primer: 5'-GTACAGTGTATCAGGTTAGGCATGC-3', creating a Wild-type allele product of 151bp or 626 targeted allele product of $241 \mathrm{bp}$ (Figs. 1A, 1B).

$627 A^{R t m^{R 3 X}}$ and $A_{t m}^{Q 35 X}$ were backcrossed with C57BI/6J mice for 9 generations (99.2\% isogenic) prior to 628 cryopreservation and subsequent rederivation using C57BI/6J surrogate mothers. Atm ${ }^{R 35 X}$ and Atm $^{\text {Q35X }}$ 629 breeders were obtained from F1 sibling Atm $^{R 35 X /+}$ and Atm $^{Q 35 X /+}$ mice. Atm $^{R 35 X / R 35 X}$ and Atm $^{Q 35 X / Q 35 X}$ were 630 both found to be fertile. Aptx knockout $\left(A p t x^{-/}\right)$mice were created and provided to Dr. Mathews as 631 embryos from Dr. McKinnon (Ahel et al. 2006), and subsequently rederived via C57BI/6J surrogate 632 mothers. Aptx $x^{-/}$mice are on a C57BI/6 and 129 mixed background. Atm ${ }^{R 35 / R 35 x x} ;$ Aptx ${ }^{-/-}$mice of various 633 wildtype, heterozygous, and homozygous combinations were created from Atm $^{\text {R35X/+}}$; Aptx+/- breeders 634 generated by crossing $A t m^{R 35 X / R 35 X}$ and $A p t x^{-/-}$mice. One cohort of double mutant and corresponding 635 control mice were used in the longitudinal behavioral study for gait analyses and SHIRPA testing (Figs.

636 2, 3). Multiple additional cohorts of age matched double mutant and control mice were used for 637 electrophysiological, immunohistological, and Vertical Pole test experiments (Figs. 4, 7). Immunological 638 and protein expression experiments were carried out using mice bred from the original $\operatorname{Atm}^{R 35 X}$ and $639 A^{Q}{ }^{Q 35 X}$ rederived mice (Figs. 5, 6, and 8).

640 Genotyping was performed from ear tissue samples of P8-11 mice. Real-time PCR methods conducted 641 by Transnetyx Inc. were used to determine each animals' genotype. Animals were made identifiable via 642 toe tattoos given at the same time as ear biopsy. Unique primers for $A_{t m}^{R 35 X}$ and Atm $^{Q 35 X}$ were 643 quantified and used to identify wildtype, hetero- and homo-zygous mice (listed above). Aptx $x^{-/}$and $644 A p t X^{+/+}$primers were used to assess their genotypes.

\section{$645 \quad 4.3$ Animal Health}

646 Animals were weighed via a digital scale at P8, 45, 120, 210, 400. Animal death was recorded as the 647 day found dead, or on the day of euthanization when the animals reached a humane endpoint (animal 648 unable to right itself within 60 s, significant hair matting indicating lack of self-grooming, or excessive 
Perez et al. Resubmission

649 distress as noted by the veterinary staff). Animal carcasses were immediately frozen upon death, and 650 postmortem necropsies were carried out in batch. Probable cause of death was determined to the best 651 of our ability in collaboration with the staff veterinarian (Dr. Catalina Guerra) by visual inspection of the 652 internal organs. Some mice were cannibalized or accidentally disposed of by vivarium staff and were 653 therefore labelled as "missing." Mice with no discernable visual cause of death were labelled 654 "indeterminable." Mice that were found with thoracic masses near where the thymus would normally be 655 in young mice were listed as "thymic cancer." All other identified probable causes of death (e.g., 656 enlarged livers, urinary blockage) were labelled "other."

\subsection{Behavior}

Before performing any behavioral test, mice were acclimated to the behavioral suite for $~ 20$-minutes. Mice were tested at varying times of the day, in line with their day cycle. A battery of behavioral tests was performed on naïve double mutant mice of the indicated genotypes at various time points depending on the behavior but in the same cohort of mice. The battery of tests included Catwalk Gait assessment $(P 45,120,210,400)$ and a subset of the SmithKline-Beecham Harwell Imperial-College and Royal-London-Hospital Phenotype Assessment (SHIRPA) tests (P30 and 400). These tests were conducted by the UCLA Behavioral Core. Double mutant and control mice were additionally examined on the Vertical Pole test. All behavioral apparatus was wiped down with ethanol (70\%) between each testing each subject.

\section{Gait Analysis}

668 We used a Noldus Catwalk Gait analysis system designed to semi-automatically measure and analyze 669 the gait of mice during normal ambulation. Briefly, the movement of mice across a glass bottom corridor 670 is video recorded from a ventral position. Paw prints are highlighted in the video due to light illumination 671 across the glass walking platform. Each mouse step within a video is subsequently detected using 672 Catwalk XT (Noldus) in a semi-automated fashion. A run for each mouse consists of 3 trials of 673 consistent ambulation across the monitored platform. Only consistent trials are accepted, and mice may 674 take up to 10 attempts to complete 3 compliant trials in either direction across the corridor. Compliant 
Perez et al. Resubmission

675 trials were defined as those with movement across the platform under 5 s-long and with no more than $67660 \%$ speed variation. Once placed onto the platform, mice generally ran back and forth without any 677 need for experimenter prompting.

\section{$678 \quad$ Vertical Pole}

679 Mice are placed at the top of an $80 \mathrm{~cm}$ tall bolt with their nose faced down and hind paws as close to the 680 top as possible. Mice are immediately released, and time started immediately upon placement. Time is 681 stopped when the first forepaw touches the surface below the pole. A mouse's natural predilection is to 682 immediately climb down the pole, and they are given up to $60 \mathrm{~s}$ to traverse the pole, otherwise they are 683 helped off the pole. A non-completed trial is automatically given a time of $30 \mathrm{~s}$, as $95 \%$ of mice that did 684 not descend within $30 \mathrm{~s}$ were still on the pole at the $60 \mathrm{~s}$ mark.

\section{$\underline{\text { SHIRPA }}$}

686 Behavioral tests were conducted by the University of California, Los Angeles Behavioral Core at P30 687 and P400. All parameters are scored to provide a quantitative assessment, which enables comparison 688 of results both over time and between different laboratories. Each mouse was sequentially tested 689 across all behaviors within 20 -min time span before moving onto the next mouse. The experimenter 690 was blinded to animal genotype. The screen was performed as described previously (Rogers et al. 691 1997).

\section{Behavioral Observation}

693 The primary screen provides a behavioral observation profile and assessment of each animal begins by 694 observing undisturbed behavior in a viewing jar (10 cm diameter) for 5-min In addition to the scored 695 behaviors of body position, spontaneous activity, respiration rate, and tremor, the observer logs 696 any instances of bizarre or stereotyped behavior and convulsions, compulsive licking, self-destructive 697 biting, retropulsion (walking backwards) and indications of spatial disorientation. 
Perez et al. Resubmission

699 Thereafter, the mouse is transferred to the arena $(30 \mathrm{~cm} \mathrm{X} 50 \mathrm{~cm})$ for testing of transfer arousal and

700 observation of normal behavior. The arena is marked into a grid of $10 \mathrm{~cm}^{2}$ squares to measure 701 locomotor activity within a 30 s-period. While the mouse is active in the arena, measures of startle 702 response, gait, pelvic elevation, and tail elevation are recorded.

703 Supine Restraint

704 The animal is restrained in a supine position to record autonomic behaviors. During this assessment, 705

grip strength, body tone, pinna reflex, corneal reflex, toe pinch, wire maneuver, and heart rate, were evaluated.

708 Finally, several measures of vestibular system function were performed. The righting reflex, contact 709 righting reflex, and negative geotaxis tests were performed. Throughout this procedure vocalization, 710 urination and general fear, irritability, or aggression were recorded.

711 Equipment Used

712 1. Clear Plexiglas arena (approximate internal dimensions $55 \times 33 \times 18 \mathrm{~cm}$ ). On the floor of the arena 713 is a Plexiglas sheet marked with 15 squares $(11 \mathrm{~cm})$. A rigid horizontal wire $(3 \mathrm{~mm}$ diameter) is 714 secured across the rear right corner such that the animals cannot touch the sides during the wire 715 maneuver. A grid $(40 \times 20 \mathrm{~cm})$ with $12 \mathrm{~mm}$ mesh (approximate) is secured across the width of the 716 box for measuring tail suspension and grip strength behavior.

717 2. A clear Plexiglas cylinder $(15 \times 11 \mathrm{~cm})$ was used as a viewing jar.

718 3. One grid floor $(40 \times 20 \mathrm{~cm})$ with $12 \mathrm{~mm}$ meshes on which viewing jars stand.

719 4. Four cylindrical stainless-steel supports $(3 \mathrm{~cm}$ high $\times 2.5 \mathrm{~cm}$ diameter $)$ to raise grids off the bench.

$720 \quad 5$. One square $(13 \mathrm{~cm})$ stainless steel plate for transfer of animals to the arena.

7216 6ut lengths of $3 / 0$ Mersilk held in the forceps for corneal and pinna reflex tests

722 7. A plastic dowel rod sharpened to a pencil point to test salivation and biting.

723 8. A pair of dissecting equipment forceps, curved with fine points (125 mm forceps, Philip Harris 724 Scientific, Cat. No. D46-174), for the toe pinch. 
Perez et al. Resubmission

9. A stopwatch.

10. An IHR Click box is used for testing the startle responses. The Click Box generates a brief 20 $\mathrm{KHz}$ tone at $90 \mathrm{~dB}$ SPL when held $30 \mathrm{~cm}$ above the mouse. Contact Prof. K.P. Steel, MRC Institute of Hearing Research, University Park, Nottingham NG7 2RD.

11. A ruler.

12. A $30 \mathrm{~cm}$ clear Plexiglas tube with an internal diameter of $2.5 \mathrm{~cm}$ for the contact righting reflex.

\subsection{Electrophysiology}

\section{Preparation of acute cerebellar slices}

733 Acute parasagittal slices of $300 \mu \mathrm{m}$ thickness were prepared from the cerebellum of experimental and control littermate mice by following published methods (Hansen et al., 2013). In brief, cerebella were quickly removed and immersed in an ice-cold extracellular solution with composition of $(\mathrm{mM}): 119 \mathrm{NaCl}$, $26 \mathrm{NaHCO}_{3}, 11$ glucose, $2.5 \mathrm{KCl}, 2.5 \mathrm{CaCl}_{2}, 1.3 \mathrm{MgCl}_{2}$ and $1 \mathrm{NaH}_{2} \mathrm{PO}_{4}, \mathrm{pH} 7.4$ when gassed with $5 \%$ $\mathrm{CO}_{2} / 95 \% \quad \mathrm{O}_{2}$. Cerebella were sectioned parasagittally using a vibratome (Leica VT-1000, Leica Biosystems, Nussloch, Germany) and initially incubated at $35^{\circ} \mathrm{C}$ for $\sim 30 \mathrm{~min}$, and then equilibrated and stored at room temperature until use.

\section{Extracellular Electrophysiology}

741 Extracellular and intracellular recordings were obtained from Purkinje neurons (PNs) in slices 742 constantly perfused with carbogen-bubbled extracellular solution and maintained at either $37^{\circ} \mathrm{C}$ 743 (extracellular) or $32^{\circ} \mathrm{C}$ (intracellular) $\pm 1^{\circ} \mathrm{C}$ (see above). Cells were visualized with DIC optics and a 744 water-immersion $40 \times$ objective (NA 0.75) using a Zeiss Examiner microscope. Glass pipettes of $\sim 3 \mathrm{M} \Omega$ 745 resistance (Model P-1000, Sutter instruments, Novato, CA) were filled with either extracellular solution 746 and positioned near PN axon hillocks in order to measure action potential-associated capacitive current 747 transients in voltage clamp mode with the pipette potential held at $0 \mathrm{mV}$. For whole-cell patch clamp 748 recordings, pipettes were filled with an intracellular solution $(\mathrm{mM}): 140 \mathrm{KMeth}(\mathrm{CH} 3 \mathrm{KO} S), 10 \mathrm{NaCl}, 2$ $749 \mathrm{MgCl}_{2}, 0.2 \mathrm{CaCl}_{2}, 10 \mathrm{HEPES}, 14$ Phosphocreatine (tris salt), 1 EGTA, 4 Mg-ATP, 0.4 Na-GTP. $100 \mu \mathrm{M}$ 750 Picrotoxin (Sigma) was added to block inhibitory GABAegeric synaptic inputs. Data was acquired using 
Perez et al. Resubmission

751 a MultiClamp 700B amplifier at 20 or $100 \mathrm{kHz}$ in voltage or current clamp mode, Digidata 1440 with

752 pClamp10 (Molecular Devices, Sunnyvale, CA) and filtered at 2 to $4 \mathrm{kHz}$. The series resistance was

753 usually between 10 and $15 \mathrm{M} \Omega$. Series resistance was compensated at $80 \%$ for short term plasticity

754 experiments only.

755 For extracellular recordings, a total of 20 to 45 PNs were recorded from for each animal across all 756 genotypes, sexes, and age groups. Recordings were distributed across both the medial-lateral and 757 rostro-caudal axis of the cerebellum. Only cells with a "healthy" look (low contrast of cellular borders), 758 and regular, uninterrupted firing rate were examined. During analysis, a few cells were found to have 759 gaps in firing of greater than 2 second and these cells were eliminated from analysis, as this type of 760 firing is associated with being "unhealthy." Double mutant tissue did not qualitatively differ in 761 appearance under DIC microscopy prior to recordings, nor was the number of "unhealthy" cells greater 762 than that of other genotypes ( $7 \%$ vs 4 to $11 \%$ of all cells across control genotypes at P400). Spatial 763 comparison of neural activity was obtained by recording from serial sections in the flocculus, lateral (2 $2^{\text {nd }}$ 764 or $\left.3^{\text {rd }}\right)$, intermediate $\left(6^{\text {th }}\right.$ or $\left.7^{\text {th }}\right)$, and medial $\left(11^{\text {th }}\right.$ or $\left.12^{\text {th }}\right)$ slices. Lower number slices were used in the 765 younger age groups (P45 and 110) to roughly match the relative positioning of recordings across age 766 groups. 0-3 recordings were made from each lobule within each slice dependent on tissue quality and 767 health. Each recording lasted for 1-minute. 3 to 5 mice were used for each age group and the 768 experimenter was blinded to the genotype, age, and sex.

769 Intracellular recordings were obtained from PNs in either folia III or VIII of the vermis, no statistical 770 differences in properties were observed between folia.

$771 \quad$ Analyses

772 Spontaneous action potential interstimulus intervals detected and analyzed using standard and custom 773 routines in ClampFit (Molecular Device), IgorPro (Wavemetrics), and Excel (Microsoft). Specifically, 774 action potentials were threshold detected and spiking statistics (i.e., frequency and interval length), 775 determined using adapted IgorPro routines (Taro Tools; https://sites.google.com/site/tarotoolsregister/). 
Perez et al. Resubmission

776 The coefficient of variation of the mean inter-spike interval (CV) and the median inter-spike interval

$777 \quad(\mathrm{CV} 2 \square=\square 2|\mathrm{ISIn}+1-\mathrm{ISIn}| /(\mathrm{ISIn}+1+\mathrm{ISIn}))$ were calculated in Excel using custom macros.

778 Standard membrane properties were analyzed using IgorPro. $R_{M}$ was determined by averaging 3 779 voltage trace responses to a $-5 \mathrm{mV}$ step pulse from a $-80 \mathrm{mV}$ holding potential and measuring the 780 resulting current deflection between 900 and $1000 \mathrm{~ms}$ after onset. The membrane time constant was 781 measured by fitting a single exponential to the initial decay phase from 90 to $10 \%$ of the peak. $C_{M}$ was 782 calculated by dividing the membrane time constant by the $\mathrm{R}_{\mathrm{M}}$. mEPSC events were recorded over a 1783 minute epoch and detected and measured using Neuroexpress (v21.1.13). Parallel and climbing fiber 784 axons were stimulated using theta-glass electrodes (W.P.I.) and a TTL controlled stimulus isolator 785 (ISO-Flex, A.M.P.I.). Evoked EPSC amplitudes and decay time constants (1 exp. for parallel and 2 exp. 786 for climbing fibers) were analyzed using custom routines in IgorPro. Action potentials were examined as 787 part of a set of $1 \mathrm{~s}$ current injections between -500 and $2250 \mathrm{pA}$ ( $250 \mathrm{pA}$ steps) with a holding current 788 adjusted to maintain an $\sim 70 \mathrm{mV}$ potential. Action potential waveforms were measured using custom 789 routines in IgorPro. Action potential threshold was defined as the first membrane voltage in which the 790 first derivative exceeded $30 \mathrm{mV} / \mathrm{ms}$ (Zhu et al. 2006).

\section{$791 \quad 4.6$ Examination of Cerebellar Atrophy}

792 Cerebellar size

793 Immediately after brain removal from the skull, a dorsal, whole mount image was obtained. Images 794 were then processed using $\mathrm{Fiji}(\mathrm{NIH})$. The forebrain and cerebellar sizes were assessed by outlining 795 their 2-dimensional space and then calculating area. We normalized for possible differences in overall 796 brain size by dividing the results of the cerebellum by forebrain size to produce a relative cerebellum to 797 forebrain ratio. Experimenters were blind to the genotype of the animal.

\section{Immunohistochemistry}

799 At the respective study endpoints (P45, 120, 210, 400), male and female mice of all genotypes 800 represented in this study were anesthetized with isoflurane and underwent transcardial perfusion with 
Perez et al. Resubmission

801 phosphate-buffered saline followed by $4 \%(\mathrm{w} / \mathrm{v})$ buffered paraformaldehyde (PFA) and then dissected

802 to extract the brain. Images of the whole brain were taken immediately after removing the brain from 803 the skull and the brains were then submerged in 4\% PFA for 24-hours, followed by 72 -hours in $30 \%$

804 sucrose in Tris-buffered saline (TBS) with $0.05 \%$ azide, and then cryoprotected in TBS-AF and stored 805 at $4^{\circ} \mathrm{C}$ until further use. The cerebellum was separated from the forebrain and parasagittally sectioned 806 using a sliding microtome (Microm HM 430, Thermo Scientific) set to section at $40 \mu \mathrm{m}$ thickness.

807 Cerebellum sections were collected in a series of six and stored in TBS-AF at $4^{\circ} \mathrm{C}$ until further use. For 808 immunofluorescent visualization of Purkinje neurons, cerebellum sections of both Atm $^{+/+} ;$Aptx $^{+/+}$and $809 A A^{R 35 X / R 35 X} ; A^{-/-}(\mathrm{n}=5$ per genotype) were washed for $5 \mathrm{~min}$ in TBS three times, and then blocked in $81015 \%$ normal goat serum at room temperature for 30 min followed by free floating incubation in rabbit 811 anti-calbindin D-28k (1:1000) for 1 hour at room temperature on an orbital shaker, then washed for 5 812 min with TBS three times, followed by free floating incubation in goat anti-rabbit Alexa Fluor 488 $813(1: 1000)$ for $1 \mathrm{~h}$ in the dark at room temperature on an orbital shaker. Following secondary antibody 814 incubation, sections were washed for $5 \mathrm{~min}$ in TBS three times and stored in TBS until further use. 815 Sections were mounted and cover-slipped with Fluoromount-G with DAPI. Slides were scanned using 816 Stereo Investigator version 2020.1.3 64bit (MBF Bioscience) on a Zeiss Axio Imager.M2 microscope 817 (Carl Zeiss Microscopy) using a 20x objective (NA 0.5) and images captured with a Hamamatsu ORCA 818 Flash 4.0 LT C11440 digital camera (Hamamatsu Photonics). To quantify the number of calbindin819 reactive cells in each folia in the resulting images, we randomly drew 2 lines between 300 to $500 \mu \mathrm{m}$ 820 long in each folia and manually counted the total number of PNs along the length within the $40 \mu \mathrm{m}$ 821 thickness of the tissue slice. 2D density (\# of PNs/(linear length * 40 um thickness)) of the two samples 822 per folia were then averaged for further between folia and subject comparison. Experimenter was 823 blinded to mouse genotype.

824 Molecular (Calbindin) and granule cell (DAPI) layer widths were assessed by taking two width 825 measurements at two predefined locations for each folia, roughly halfway along the long extent of each 
Perez et al. Resubmission

826 folia. Experimenter was blinded to the mouse genotype in which slices were examined and the order of 827 examination was interleaved.

828

829

830

\subsection{Flow Cytometry Measurements}

Flow cytometry analysis of blood and thymus cells was performed by staining with specific anti-mouse antibodies: CD4, CD8, CD3, CD44, and CD25. Briefly, whole-blood samples (50 $\mu$ l) were stained using fluorescent-labeled antibodies, then red-blood cells were lysed using BD lysing solution while live whiteblood cells were stained using a viability stain. Thymi were mechanically dissociated. 1 to 2 million thymus cells were similarly stained using specific antibodies for CD4, CD8, CD44 and CD25. Analysis of immuno-stained white blood cells or thymus samples was performed using FACS ARIA III and data analyzed using FlowJo software as reported previously (Sanghez et al. 2017).

\subsection{Western Blots}

Protein extracts (cells/tissues) were homogenized in radioimmunoprecipitation assay (RIPA) lysis buffer $(150 \mathrm{mM} \mathrm{NaCl}, 1 \%$ Nonidet P-40 [NP-40], 0.5\% deoxycholate, $0.1 \%$ SDS, $50 \mathrm{mM}$ Tris, pH 8.0) with protease inhibitors $(10 \mathrm{ug} / \mathrm{ml}$ AEBSF, $10 \mathrm{ug} / \mathrm{ml}$ leupeptin, $5 \mathrm{ug} / \mathrm{ml}$ pepstatin, $5 \mathrm{ug} / \mathrm{ml}$ chymotrypsin, 10 $\mathrm{ug} / \mathrm{ml}$ aprotinin). The protein extracts were sonicated then pelleted by centrifugation at $13,000 \mathrm{rpm}$ for 15 min at $4^{\circ} \mathrm{C}$. BCA protein assay was used to quantify protein concentrations. Samples containing equal amounts of protein 50 to $100 \mu \mathrm{g}$ per lane were separated using 4 to $12 \%$ gradient TGX precast gels BioRad then transferred by TransBlot Semi-Dry BioRad system using Nitrocellulose transfer pack. Transferred blots were stained by Ponceau S stain for equal protein loading then washed and blocked with 5\% nonfat dry milk in TBST for $60 \mathrm{~min}$ at room temp. Primary antibodies were incubated with shaking overnight at $4^{\circ} \mathrm{C}$. Blots were probed for the following antibodies: ATM (D2E2) Rabbit mAb Cell Signaling, at 1:1000 dilution, $\beta$-Actin (D6A8) Rabbit mAb Cell Signaling, GAPDH (D16H11) Rabbit mAb Cell Signaling followed by the appropriate horseradish peroxidase-conjugated (HRP) secondary Antirabbit, Anti-mouse for 2 hours at room temperature. After multiple washes with TBST, Protein expression was detected by Radiance Plus chemiluminescence substrate using the Azure c400 and the 
Perez et al. Resubmission

851 BioRad ChemiDoc imaging systems. Densitometric analysis of the ATM was performed using ImageJ.

852 Experiments were performed with 2 technical and 2-3 biological replicates as indicated.

853

854

855

856

857

858

\subsection{Statistical Assessment}

The number of animals chosen for each group was based on a priori power analyses using GPower v3.1 based on an $\alpha$ size of 0.5 , power of 0.8 , and effect sizes estimated from preliminary data or prior studies. We used both parametric (1- and 2-way ANOVA) for normally distributed and non-parametric (Kruskal Wallace) statistical methods for interval data to test for differences between groups followed by pairwise multiple comparisons tests as indicated in the text. Outliers for immune data in Figs. 6 and 7 were excluded via the ROUT method $(\mathrm{Q}=2 \%)$. The specific analyses used for each data set is noted in each figure legend. For all figures: $* \mathrm{p} \leq 0.05, * * \mathrm{p}<0.01, * * * \mathrm{p}<0.001, * * * * \mathrm{p}<0.0001$. Data are reported as mean \pm SEM and box and whisker plots indicate the minimum, first quartile, median, third quartile, and maximum data values. All figures and statistical analyses were completed using Excel (Microsoft 360) or Prism v8 and 9 (Graphpad).

\subsection{Acknowledgements}

We would like to thank the UCLA Behavioral Core, especially Irina Zhuravka for her efforts assaying behavioral deficits in the mice. We would also like to thank Dr. Jennifer Fogel for comments and edits to the manuscript.

\subsection{Competing interests}

The authors declare that no competing interests exist.

\subsection{Citations}

Ady, Visou, Brenda Toscano-Márquez, Moushumi Nath, Philip K Chang, Jeanette Hui, Anna Cook, François Charron, Roxanne Larivière, Bernard Brais, and R Anne McKinney. 2018. 'Altered synaptic and firing properties of cerebellar Purkinje cells in a mouse model of ARSACS', The Journal of physiology, 596: 4253-67. 
Perez et al. Resubmission

875

876

877

878

879

880

881

882

883

884

885

886

887

888

889

890

891

892

893

894

895

896

897

898

899

900

901

902

903

904

905

906

907

908

909

910

911

912

913

914

915

916

Aguilar, M. J., S. Kamoshita, B. H. Landing, E. Boder, and R. P. Sedgwick. 1968a. 'Pathological observations in ataxia-telangiectasia. A report of five cases', Journal of Neuropathology and Experimental Neurology, 27: 659-76.

Aguilar, Mary Jane, Shigehiko Kamoshita, Benjamin H. Landing, Elena Boder, and Robert P. Sedgwick. 1968b. 'Pathological Observations in Ataxia-Telangiectasia: A Report on Five Cases"', Journal of Neuropathology and Experimental Neurology, 27: 659-76.

Ahel, I., U. Rass, S. F. El-Khamisy, S. Katyal, P. M. Clements, P. J. McKinnon, K. W. Caldecott, and S. C. West. 2006. 'The neurodegenerative disease protein aprataxin resolves abortive DNA ligation intermediates', Nature, 443: 713-6.

Aicardi, J., C. Barbosa, E. Andermann, F. Andermann, R. Morcos, Q. Ghanem, Y. Fukuyama, Y. Awaya, and P. Moe. 1988. 'Ataxia-ocular motor apraxia: a syndrome mimicking ataxiatelangiectasia', Annals of Neurology, 24: 497-502.

Alviña, Karina, and Kamran Khodakhah. 2010. 'KCa channels as therapeutic targets in episodic ataxia type-2', Journal of Neuroscience, 30: 7249-57.

Amromin, George D, Elena Boder, and Raymond Teplitz. 1979. 'Ataxia-telangiectasia with a 32 year survival: a clinicopathological report', Journal of Neuropathology and Experimental Neurology, 38: $621-43$.

Ando, K., J. L. Kernan, P. H. Liu, T. Sanda, E. Logette, J. Tschopp, A. T. Look, J. Wang, L. BouchierHayes, and S. Sidi. 2012. 'PIDD death-domain phosphorylation by ATM controls prodeath versus prosurvival PIDDosome signaling', Molecular Cell, 47: 681-93.

Apps, R., and R. Hawkes. 2009. 'Cerebellar cortical organization: a one-map hypothesis', Nature Reviews: Neuroscience, 10: 670-81.

Atluri, Pradeep P., and Wade G. Regehr. 1996. 'Determinants of the Time Course of Facilitation at the Granule Cell to Purkinje Cell Synapse', The Journal of Neuroscience, 16: 5661-71.

Barlow, C., S. Hirotsune, R. Paylor, M. Liyanage, M. Eckhaus, F. Collins, Y. Shiloh, J. N. Crawley, T. Ried, D. Tagle, and A. Wynshaw-Boris. 1996. 'Atm-deficient mice: a paradigm of ataxia telangiectasia', Cell, 86: 159-71.

Beraldi, R., D. K. Meyerholz, A. Savinov, A. D. Kovacs, J. M. Weimer, J. A. Dykstra, R. D. Geraets, and D. A. Pearce. 2017. 'Genetic ataxia telangiectasia porcine model phenocopies the multisystemic features of the human disease', Biochim Biophys Acta Mol Basis Dis, 1863: 2862-70.

Bhatt, Jayesh M., and Andrew Bush. 2014. 'Microbiological surveillance in lung disease in ataxia telangiectasia', European Respiratory Journal, 43: 1797-801.

Boder, Elena, and Robert P. Sedgwick. 1958. 'ATAXIA-TELANGIECTASIA', A Familial Syndrome of Progressive Cerebellar Ataxia, Oculocutaneous Telangiectasia and Frequent Pulmonary Infection, 21: 526-54.

Bogue, M. A., C. Wang, C. Zhu, and D. B. Roth. 1997. 'V(D)J recombination in Ku86-deficient mice: distinct effects on coding, signal, and hybrid joint formation', Immunity, 7: 37-47.

Bosch, Marie K, Yarimar Carrasquillo, Joseph L Ransdell, Ajay Kanakamedala, David M Ornitz, and Jeanne M Nerbonne. 2015. 'Intracellular FGF14 (iFGF14) is required for spontaneous and evoked firing in cerebellar Purkinje neurons and for motor coordination and balance', Journal of Neuroscience, 35: 6752-69.

Bradley, A., K. Anastassiadis, A. Ayadi, J. F. Battey, C. Bell, M. C. Birling, J. Bottomley, S. D. Brown, A. Bürger, C. J. Bult, W. Bushell, F. S. Collins, C. Desaintes, B. Doe, A. Economides, J. T. Eppig, R. H. Finnell, C. Fletcher, M. Fray, D. Frendewey, R. H. Friedel, F. G. Grosveld, J. Hansen, Y. Hérault, G. Hicks, A. Hörlein, R. Houghton, M. Hrabé de Angelis, D. Huylebroeck, V. Iyer, P. J. de Jong, J. A. Kadin, C. Kaloff, K. Kennedy, M. Koutsourakis, K. C. Lloyd, S. Marschall, J. Mason, C. McKerlie, M. P. McLeod, H. von Melchner, M. Moore, A. O. Mujica, A. Nagy, M. Nefedov, L. M. Nutter, G. Pavlovic, J. L. Peterson, J. Pollock, R. Ramirez-Solis, D. E. Rancourt, M. Raspa, J. E. Remacle, M. Ringwald, B. Rosen, N. Rosenthal, J. Rossant, P. Ruiz Noppinger, E. Ryder, J. Z. Schick, F. Schnütgen, P. Schofield, C. Seisenberger, M. Selloum, E. M. Simpson, W. C. Skarnes, D. Smedley, W. L. Stanford, A. F. Stewart, K. Stone, K. Swan, H. Tadepally, L. Teboul, G. P. Tocchini-Valentini, D. Valenzuela, A. P. West, K. Yamamura, Y. 
Perez et al. Resubmission

Yoshinaga, and W. Wurst. 2012. 'The mammalian gene function resource: the International Knockout Mouse Consortium', Mammalian Genome, 23: 580-6.

Bredemeyer, Andrea L, Girdhar G Sharma, Ching-Yu Huang, Beth A Helmink, Laura M Walker, Katrina C Khor, Beth Nuskey, Kathleen E Sullivan, Tej K Pandita, and Craig H Bassing. 2006. 'ATM stabilizes DNA double-strand-break complexes during V (D) J recombination', Nature, 442: 46670.

Browne, Susan E., L. Jackson Roberts, Phyllis A. Dennery, Susan R. Doctrow, M. Flint Beal, Carrolee Barlow, and Rodney L. Levine. 2004. 'Treatment with a catalytic antioxidant corrects the neurobehavioral defect in ataxia-telangiectasia mice', Free Radical Biology and Medicine, 36: 938-42.

Çaglayan, Melike, Rajendra Prasad, Rachel Krasich, Matthew J. Longley, Kei Kadoda, Masataka Tsuda, Hiroyuki Sasanuma, Shunichi Takeda, Keizo Tano, William C. Copeland, and Samuel H. Wilson. 2017. 'Complementation of aprataxin deficiency by base excision repair enzymes in mitochondrial extracts', Nucleic Acids Research, 45: 10079-88.

Campbell, A., B. Krupp, J. Bushman, M. Noble, C. Pröschel, and M. Mayer-Pröschel. 2015. 'A novel mouse model for ataxia-telangiectasia with a $\mathrm{N}$-terminal mutation displays a behavioral defect and a low incidence of lymphoma but no increased oxidative burden', Human Molecular Genetics, 24: 6331-49.

Campbell, Andrew, Jared Bushman, Joshua Munger, Mark Noble, Christoph Pröschel, and Margot Mayer-Pröschel. 2016. 'Mutation of ataxia-telangiectasia mutated is associated with dysfunctional glutathione homeostasis in cerebellar astroglia', Glia, 64: 227-39.

Chao, Connie, Eva Marie Yang, and Yang Xu. 2000. 'Rescue of Defective T Cell Development and Function in $\mathrm{Atm}^{-/}$Mice by a Functional TCRaß Transgene', The Journal of Immunology, 164: 345-49.

Chatterjee, Nimrat, and Graham C. Walker. 2017. 'Mechanisms of DNA damage, repair, and mutagenesis', Environmental and Molecular Mutagenesis, 58: 235-63.

Chen, Philip, Cheng Peng, John Luff, Kevin Spring, Dianne Watters, Steven Bottle, Shigeki Furuya, and Martin F. Lavin. 2003. 'Oxidative Stress Is Responsible for Deficient Survival and Dendritogenesis in Purkinje Neurons from Ataxia-Telangiectasia Mutated Mutant Mice', The Journal of Neuroscience, 23: 11453-60.

Chen, Xi, Tie-Shan Tang, Huiping Tu, Omar Nelson, Mark Pook, Robert Hammer, Nobuyuki Nukina, and llya Bezprozvanny. 2008. 'Deranged calcium signaling and neurodegeneration in spinocerebellar ataxia type 3', Journal of Neuroscience, 28: 12713-24.

Chou, W. C., L. Y. Hu, C. N. Hsiung, and C. Y. Shen. 2015. 'Initiation of the ATM-Chk2 DNA damage response through the base excision repair pathway', Carcinogenesis, 36: 832-40.

Clark, H Brent, Eric N Burright, Wael S Yunis, Seth Larson, Claire Wilcox, Boyd Hartman, Antoni Matilla, Huda Y Zoghbi, and Harry T Orr. 1997. 'Purkinje Cell Expression of a Mutant Allele of SCA1in Transgenic Mice Leads to Disparate Effects on Motor Behaviors, Followed by a Progressive Cerebellar Dysfunction and Histological Alterations', Journal of Neuroscience, 17: 7385-95.

Clements, P. M., C. Breslin, E. D. Deeks, P. J. Byrd, L. Ju, P. Bieganowski, C. Brenner, M. C. Moreira, A. M. Taylor, and K. W. Caldecott. 2004. 'The ataxia-oculomotor apraxia 1 gene product has a role distinct from ATM and interacts with the DNA strand break repair proteins XRCC1 and XRCC4', DNA Repair (Amst), 3: 1493-502.

Concannon, P., and R. A. Gatti. 1997. 'Diversity of ATM gene mutations detected in patients with ataxia-telangiectasia', Human Mutation, 10: 100-7.

Cook, Anna A., Eviatar Fields, and Alanna J. Watt. 2020. 'Losing the Beat: Contribution of Purkinje Cell Firing Dysfunction to Disease, and Its Reversal', Neuroscience.

Coutinho P, Barbot C, Coutinho P. 2002. 'Ataxia with Oculomotor Apraxia Type 1.' in Ardinger HH Adam MP, Pagon RA, et al. (ed.), GeneReviews ${ }^{\circledR}$ (GeneReviews ${ }^{\circledR}$ [Internet]: University of Washington, Seattle).

Crawford, T. O., R. L. Skolasky, R. Fernandez, K. J. Rosquist, and H. M. Lederman. 2006. 'Survival probability in ataxia telangiectasia', Archives of Disease in Childhood, 91: 610-11. 
Perez et al. Resubmission

1012

1013

1014

1015

1016

1017

1018

1019

1020

1021

1022

1023

1024

1025

1026

1027

1028

1029

1030

De Leon, G. A., W. D. Grover, and D. S. Huff. 1976. 'Neuropathologic changes in ataxia-telangiectasia', Neurology, 26: 947-51.

Dell'Orco, James M., Aaron H. Wasserman, Ravi Chopra, Melissa A. C. Ingram, Yuan-Shih Hu, Vikrant Singh, Heike Wulff, Puneet Opal, Harry T. Orr, and Vikram G. Shakkottai. 2015. 'Neuronal Atrophy Early in Degenerative Ataxia Is a Compensatory Mechanism to Regulate Membrane Excitability', The Journal of Neuroscience, 35: 11292-307.

Dell'Orco, James M, Stefan M Pulst, and Vikram G Shakkottai. 2017. 'Potassium channel dysfunction underlies Purkinje neuron spiking abnormalities in spinocerebellar ataxia type 2', Human Molecular Genetics, 26: 3935-45.

Demaerel, PH, BE Kendall, and D Kingsley. 1992. 'Cranial CT and MRI in diseases with DNA repair defects', Neuroradiology, 34: 117-21.

Dineen, Rob A., Felix Raschke, Hannah L. McGlashan, Stefan Pszczolkowski, Lorna Hack, Andrew D. Cooper, Manish Prasad, Gabriel Chow, William P. Whitehouse, and Dorothee P. Auer. 2020. 'Multiparametric cerebellar imaging and clinical phenotype in childhood ataxia telangiectasia', Neurolmage: Clinical, 25: 102110.

Du, L., M. E. Jung, R. Damoiseaux, G. Completo, F. Fike, J. M. Ku, S. Nahas, C. Piao, H. Hu, and R. A. Gatti. 2013. 'A new series of small molecular weight compounds induce read through of all three types of nonsense mutations in the ATM gene', Molecular Therapy, 21: 1653-60.

El-Brolosy, Mohamed A., and Didier Y. R. Stainier. 2017. 'Genetic compensation: A phenomenon in search of mechanisms', Plos Genetics, 13: e1006780-e80.

Elson, A., Y. Wang, C. J. Daugherty, C. C. Morton, F. Zhou, J. Campos-Torres, and P. Leder. 1996. 'Pleiotropic defects in ataxia-telangiectasia protein-deficient mice', Proceedings of the National Academy of Sciences of the United States of America, 93: 13084-9.

Gao, Zhenyu, Boeke J van Beugen, and Chris I De Zeeuw. 2012. 'Distributed synergistic plasticity and cerebellar learning', Nature Reviews: Neuroscience, 13: 619-35.

Gatti, R. A., and H. V. Vinters. 1985. 'Cerebellar pathology in ataxia-telangiectasia: the significance of basket cells', Kroc Foundation Series, 19: 225-32.

Genik, P. C., H. Bielefeldt-Ohmann, X. Liu, M. D. Story, L. Ding, J. M. Bush, C. M. Fallgren, and M. M. Weil. 2014. 'Strain background determines lymphoma incidence in Atm knockout mice', Neoplasia, 16: 129-36.

Germain, Ronald N. 2002. 'T-cell development and the CD4-CD8 lineage decision', Nature Reviews Immunology, 2: 309-22.

Gertsenstein, Marina, Lauryl M. J. Nutter, Tammy Reid, Monica Pereira, William L. Stanford, Janet Rossant, and Andras Nagy. 2010. 'Efficient Generation of Germ Line Transmitting Chimeras from C57BL/6N ES Cells by Aggregation with Outbred Host Embryos', PloS One, 5: e11260.

Gilad, Shlomit, Rami Khosravi, Dganit Shkedy, Tamar Uziel, Yael Ziv, Kinneret Savitsky, Galit Rotman, Sara Smith, Luciana Chessa, Timothy J. Jorgensen, Reli Harnik, Moshe Frydman, Ozden Sanal, Sima Portnoi, Zipora Goldwicz, N. G. J. Jaspers, Richard A. Gatti, Gilbert Lenoir, Martin F. Lavin, Kouichi Tatsumi, Rolf D. Wegner, Yosef Shiloh, and Anat Bar-Shira. 1996. 'Predominance of Null Mutations in Ataxia-Telangiectasia', Human Molecular Genetics, 5: 43339.

Gueven, N., O. J. Becherel, A. W. Kijas, P. Chen, O. Howe, J. H. Rudolph, R. Gatti, H. Date, O. Onodera, G. Taucher-Scholz, and M. F. Lavin. 2004. 'Aprataxin, a novel protein that protects against genotoxic stress', Human Molecular Genetics, 13: 1081-93.

Guo, Zhi, Sergei Kozlov, Martin F. Lavin, Maria D. Person, and Tanya T. Paull. 2010. 'ATM Activation by Oxidative Stress', Science, 330: 517-21.

Hansel, Christian, and David J. Linden. 2000. 'Long-Term Depression of the Cerebellar Climbing FiberPurkinje Neuron Synapse', Neuron, 26: 473-82.

Hansen, Stephen T, Pratap Meera, Thomas S Otis, and Stefan M Pulst. 2013. 'Changes in Purkinje cell firing and gene expression precede behavioral pathology in a mouse model of SCA2', Human Molecular Genetics, 22: 271-83. 
1031

1032

1033

1034

1035

1036

1037

1038

1039

1040

1041

1042

1043

1044

1045

1046

1047

1048

1049

1050

1051

1052

1053

1054

1055

1056

1057

1058

1059

1060

1061

1062

1063

1064

1065

1066

1067

1068

1069

1070

1071

1072

1073

1074

1075

1076

1077

1078

1079

1080

1081

Perez et al. Resubmission

Hathcock, K. S., S. Bowen, F. Livak, and R. J. Hodes. 2013. 'ATM influences the efficiency of TCRbeta rearrangement, subsequent TCRbeta-dependent T cell development, and generation of the preselection TCRbeta CDR3 repertoire', PloS One, 8: e62188.

Herzog, Karl-Heinz, Miriam J. Chong, Manuela Kapsetaki, James I. Morgan, and Peter J. McKinnon. 1998. 'Requirement for Atm in lonizing Radiation-Induced Cell Death in the Developing Central Nervous System', Science, 280: 1089-91.

Hoche, F., K. Seidel, M. Theis, S. Vlaho, R. Schubert, S. Zielen, and M. Kieslich. 2012. 'Neurodegeneration in ataxia telangiectasia: what is new? What is evident?', Neuropediatrics, 43: 119-29.

Hourez, Raphael, Laurent Servais, David Orduz, David Gall, Isabelle Millard, Alban de Kerchove d'Exaerde, Guy Cheron, Harry T Orr, Massimo Pandolfo, and Serge N Schiffmann. 2011. 'Aminopyridines correct early dysfunction and delay neurodegeneration in a mouse model of spinocerebellar ataxia type 1', Journal of Neuroscience, 31: 11795-807.

Hoxha, Eriola, Ilaria Balbo, Maria Concetta Miniaci, and Filippo Tempia. 2018. 'Purkinje Cell Signaling Deficits in Animal Models of Ataxia', Frontiers in Synaptic Neuroscience, 10: 6-6.

Hurlock, Edward C, Anne McMahon, and Rolf H Joho. 2008. 'Purkinje-cell-restricted restoration of Kv3. 3 function restores complex spikes and rescues motor coordination in Kcnc3 mutants', Journal of Neuroscience, 28: 4640-48.

Jackson, Thomas J, Gabriel Chow, Mohnish Suri, Philip Byrd, Malcolm R Taylor, and William P Whitehouse. 2016. 'Longitudinal analysis of the neurological features of ataxia-telangiectasia', Developmental Medicine and Child Neurology, 58: 690-97.

Jayabal, Sriram, Hui Ho Vanessa Chang, Kathleen E Cullen, and Alanna J Watt. 2016. '4aminopyridine reverses ataxia and cerebellar firing deficiency in a mouse model of spinocerebellar ataxia type 6', Scientific Reports, 6: 1-12.

Kaminsky, Natalie, Ofer Bihari, Sivan Kanner, and Ari Barzilai. 2016. 'Connecting Malfunctioning Glial Cells and Brain Degenerative Disorders', Genomics, Proteomics \& Bioinformatics, 14: 155-65.

Kano, Masanobu, and Takaki Watanabe. 2017. 'Type-1 metabotropic glutamate receptor signaling in cerebellar Purkinje cells in health and disease', F1000Research, 6: 416-16.

Kastan, M. B., and J. Bartek. 2004. 'Cell-cycle checkpoints and cancer', Nature, 432: 316-23.

Kasumu, Adebimpe, and llya Bezprozvanny. 2012. 'Deranged calcium signaling in Purkinje cells and pathogenesis in spinocerebellar ataxia 2 (SCA2) and other ataxias', The Cerebellum, 11: 63039.

Kim, Jusik, Keeeun Kim, Jung-Soon Mo, and Youngsoo Lee. 2020. 'Atm deficiency in the DNA polymerase $\beta$ null cerebellum results in cerebellar ataxia and Itpr1 reduction associated with alteration of cytosine methylation', Nucleic Acids Research, 48: 3678-91.

Krangel, Michael S. 2009. 'Mechanics of T cell receptor gene rearrangement', Current Opinion in Immunology, 21: 133-39.

Larivière, Roxanne, Nicolas Sgarioto, Brenda Toscano Márquez, Rébecca Gaudet, Karine Choquet, R Anne McKinney, Alanna J Watt, and Bernard Brais. 2019. 'Sacs R272C missense homozygous mice develop an ataxia phenotype', Molecular Brain, 12: 1-15.

Lavin, M. F. 2013. 'The appropriateness of the mouse model for ataxia-telangiectasia: neurological defects but no neurodegeneration', DNA Repair (Amst), 12: 612-9.

Levy, Ariel, and Anthony E. Lang. 2018. 'Ataxia-telangiectasia: A review of movement disorders, clinical features, and genotype correlations', Movement Disorders, 33: 1238-47.

Li, J., Y. R. Han, M. R. Plummer, and K. Herrup. 2009. 'Cytoplasmic ATM in neurons modulates synaptic function', Current Biology, 19: 2091-6.

Li, Jiali, Jianmin Chen, Harry V. Vinters, Richard A. Gatti, and Karl Herrup. 2011. 'Stable Brain $<$ em $>$ ATM $</$ em $>$ Message and Residual Kinase-Active ATM Protein in Ataxia-Telangiectasia', The Journal of Neuroscience, 31: 7568-77.

Lindahl, T., and D. E. Barnes. 2000. 'Repair of endogenous DNA damage', Cold Spring Harbor Symposia on Quantitative Biology, 65: 127-33. 
Perez et al. Resubmission

1082 1083 1084 1085 1086 1087 1088 1089 1090 1091 1092 1093 1094 1095 1096 1097 1098 1099 1100 1101 1102 1103 1104 1105 1106 1107 1108 1109 1110 1111 1112 1113 1114 1115 1116 1117 1118 1119 1120 1121 1122 1123 1124 1125 1126 1127 1128 1129 1130 1131 1132 1133 1134

Liu, Jing, Tie-Shan Tang, Huiping Tu, Omar Nelson, Emily Herndon, Duong P Huynh, Stefan M Pulst, and llya Bezprozvanny. 2009. 'Deranged calcium signaling and neurodegeneration in spinocerebellar ataxia type 2', Journal of Neuroscience, 29: 9148-62.

Livák, Ferenc, Michelle Tourigny, David G. Schatz, and Howard T. Petrie. 1999. 'Characterization of TCR Gene Rearrangements During Adult Murine T Cell Development', The Journal of Immunology, 162: 2575-80.

Lorenzetti, Diego, Kei Watase, Bisong Xu, Martin M Matzuk, Harry T Orr, and Huda Y Zoghbi. 2000. 'Repeat instability and motor incoordination in mice with a targeted expanded CAG repeat in the Sca1 locus', Human Molecular Genetics, 9: 779-85.

Marshall, Jean S., Richard Warrington, Wade Watson, and Harold L. Kim. 2018. 'An introduction to immunology and immunopathology', Allergy, asthma, and clinical immunology : official journal of the Canadian Society of Allergy and Clinical Immunology, 14: 49-49.

Matei, I. R., C. J. Guidos, and J. S. Danska. 2006. 'ATM-dependent DNA damage surveillance in T-cell development and leukemogenesis: the DSB connection', Immunological Reviews, 209: 142-58.

Matsuoka, Shuhei, Bryan A. Ballif, Agata Smogorzewska, E. Robert McDonald, Kristen E. Hurov, Ji Luo, Corey E. Bakalarski, Zhenming Zhao, Nicole Solimini, Yaniv Lerenthal, Yosef Shiloh, Steven P. Gygi, and Stephen J. Elledge. 2007. 'ATM and ATR Substrate Analysis Reveals Extensive Protein Networks Responsive to DNA Damage', Science, 316: 1160-66.

McKinnon, P. J. 2009. 'DNA repair deficiency and neurological disease', Nature Reviews: Neuroscience, 10: 100-12.

Meagher, M., and R. N. Lightowlers. 2014. 'The role of TDP1 and APTX in mitochondrial DNA repair', Biochimie, 100: 121-4.

Micol, R., L. Ben Slama, F. Suarez, L. Le Mignot, J. Beauté, N. Mahlaoui, C. Dubois d'Enghien, A. Laugé, J. Hall, J. Couturier, L. Vallée, B. Delobel, F. Rivier, K. Nguyen, T. Billette de Villemeur, J. L. Stephan, P. Bordigoni, Y. Bertrand, N. Aladjidi, J. M. Pedespan, C. Thomas, I. Pellier, M. Koenig, O. Hermine, C. Picard, D. Moshous, B. Neven, F. Lanternier, S. Blanche, M. Tardieu, M. Debré, A. Fischer, and D. Stoppa-Lyonnet. 2011. 'Morbidity and mortality from ataxiatelangiectasia are associated with ATM genotype', Journal of Allergy and Clinical Immunology, 128: 382-9.e1.

Monaco, S., E. Nardelli, G. Moretto, T. Cavallaro, and N. Rizzuto. 1988. 'Cytoskeletal pathology in ataxia-telangiectasia', Clinical Neuropathology, 7: 44-6.

Moreira, M. C., S. Klur, M. Watanabe, A. H. Németh, I. Le Ber, J. C. Moniz, C. Tranchant, P. Aubourg, M. Tazir, L. Schöls, M. Pandolfo, J. B. Schulz, J. Pouget, P. Calvas, M. Shizuka-lkeda, M. Shoji, M. Tanaka, L. Izatt, C. E. Shaw, A. M'Zahem, E. Dunne, P. Bomont, T. Benhassine, N. Bouslam, G. Stevanin, A. Brice, J. Guimarães, P. Mendonça, C. Barbot, P. Coutinho, J. Sequeiros, A. Dürr, J. M. Warter, and M. Koenig. 2004. 'Senataxin, the ortholog of a yeast RNA helicase, is mutant in ataxia-ocular apraxia 2', Nature Genetics, 36: 225-7.

Morrell, Daphne, Elizabeth Cromartie, and Michael Swift. 1986. 'Mortality and cancer incidence in 263 patients with ataxia-telangiectasia', Journal of the National Cancer Institute, 77: 89-92.

Paula-Barbosa, M. M., C. Ruela, M. A. Tavares, C. Pontes, A. Saraiva, and C. Cruz. 1983. 'Cerebellar cortex ultrastructure in ataxia-telangiectasia', Annals of Neurology, 13: 297-302.

Perkins, Emma M, Yvonne L Clarkson, Nancy Sabatier, David M Longhurst, Christopher P Millward, Jennifer Jack, Junko Toraiwa, Mitsunori Watanabe, Jeffrey D Rothstein, and Alastair R Lyndon. 2010. 'Loss of $\beta$-III spectrin leads to Purkinje cell dysfunction recapitulating the behavior and neuropathology of spinocerebellar ataxia type 5 in humans', Journal of Neuroscience, 30: 485767.

Petersen, Andrew J., Stacey A. Rimkus, and David A. Wassarman. 2012. 'ATM kinase inhibition in glial cells activates the innate immune response and causes neurodegeneration in $<$ em>Drosophila</em>', Proceedings of the National Academy of Sciences, 109: E656-E64.

Pizzamiglio, L., E. Focchi, and F. Antonucci. 2020. 'ATM Protein Kinase: Old and New Implications in Neuronal Pathways and Brain Circuitry', Cells, 9.

Quarantelli, Mario, Giuliana Giardino, Anna Prinster, Giuseppina Aloj, Barbara Carotenuto, Emilia Cirillo, Angela Marsili, Elena Salvatore, Ennio Del Giudice, and Claudio Pignata. 2013. 'Steroid 
1135

1136

1137

1138

1139

1140

1141

1142

1143

1144

1145

1146

1147

1148

1149

1150

1151

1152

1153

1154

1155

1156

1157

1158

1159

1160

1161

1162

1163

1164

1165

1166

1167

1168

1169

1170

1171

1172

1173

1174

1175

1176

1177

1178

1179

1180

1181

1182

1183

1184

1185

1186

1187

Perez et al. Resubmission

treatment in Ataxia-Telangiectasia induces alterations of functional magnetic resonance imaging during prono-supination task', European Journal of Paediatric Neurology, 17: 135-40.

Quek, Hazel, John Luff, KaGeen Cheung, Sergei Kozlov, Magtouf Gatei, C. Soon Lee, Mark C. Bellingham, Peter G. Noakes, Yi Chieh Lim, Nigel L. Barnett, Steven Dingwall, Ernst Wolvetang, Tomoji Mashimo, Tara L. Roberts, and Martin F. Lavin. 2016. 'A rat model of ataxiatelangiectasia: evidence for a neurodegenerative phenotype', Human Molecular Genetics, 26: 109-23.

Rashi-Elkeles, S., R. Elkon, N. Weizman, C. Linhart, N. Amariglio, G. Sternberg, G. Rechavi, A. Barzilai, R. Shamir, and Y. Shiloh. 2006. 'Parallel induction of ATM-dependent pro- and antiapoptotic signals in response to ionizing radiation in murine lymphoid tissue', Oncogene, 25: 1584-92.

Rass, Ulrich, Ivan Ahel, and Stephen C. West. 2007. 'Defective DNA Repair and Neurodegenerative Disease', Cell, 130: 991-1004.

Rogers, D. C., E. M. Fisher, S. D. Brown, J. Peters, A. J. Hunter, and J. E. Martin. 1997. 'Behavioral and functional analysis of mouse phenotype: SHIRPA, a proposed protocol for comprehensive phenotype assessment', Mammalian Genome, 8: 711-3.

Rothblum-Oviatt, Cynthia, Jennifer Wright, Maureen A. Lefton-Greif, Sharon A. McGrath-Morrow, Thomas O. Crawford, and Howard M. Lederman. 2016. 'Ataxia telangiectasia: a review', Orphanet Journal of Rare Diseases, 11: 159.

Sahama, Ishani, Kate Sinclair, Simona Fiori, James Doecke, Kerstin Pannek, Lee Reid, Martin Lavin, and Stephen Rose. 2015. 'Motor pathway degeneration in young ataxia telangiectasia patients: A diffusion tractography study', Neurolmage: Clinical, 9: 206-15.

Sahama, Ishani, Kate Sinclair, Kerstin Pannek, Martin Lavin, and Stephen Rose. 2014. 'Radiological imaging in ataxia telangiectasia: a review', The Cerebellum, 13: 521-30.

Sandoval, N., M. Platzer, A. Rosenthal, T. Dork, R. Bendix, B. Skawran, M. Stuhrmann, R. D. Wegner, K. Sperling, S. Banin, Y. Shiloh, A. Baumer, U. Bernthaler, H. Sennefelder, M. Brohm, B. H. Weber, and D. Schindler. 1999. 'Characterization of ATM gene mutations in 66 ataxia telangiectasia families', Human Molecular Genetics, 8: 69-79.

Sanghez, Valentina, Anna Luzzi, Don Clarke, Dustin Kee, Steven Beuder, Danielle Rux, Mitsujiro Osawa, Joaquín Madrenas, Tsui-Fen Chou, Michael Kyba, and Michelina lacovino. 2017. 'Notch activation is required for downregulation of HoxA3-dependent endothelial cell phenotype during blood formation', PloS One, 12: e0186818.

Savitsky, K., A. Bar-Shira, S. Gilad, G. Rotman, Y. Ziv, L. Vanagaite, D. A. Tagle, S. Smith, T. Uziel, S. Sfez, M. Ashkenazi, I. Pecker, M. Frydman, R. Harnik, S. R. Patanjali, A. Simmons, G. A. Clines, A. Sartiel, R. A. Gatti, L. Chessa, O. Sanal, M. F. Lavin, N. G. Jaspers, A. M. Taylor, C. F. Arlett, T. Miki, S. M. Weissman, M. Lovett, F. S. Collins, and Y. Shiloh. 1995. 'A single ataxia telangiectasia gene with a product similar to PI-3 kinase', Science, 268: 1749-53.

Schellenberg, M. J., P. P. Tumbale, and R. S. Williams. 2015. 'Molecular underpinnings of Aprataxin RNA/DNA deadenylase function and dysfunction in neurological disease', Progress in Biophysics and Molecular Biology, 117: 157-65.

Schubert, R., J. Reichenbach, and S. Zielen. 2002. 'Deficiencies in CD4+ and CD8+ T cell subsets in ataxia telangiectasia', Clinical and Experimental Immunology, 129: 125-32.

Sedghi, Maryam, Mehri Salari, Ali-Reza Moslemi, Ariana Kariminejad, Mark Davis, Hayley Goullée, Björn Olsson, Nigel Laing, and Homa Tajsharghi. 2018. 'Ataxia-telangiectasia-like disorder in a family deficient for MRE11A, caused by a <em>MRE11</em> variant', Neurology Genetics, 4: e295.

Shakkottai, Vikram G, Maria do Carmo Costa, James M Dell'Orco, Ananthakrishnan Sankaranarayanan, Heike Wulff, and Henry L Paulson. 2011a. 'Early changes in cerebellar physiology accompany motor dysfunction in the polyglutamine disease spinocerebellar ataxia type 3', Journal of Neuroscience, 31: 13002-14.

Shakkottai, Vikram G, Maolei Xiao, Lin Xu, Michael Wong, Jeanne M Nerbonne, David M Ornitz, and Kelvin A Yamada. 2009. 'FGF14 regulates the intrinsic excitability of cerebellar Purkinje neurons', Neurobiology of Disease, 33: 81-88. 
1188

1189

1190

1191

1192

1193

1194

1195

1196

1197

1198

1199

1200

1201

1202

1203

1204

1205

1206

1207

1208

1209

1210

1211

1212

1213

1214

1215

1216

1217

1218

1219

1220

1221

1222

1223

1224

1225

1226

1227

1228

1229

1230

1231

1232

1233

1234

1235

1236

1237

1238

1239

Perez et al. Resubmission

Shakkottai, Vikram G., Maria do Carmo Costa, James M. Dell'Orco, Ananthakrishnan Sankaranarayanan, Heike Wulff, and Henry L. Paulson. 2011b. 'Early Changes in Cerebellar Physiology Accompany Motor Dysfunction in the Polyglutamine Disease Spinocerebellar Ataxia Type 3', The Journal of Neuroscience, 31: 13002-14.

Shiloh, Yosef. 2020. 'The cerebellar degeneration in ataxia-telangiectasia: A case for genome instability', DNA Repair, 95: 102950.

Shiloh, Yosef, and Yael Ziv. 2013. 'The ATM protein kinase: regulating the cellular response to genotoxic stress, and more', Nature Reviews Molecular Cell Biology, 14: 197-210.

Solitare, G. B. 1968. 'Louis-Bar's syndrome (ataxia-telangiectasia). Anatomic considerations with emphasis on neuropathologic observations', Neurology, 18: 1180-6.

Solitare, G. B., and V. F. Lopez. 1967. 'Louis-bar's syndrome (ataxia-telangiectasia). Neuropathologic observations', Neurology, 17: 23-31.

Spring, K., S. Cross, C. Li, D. Watters, L. Ben-Senior, P. Waring, F. Ahangari, S. L. Lu, P. Chen, I. Misko, C. Paterson, G. Kay, N. I. Smorodinsky, Y. Shiloh, and M. F. Lavin. 2001. 'Atm knock-in mice harboring an in-frame deletion corresponding to the human ATM 7636del9 common mutation exhibit a variant phenotype', Cancer Research, 61: 4561-8.

Staples, E. R., E. M. McDermott, A. Reiman, P. J. Byrd, S. Ritchie, A. M. Taylor, and E. G. Davies. 2008. 'Immunodeficiency in ataxia telangiectasia is correlated strongly with the presence of two null mutations in the ataxia telangiectasia mutated gene', Clinical and Experimental Immunology, 153: 214-20.

Stoyas, Colleen A, David D Bushart, Pawel M Switonski, Jacqueline M Ward, Akshay Alaghatta, Mi-bo Tang, Chenchen Niu, Mandheer Wadhwa, Haoran Huang, and Alex Savchenko. 2020. 'Nicotinamide pathway-dependent Sirt1 activation restores calcium homeostasis to achieve neuroprotection in spinocerebellar ataxia type 7', Neuron, 105: 630-44. e9.

Strich, Sabina J. 1966. 'Pathological findings in three cases of ataxia-telangiectasia', Journal of Neurology, Neurosurgery, and Psychiatry, 29: 489.

Swift, M., D. Morrell, E. Cromartie, A. R. Chamberlin, M. H. Skolnick, and D. T. Bishop. 1986. 'The incidence and gene frequency of ataxia-telangiectasia in the United States', American Journal of Human Genetics, 39: 573-83.

Sykora, Peter, Deborah L. Croteau, Vilhelm A. Bohr, and David M. Wilson, 3rd. 2011. 'Aprataxin localizes to mitochondria and preserves mitochondrial function', Proceedings of the National Academy of Sciences of the United States of America, 108: 7437-42.

Takashima, H., C. F. Boerkoel, J. John, G. M. Saifi, M. A. Salih, D. Armstrong, Y. Mao, F. A. Quiocho, B. B. Roa, M. Nakagawa, D. W. Stockton, and J. R. Lupski. 2002. 'Mutation of TDP1, encoding a topoisomerase I-dependent DNA damage repair enzyme, in spinocerebellar ataxia with axonal neuropathy', Nature Genetics, 32: 267-72.

Tal, Efrat, Marina Alfo, Shan Zha, Ari Barzilai, Chris I. De Zeeuw, Yael Ziv, and Yosef Shiloh. 2018. 'Inactive Atm abrogates DSB repair in mouse cerebellum more than does Atm loss, without causing a neurological phenotype', DNA Repair, 72: 10-17.

Tavani, F., R. A. Zimmerman, G. T. Berry, K. Sullivan, R. Gatti, and P. Bingham. 2003. 'Ataxiatelangiectasia: the pattern of cerebellar atrophy on MRI', Neuroradiology, 45: 315-19.

Taylor, A. M., Z. Lam, J. I. Last, and P. J. Byrd. 2015. 'Ataxia telangiectasia: more variation at clinical and cellular levels', Clinical Genetics, 87: 199-208.

Terplan, K. L., and R. F. Krauss. 1969. 'Histopathologic brain changes in association with ataxiatelangiectasia', Neurology, 19: 446-54.

Tsutsumi, S., M. Yamazaki, T. Miyazaki, M. Watanabe, K. Sakimura, M. Kano, and K. Kitamura. 2015. 'Structure-function relationships between aldolase C/zebrin II expression and complex spike synchrony in the cerebellum', Journal of Neuroscience, 35: 843-52.

Tumbale, Percy, Matthew J Schellenberg, Geoffrey A Mueller, Emma Fairweather, Mandy Watson, Jessica N Little, Juno Krahn, lan Waddell, Robert E London, and R Scott Williams. 2018. 'Mechanism of APTX nicked DNA sensing and pleiotropic inactivation in neurodegenerative disease', The EMBO Journal, 37: e98875. 
Perez et al. Resubmission

Vacchio, Melanie S., Alexandru Olaru, Ferenc Livak, and Richard J. Hodes. 2007. 'ATM deficiency impairs thymocyte maturation because of defective resolution of T cell receptor a locus coding end breaks', Proceedings of the National Academy of Sciences, 104: 6323-28.

Vail, Graham, Aifang Cheng, Yu Ray Han, Teng Zhao, Shengwang Du, Michael M. T. Loy, Karl Herrup, and Mark R. Plummer. 2016. 'ATM protein is located on presynaptic vesicles and its deficit leads to failures in synaptic plasticity', Journal of Neurophysiology, 116: 201-09.

Valentin-Vega, Y. A., and M. B. Kastan. 2012. 'A new role for ATM: regulating mitochondrial function and mitophagy', Autophagy, 8: 840-1.

van der Burgt, I, K H Chrzanowska, D Smeets, and C Weemaes. 1996. 'Nijmegen breakage syndrome', Journal of Medical Genetics, 33: 153-56.

Verhagen, Mijke M.M., Jean-Jacques Martin, Marcel van Deuren, Chantal Ceuterick-de Groote, Corry M.R. Weemaes, Berry H.P.H. Kremer, Malcolm A.R. Taylor, Michèl A.A.P. Willemsen, and Martin Lammens. 2012. 'Neuropathology in classical and variant ataxia-telangiectasia', Neuropathology, 32: 234-44.

Voogd, Jan, and Mitchell Glickstein. 1998. 'The anatomy of the cerebellum', Trends in Neurosciences, 21: $370-75$.

Wakasugi, M., T. Sasaki, M. Matsumoto, M. Nagaoka, K. Inoue, M. Inobe, K. Horibata, K. Tanaka, and T. Matsunaga. 2014. 'Nucleotide excision repair-dependent DNA double-strand break formation and ATM signaling activation in mammalian quiescent cells', Journal of Biological Chemistry, 289: $28730-7$.

Wallis, LI, PD Griffiths, SJ Ritchie, CAJ Romanowski, G Darwent, and ID Wilkinson. 2007. 'Proton spectroscopy and imaging at $3 \mathrm{~T}$ in ataxia-telangiectasia', American journal of neuroradiology, 28: 79-83.

Walter, Joy T, Karina Alvina, Mary D Womack, Carolyn Chevez, and Kamran Khodakhah. 2006. 'Decreases in the precision of Purkinje cell pacemaking cause cerebellar dysfunction and ataxia', Nature Neuroscience, 9: 389-97.

Weyemi, Urbain, Christophe E. Redon, Towqir Aziz, Rohini Choudhuri, Daisuke Maeda, Palak R. Parekh, Michael Y. Bonner, Jack L. Arbiser, and William M. Bonner. 2015. 'NADPH oxidase 4 is a critical mediator in Ataxia telangiectasia disease', Proceedings of the National Academy of Sciences, 112: 2121-26.

$\mathrm{Xu}, \mathrm{Y}$., and D. Baltimore. 1996. 'Dual roles of ATM in the cellular response to radiation and in cell growth control', Genes and Development, 10: 2401-10.

Yamasaki, Miwako, Kouichi Hashimoto, and Masanobu Kano. 2006. 'Miniature Synaptic Events Elicited by Presynaptic $\mathrm{Ca}^{2}+$ Rise Are Selectively Suppressed by Cannabinoid Receptor Activation in Cerebellar Purkinje Cells', The Journal of Neuroscience, 26: 86-95.

Zhou, Haibo, Zhanmin Lin, Kai Voges, Chiheng Ju, Zhenyu Gao, Laurens W. J. Bosman, Tom J. H. Ruigrok, Freek E. Hoebeek, Chris I. De Zeeuw, and Martijn Schonewille. 2014. 'Cerebellar modules operate at different frequencies', Elife, 3: e02536.

Zhu, L., B. Scelfo, F. Tempia, B. Sacchetti, and P. Strata. 2006. 'Membrane excitability and fear conditioning in cerebellar Purkinje cell', Neuroscience, 140: 801-10. 
Perez et al. Resubmission

\subsection{Figure Legends}

Figure 1. New A-T mouse models expressing clinically related PTCs. A) The Atm gene locus was targeted by homologous recombination of a targeting vector containing a modified NorCOMM cassette

in intron one and the corresponding A-T PTC mutation in exon 3 to create the targeted Atm $^{R 35 X}$ and 1285 $A t m^{Q 35 X}$ ES cell lines. Following germline transmission of these alleles in mice, the floxed NorCOMM cassette was removed by Cre excision in vivo to produce the final $A_{t m^{R 35 X}}$ and $A_{t m}^{Q 35 X}$ mouse lines. B) 1287 Genotyping of A-T mouse models. PCR agarose gel of mouse DNA shows 151 bp wildtype (+) allele 1288 band and 241 bp Cre-excised targeted allele band. C) ATM levels were examined using immunoblot 1289 analyses of the spleen due to its high expression density in this tissue. Exemplar blots illustrate a gene 1290 dose effect of ATM protein expression in samples harvested from wildtype (+), heterozygous (R35X/+,

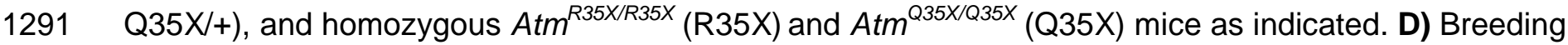
1292 scheme schematic for double mutant and control mice for this study. E) Atm $^{R 35 X / R 35 X}$; Aptx ${ }^{-/-}$mice 1293 develop an ataxia that at late stages results in a severe loss of motor coordination and ability to ambulate (see Videos 1-4). Abbreviations for panel 1: h $\beta$ A-human beta Actin promotor; $\Delta$ TK1-delta 1295 TK1, inactivated Thymidine Kinase 1; T2A-self-cleaving peptide sequence; Neo-Neomycin gene; 1296 PGKpA-Phosphoglycerate kinase poly A tail; loxP-recombination elements are show as a blue 1297 triangle; orientation of the Gateway attB recombination elements by an orange arrow; orientation of the 1298 genotyping $\mathbf{F}$ and $\mathbf{R}$ primers is shown by green and blue arrows respectively; and engineered PTC 1299 sites are shown in exon 3 by a red circle.

1300 Figure 2. Health and survivability of single and double mutant mice. A) Left: The line color and 1301 symbol for each genotype is denoted and is consistent across all figures (1-8). Right: Atm $^{R 35 X / R 35 X}$; $1302 A p t x^{-/}$mice weighed significantly less than all control genotypes as indicated by the growth curves $( \pm$ $130395 \%$ confidence interval; dotted lines). Growth curve (Atm ${ }^{R 35 X / R 35 X} ;$ Aptx $^{-/}$vs. controls): Male $\mathrm{k}=0.024$ 1304 vs. $0.011-0.019, \mathrm{Y}_{\max }=21.8$ vs. 32.9-41.0 $\mathrm{g},(\mathrm{n}=3$ to 18$)$; Female $\mathrm{k}=0.030$ vs. $0.017-0.022, \mathrm{Y}_{\max }=$ 130516.9 vs. 23.3-31.3, $(\mathrm{n}=2$ to 19$)$. Sum of squares F-test run across all curves: Male $\mathrm{F}_{(12,364)}=30.5$, $1306 * * * * \mathrm{p}<0.0001$, Female $\mathrm{F}_{(12,339)}=28.3$, ****p<0.0001. B) ATM deficient mice, regardless of APTX 
Perez et al. Resubmission

1307 expression, displayed significantly lower survivability with $\sim 55 \%$ of mice deceased by P400. No 1308 statistical differences between ATM deficient mice were detected. Moreover, a single wildtype copy of 1309 the Atm gene was sufficient to prevent premature death (no statistical difference detected between $1310 \mathrm{Atm}^{R 35 \mathrm{X} /+} ; \mathrm{Aptx}^{-/-}$and $\mathrm{Atm}^{+/+} ; \mathrm{Aptx}^{+/+}$mice). Log-rank (Mantel-Cox) tests across all $\left(\chi^{2}(6,217)=48.4\right.$, $1311 * * * * \mathrm{p}<0.0001)$, just the ATM deficient $\left(\chi_{(2,217)}^{2}=1.06, \mathrm{p}=0.6\right)$, and single comparisons to wildtype (see

1312 figure) were conducted. Total number of animals indicated in panel C. C) Pie charts illustrating that 1313 ATM deficient mice displayed a high prevalence of thymomas based on postmortem necropsies. 1314 "Other" probable causes of death included enlarged livers, and obstructed kidneys. "Missing" mice were presumed dead and cannibalized by cage mates, cause of death unknown. Figure 2-figure

\section{supplement 1, Figure 2-source data}

1317 Figure 2-figure supplement 1. Animal weight for each time point and genotype. A) The average 1318 weights are plotted for each genotype at each of the indicated time points. Growth curves without 1319 experimental, 2-way ANOVA with age and genotype as factors. Male: $\mathrm{F}_{(10,226)}=5.6$, $\mathrm{p}<0.0001$; Female: $1320 \mathrm{~F}_{(10,197)}=7.3, \mathrm{p}<0.0001$. B) The survivability of each genotype of mice are plotted for male and female 1321 individually.

Figure 3. Atm ${ }^{R 35 X / R 35 X} ; A^{-1 /}$ mice develop a progressive loss in motor coordination. A) $\mathrm{Atm}^{R 35 X / R 35 X} ;$ Aptx $^{-/}$mice take a similar amount of time to descend a vertical pole at P45, 120, and 210, but significantly longer at P400. These overall results were found to be similar for both male (left, $n=2$

to 12) and female (right, $n=4$ to 12) mice. B) Consistent with the vertical pole test, the gait of Atm $^{\text {R35X/R35X }} ;$ Aptx $^{-/-}$mice measured during ambulation on a Catwalk gait analysis system was significantly different to controls by P400, but not before P210. This includes the percent of time a mouse spends with 3 vs. 1, 2, or 4 paws on the ground and the speed and cadence during each run across the platform. The effects of the two null mutations were generally similar between males (left, $n$ $1330=4$ to 21 ) and females (right, $n=3$ to 18). C) Behavioral data for male (blue) and female (pink) $1331 \mathrm{Atm}{ }^{R 35 X / R 35 X} ;$ Aptx $^{-/}$(dark purple, left) and $\mathrm{Atm}^{+/+} ; \mathrm{Aptx}^{+/+}$(orange, right) mice are plotted at P30 (left 2 1332 columns) and 400 (right 2 columns). Left-right asymmetries of the horizontal bars indicate a difference 
Perez et al. Resubmission

1333 in performance between genotypes for the behavioral test listed in a column on the far left. A significant 1334 difference in the time to right during the righting reflex at P8 was observed in both Male and Female 1335 mice (bottom). A and B were examined via two-way ANOVA with age and genotype as factors followed 1336 by potshot Tukey's multiple comparison tests between Atm $^{R 35 X / R 35 X} ; A p t x^{-/-}$and each of the control 1337 genotypes. Behavioral tests in $\mathbf{C}$ were examined using a non-parametric Kruskal Wallace followed by

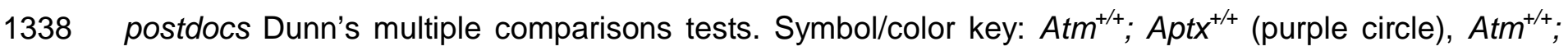
$1339 A^{A p t x^{-/}}$(blue diamond), Atm ${ }^{R 35 X / R 35 X} ; A^{2} x^{+/+}$(green triangle), Atm ${ }^{R 35 X / R 35 X} ; A p t x^{-/-}$(orange square), $1340 A \mathrm{Atm}^{R 35 \mathrm{X}++} ; \mathrm{AptX}^{-/-}$(red inverted triangle) Figure 3-figure supplement 1, Figure 3-source data

1341 Figure 3-figure supplement 1. Atm ${ }^{R 35 X / R 35 X} ; A^{-1 /}$ mice develop progressive ataxia. A) $1342 A A^{R 35 X / R 35 X} ; A p t x^{-/-}$mice develop an ataxia that at late stages results in a severe loss of coordination 1343 and ability to ambulate. B) Additional gait analyses measuring stride length and time of overlap of the 1344 hindlimbs. Examined via two-way ANOVA with age and genotype as factors followed by potshot 1345 Tukey's multiple comparison tests between Atm $^{R 35 X / R 35 X} ;$ Aptx ${ }^{-/-}$and each of the control genotypes. C) 1346 Behavioral deficits are seen only in $A t m^{R 35 X / R 35 X} ;$ Aptx ${ }^{-/-}$mice across all behavioral tests and sexes. 1347 Behavioral tests were examined using a non-parametric Kruskal Wallace followed by posthoc Dunn's 1348 multiple comparisons tests.

1349 Figure 4. The biophysical properties of PNs are significantly perturbed in Atm $^{R 35 X / R 35 X}$; Aptx 1350 mice. A) Schematic diagram of intracellular recording from a single Purkinje neuron (PN) in an acute 1351 cerebellar tissue slice preparation used to examine their biophysical properties. B) Left: Voltage clamp 1352 measurements of $\mathrm{PN}$ neuron membrane properties were made from a $1 \mathrm{~s},-5 \mathrm{mV}$ step pulse as 1353 illustrated. Right: The membrane input resistance $\left(R_{m}\right)$, time constant $(\tau)$, and capacitance $\left(C_{m}\right)$ were 1354 perturbed in Atm ${ }^{R 35 X / R 35 X} ;$ Aptx ${ }^{-/-}$compared to Atm $^{+/+} ;$Aptx ${ }^{+/+}$mice. C) Current clamp recordings of PN 1355 action potentials (AP) after $2 \mathrm{nA}$ step pulses from a $-70 \mathrm{mV}$ holding potential. PN action potentials 1356 recorded from $A t m^{R 35 X / R 35 X} ; A p t x^{-/-}$fail to maintain constant firing and summary plots show that they 1357 have lower $1^{\text {st }}$ AP amplitudes, firing threshold, and area under the curve. D) Top: Example mEPSC 1358 traces taken from a PN under voltage clamp at a $-80 \mathrm{mV}$ holding potential. Bottom: Median frequency 
Perez et al. Resubmission

1359 and amplitude data, along with the overall probability distribution function are plotted for both $\mathrm{Atm}^{+/+}$; $1360 A p t x^{+/+}(\mathrm{n}=11)$ and $\operatorname{Atm}^{R 35 X / R 35 X} ; \operatorname{Aptx}^{-/-}(\mathrm{n}=11)$ mice. The frequency, but not amplitude of PNs recorded 1361 in Atm $^{R 35 X / R 35 X}$; Aptx ${ }^{-/-}$mice was found to be perturbed. $\mathbf{E}$ and F) Left: Example traces of evoked 1362 EPSCs recorded from PNs as a result of a 2-pulse stimulation (50 ms interval) of either parallel (E) or 1363 climbing $(\mathbf{F})$ axon fibers. Traces illustrate the first $\left(A_{1}\right)$ and second $\left(A_{2}\right)$ amplitude (normalized) and time 1364 course of first decay (blue fitted line) of each synaptic response. Right: Summary plots of the paired 1365 pulse ratio. While parallel fiber paired pulse facilitation was normal in $\mathrm{Atm}^{R 35 X / R 35 X} ;$ Aptx ${ }^{-/-}$mice, climbing 1366 fiber paired pulse depression and halfwidth was significantly perturbed compared to Atm $^{+/+}$; Aptx $^{+/+}$ 1367 mice. Data in B were compared using an ANOVA (Kruskal-Wallis) followed by Dunn's multiple 1368 comparisons test while data in $\mathbf{D}$ to $\mathbf{F}$ were compared via Welch's $t$-test. Symbol/color key: Atm $^{+/+}$; $1369 A p t x^{+/+}$(purple circle), $A^{R 3 m^{R 3 / R 35 X}} ; A^{-/-}$(orange square) Figure 4-figure supplement 1

Figure 4-figure supplement 1. Current vs. voltage responses significantly differ between $\mathrm{Atm}^{+/+}$; $\boldsymbol{A p t x}^{+/+}$and $\mathbf{A t m}^{\mathbf{R 3 5 X / R 3 5 X}} ; \boldsymbol{A p t x}^{-/-}$mice. A) PN voltage responses to various current steps between -500 1372 and $2250 \mathrm{pA}$ (250 pA steps) from a $-70 \mathrm{mV}$ holding current in $\mathrm{Atm}^{+/+}$; Aptx ${ }^{+/+}$(top, purple) and $1373 A A^{R 35 X / R 35 X} ;$ Aptx ${ }^{-/-}$(bottom, orange) mice. (B) I $\square \mathrm{V}$ curves calculated from either max deflection $\left(\mathrm{V}_{\mathrm{m} \text { max }}\right)$

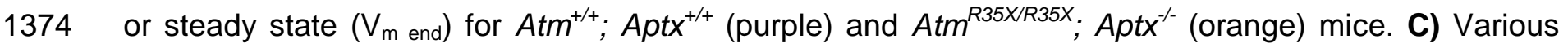
1375 measurements of the voltage response to -500 pA step pulse (blue box in B) in Atm $^{+/+}$; Aptx ${ }^{+/+}$(purple) 1376 and Atm $^{R 35 X / R 35 X} ;$ Aptx $^{-/}$(orange) mice. Significance was tested using a non-parametric Mann Whitney 1377 test.

Figure 5. Cerebellar atrophy is associated with a progressive reduction in PN neural action potential firing frequency and PN dendritic length. A) Schematic diagram of extracellular recording from a single Purkinje neuron $(P N)$ in an acute cerebellar tissue slice preparation. Example electrophysiological traces for $\mathrm{Atm}^{+/+} ; \mathrm{Aptx}^{+/+}$(purple, top) and $\mathrm{Atm}^{R 35 \mathrm{X} / \mathrm{R} 35 \mathrm{X}} ;$ Aptx $^{-/}$(orange, bottom) PNs progressively decreased with age and was significantly slower in comparison to all control genotypes

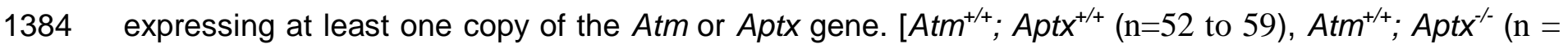


Perez et al. Resubmission

1385

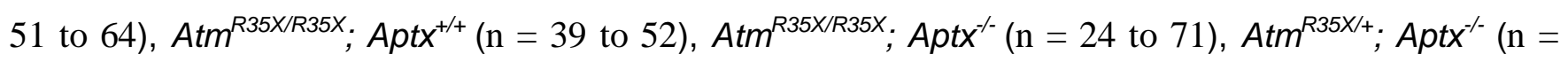

69)] C) Cartoon image of the brain highlighting the dorsal forebrain and cerebellar surface. 2-

dimensional area estimates from dorsal images of the brain were used to determine the cerebellum to forebrain ratio allowing us to control for any differences in overall size of the brain. We found the cerebellum decreased in size over age in $\operatorname{Atm}^{R 35 X / R 35 X} ; A \operatorname{Apt}{ }^{---}(\mathrm{n}=5$ to 10$)$, but not control mice $\left[\operatorname{Atm}^{+/+}\right.$;

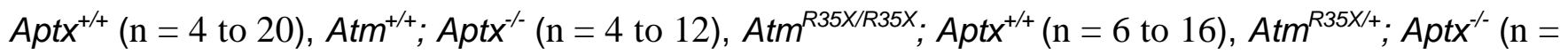

6)]. D) Immunofluorescent images of $\mathrm{Atm}^{+/+} ; \mathrm{Aptx}^{+/+}$(top) and $\mathrm{Atm}^{\mathrm{R35X/R35X}} ; \mathrm{Aptx}^{-/-}$(bottom) at P400 1392 (medial cerebellar lobule VIII). Scale bar $=50 \mu \mathrm{m} \mathrm{E}$ ) The width of the molecular layer, but not the 1393 granule cell layer progressively declined over age $(n=5$ to 7$)$. Statistical significances were assessed 1394 via 2-way ANOVA with age and genotype as factors followed by posthoc Holm-Sidak (B, C, and E 1395 (top)) or Sidak (E bottom) pairwise multiple comparisons test. Figure 5-figure supplements 1-5, 1396 Figure 5-source data

Figure 5-figure supplement 1. Mean PN firing frequency across the cerebellum. Average PN firing frequency is plotted across the indicated locations at P45, 120, 210, and 400.

Figure 5-figure supplement 2. Mean PN firing frequency across genotype and sex. Average PN

1401 No significant differences were observed between sex. 2-Way ANOVA with age and sex as factors, $\operatorname{Atm}^{+/+} ; \operatorname{Aptx}^{+/+}\left(\mathrm{F}_{(1,751}=1.15, \mathrm{p}=0.3\right), \operatorname{Atm}^{+/+} ; \operatorname{Aptx}^{-/-}\left(\mathrm{F}_{(1,797)}=1.10, \mathrm{p}=0.3\right), \operatorname{Atm}^{R 35 X / R 35 X} ; \operatorname{Aptx}^{+/+}\left(\mathrm{F}_{(1,630)}=\right.$

0.17, $\mathrm{p}=0.7)$, Atm $^{R 35 X / R 35 X} ; \operatorname{Aptx}^{-/}\left(\mathrm{F}_{(1,666)}=1.10, \mathrm{p}=0.4\right), t$-test for P400 Atm ${ }^{R 35 X /+} ; \operatorname{Aptx}^{-/}(\mathrm{p}=0.9)$

Figure 5-figure supplement 3. Coefficient of Variation of PN firing frequency across the cerebellum. Average CV of PN firing frequency is plotted across the indicated locations at P45, 120, 1406 210, and 400. No significant differences $(\mathrm{p}<0.5)$ were detected across all areas using 2-way ANOVA 1407 with age and genotype as factors.

1408 Figure 5-figure supplement 4. Mean variation between PN firing intervals across the cerebellum. 1409 Average CV2 of PN firing frequency is plotted across the indicated locations at P45, 120, 210 , and 400. 
Perez et al. Resubmission

1410 No significant differences $(\mathrm{p}<0.5)$ were detected across all areas using 2-way ANOVA with age and 1411 genotype as factors.

1412 Figure 5-figure supplement 5. Histopathological effects of ATM and APTX deficiency. A) Width 1413 measurements of the molecular and granule cell layer (ML and GCL respectively) for each folia across 1414 the medial intermediate and lateral areas of the cerebellum. B) (Top) Summary plot indicates no 1415 significant differences in the 2D linear density of PNs across each folia in Atm $^{R 35 X / R 35 X} ;$ Aptx $^{-/-}$vs. Atm $^{+/+}$; $1416 A p t x^{+/}$. (Bottom) Images of parasagittal cerebellar slices (2.5X) illustrating the lack of significant gaps 1417 in PN (green, Calbindin) or granule cell layers (magenta, DAPI). Scale bar $=0.5 \mathrm{~mm}$ (C) Images of

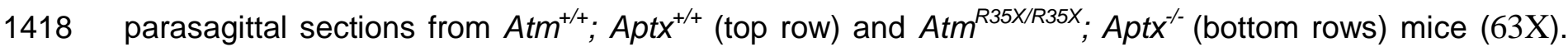
1419 PNs (green, Calbindin) were found to have a larger diameter than those found in Atm $^{+/+} ;$Aptx $^{+/+}$cells 1420 (red arrows). PN axonal swellings were also observed in $A t m^{R 35 X / R 35 X} ; A p t x^{-/}$sections (magenta arrows). 1421 Scale bar $=50 \mu \mathrm{m}$

1422 Figure 6. T-cell deficits are found in the blood of $\mathbf{A t m}^{R 35 X / R 35 X}$; Aptx $^{-/-}$mice. A) Representative flow 1423 cytometric profiles of T-cell glycoprotein marker CD3 and summary plots indicate ATM and/or APTX 1424 deficient mice have decreased proportions of $\mathrm{CD}^{+}$T-cells in the blood. B) Representative flow 1425 cytometric profiles of T-cell glycoprotein markers CD4 and CD8 gated on CD3 ${ }^{+}$cells and summary plots 1426 for CD8 and CD4 single positive cell proportions. ATM deficient mice had reduced CD4 ${ }^{+}$proportions 1427 compared to mice with at least one copy of the Atm gene. Statistical significances were assessed via 11428 way ANOVA followed by posthoc Tukey's pairwise multiple comparisons tests. Number of animals

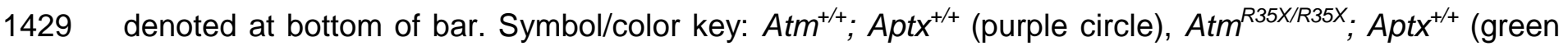
1430 triangle), Atm $^{R 35 X /+} ; A p t X^{-/}$(red inverted triangle), Atm ${ }^{R 35 X / R 35 X} ;$ Aptx ${ }^{-/}$(orange square) Figure 6/7-source 1431 data

1432 Figure 7. ATM and APTX deficiency confer deficits in T-cell expression, but at different 1433 developmental stages. A) Representative flow cytometric profiles of T-cell glycoprotein markers CD44 1434 and CD25 gated on $\mathrm{CD}^{-} \mathrm{CD} 8^{-}$double negative (DN) cells. Summary plots show proportions of 1435 thymocytes at DN stages 1-4 (left to right). APTX deficient mice display increased proportions for DN1- 
Perez et al. Resubmission

14363 and decreased proportion at DN4 consistent with a deficit in ontogeny from DN3 to DN4. B) 1437 Representative flow cytometric profiles of T-cell glycoprotein markers CD4 and CD8 gated. ATM 1438 deficient mice display decreased proportions for CD4 and CD8 single positive cells consistent with a 1439 deficit in ontogeny from $\mathrm{CD} 4^{+} \mathrm{CD} 8^{+}$double positive to $\mathrm{CD} 4^{+}$and $\mathrm{CD} 8^{+}$single positive fates. Statistical 1440 significances were assessed via 1-way ANOVA followed by posthoc Tukey's pairwise multiple 1441 comparisons tests. Number of animals denoted at bottom of bars. Symbol/color key: Atm $^{+/+}$; Aptx $^{+/+}$

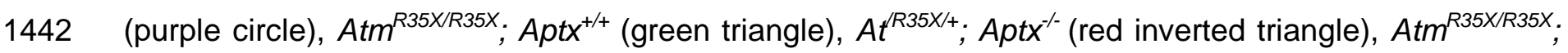
$1443 \operatorname{Aptx}^{-/}$(orange square)

1444 Figure 8. ATM protein expression is restored after readthrough compound exposure in explant

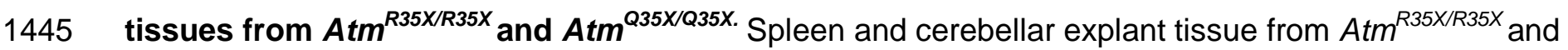
$1446 \mathrm{Atm}^{+/ t}$ mice were treated with vehicle, the readthrough compounds G418 $(100 \mu \mathrm{M})$, or GJ103 $(100 \mu \mathrm{M})$ 1447 for 72 hrs. ATM immunoblots show recovery of ATM (MW $350 \mathrm{kDa})$ production in both the spleen $(\mathrm{n}=2)$ 1448 and cerebellum $(\mathrm{n}=3$ ). Equal loading was assessed via housekeeping genes (Actin or GAPDH) and 1449 ponceau staining. Figure 8-source data

\subsection{Source files}

Figure 2- source data. Weight, age of death, and probable cause of death

Figure 3-source data. Raw behavior data

Figure 4-source data. Electrophysiological data

Figure 5- source data. Individual average firing frequencies for each recorded cell; Individual CV for each recorded cell; Brain area

Figure 6/7- source data. Tables of FACs data

Figure 8-source data. Western blot measurements

1460 Video 2. Pole test, Aptx $^{+/+}$vs. Aptx $^{-/}$. Aptx ${ }^{-/-}$mice do not display an ataxic phenotype at P460.

1461 Video 3. Pole test, $\mathbf{A t m}^{+/+} ; \mathbf{A p t x}^{+/+}$vs. $\mathbf{A t m}^{\text {R35X/R35X }} ; \mathbf{A p t x}^{-/-}$. Atm $^{R 35 X / R 35 X} ;$ Aptx $^{-/-}$have considerable 1462 motor disability at P460.

1463 Video 4. Open field, Atm $^{+/+} ; \boldsymbol{A p t x}^{+/+}$vs. Atm $^{\text {R35X/R35X }} ; \boldsymbol{A p t x}^{-/-}$. Atm ${ }^{R 35 X / R 35 X} ;$ Aptx $x^{-/-}$display a clear 1464 inability to ambulate in the open field at P460. 
bioRxiv preprint doi: https://doi.org/10.1101/2020.11.23.394098; this version posted June 28, 2021. The copyright holder for this preprint (which was not certified by peer review) is the author/funder. All rights reserved. No reuse allowed without permission.

\section{Perez et al. Resubmission}

\section{5}

1466

1467

1468 
Fig. 2

A

$\rightarrow A t m^{+/+} ; A p t x^{+/+}$

$\rightarrow \mathrm{Atm}^{+/+} ;$Aptx $^{-/-}$

$-A t m^{R 35 X / R 35 X} ;$ Aptx ${ }^{+/+}$

- Atm R35X/R35X; Aptx ${ }^{-/-}$

$\rightarrow A t m^{R 35 X /+} ; A p t x^{-/-}$

* Atm R35X/R35X; Aptx $^{+/-}$

- $A t m^{R 35 X /+} ; A p t x^{+/+}$

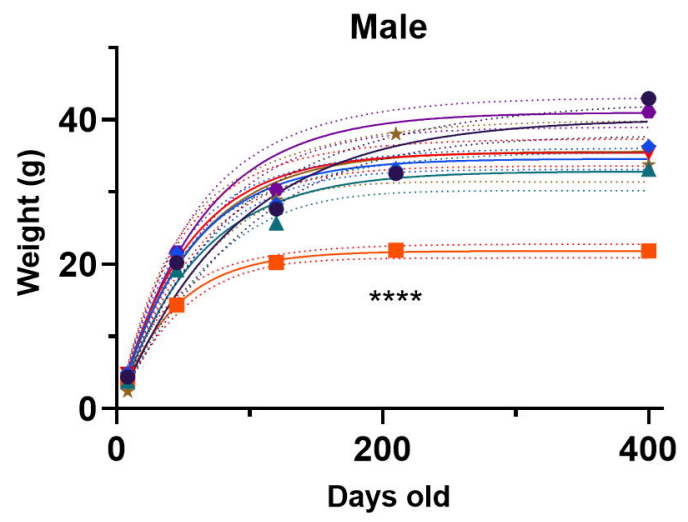

B
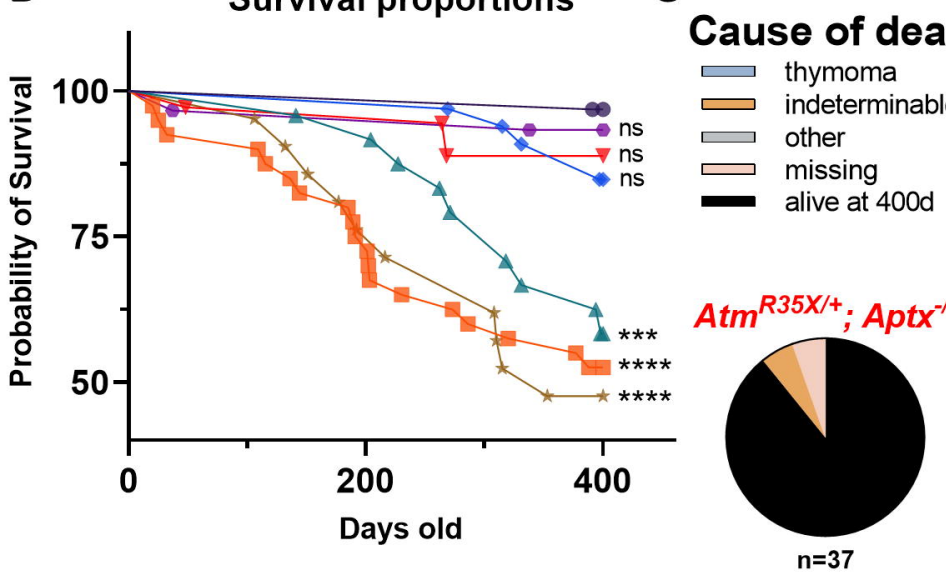

C Cause of death

$\square$ thymoma

$\Longleftarrow$ indeterminable

$\square$ other

missing

alive at $400 \mathrm{~d}$

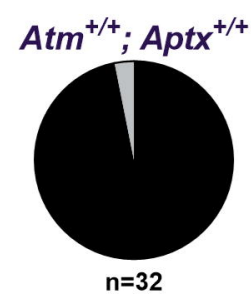

Female

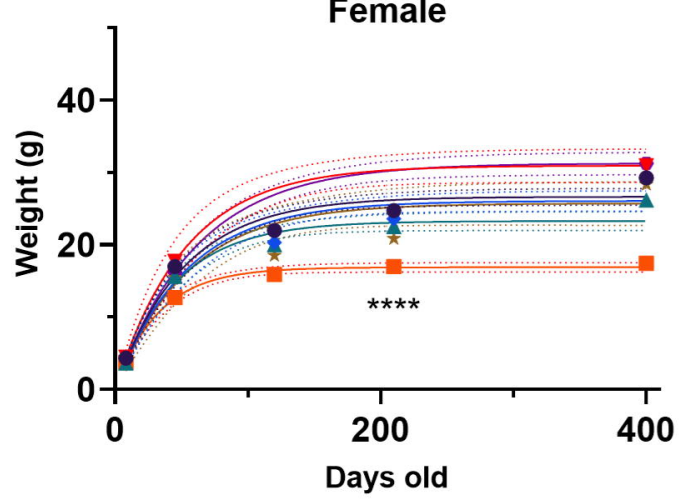

$A t m^{R 35 X /+} ; A$ tx $^{+/+}$

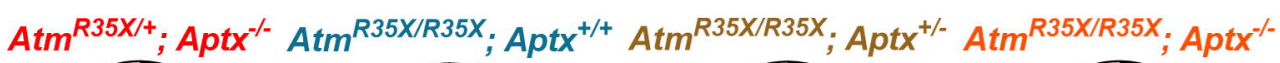
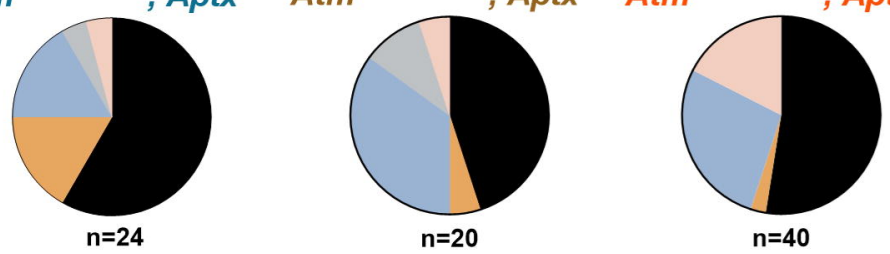
Fig. 3

A

$\rightarrow \mathrm{Atm}^{+/+} ; \mathrm{Aptx}^{+/+} \longrightarrow \mathrm{Atm}^{\text {R35X/R35X}} ; \mathrm{Aptx}^{-/-}$

$\rightarrow \mathrm{Atm}^{+/+} ; \mathrm{Aptx}^{-/-} \rightarrow \mathrm{Atm}^{R 35 \mathrm{X} / \mathrm{R} 35 \mathrm{X}} ; \mathrm{Aptx}^{+/+}$ $\rightarrow A t m^{R 35 X /+} ;$ Aptx ${ }^{-/-}$

Pole test
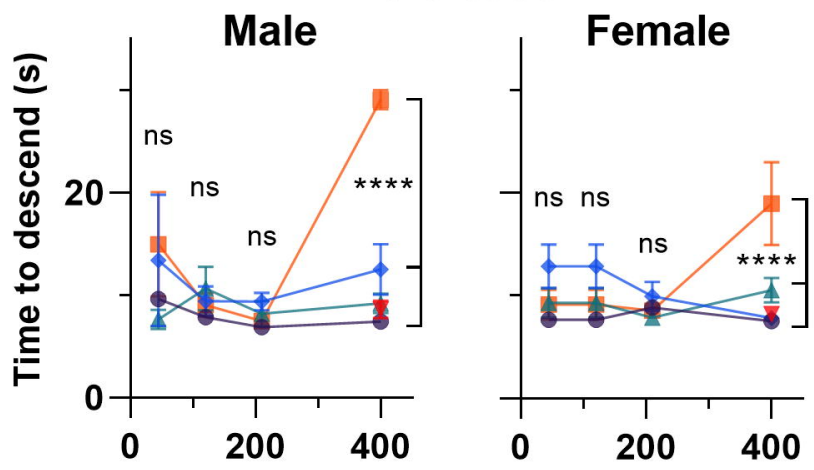

B
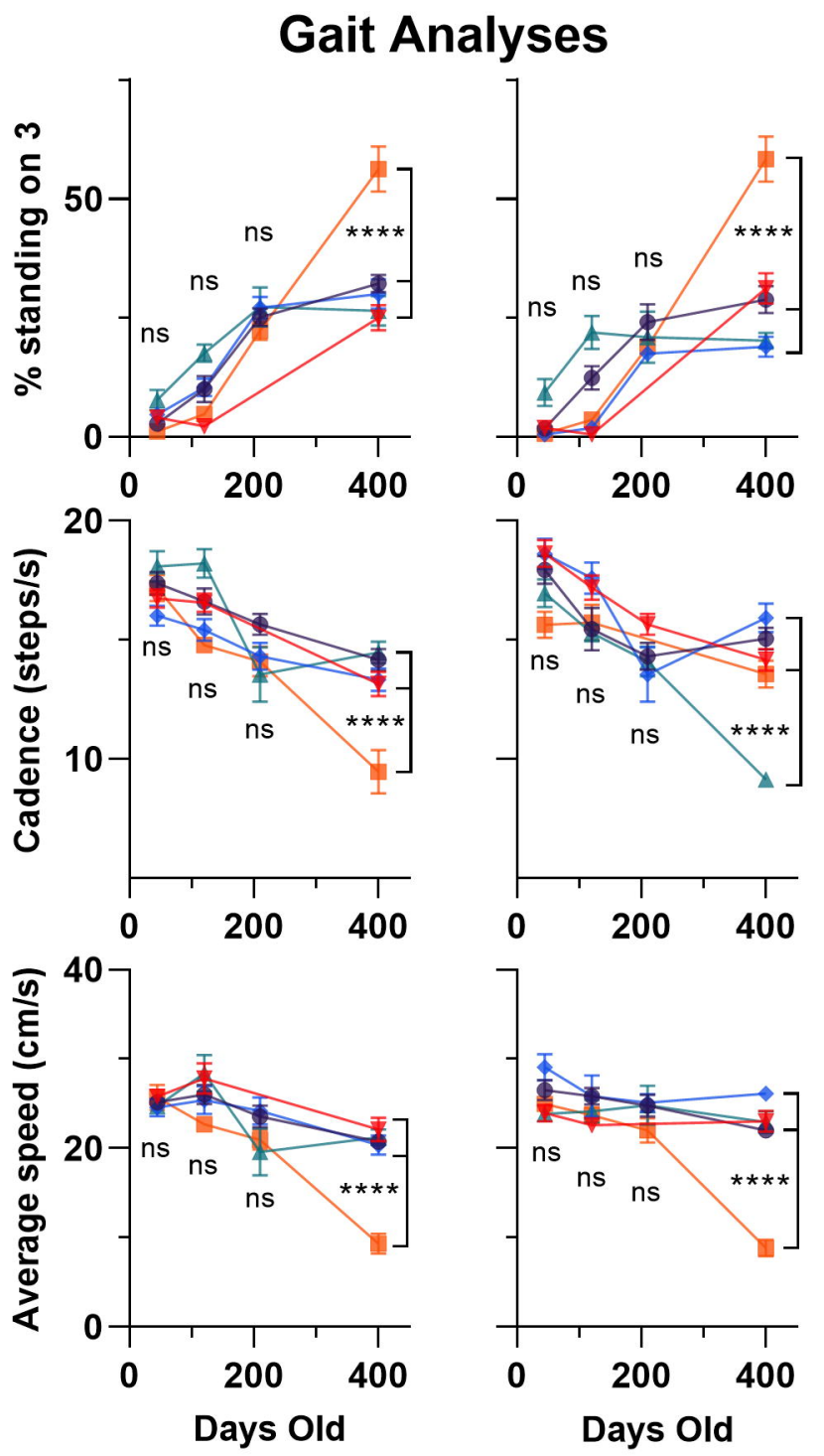

C

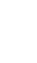

\section{SHIRPA}

30 Days old $\mathrm{Atm}^{+/+} \quad \mathrm{Atm}^{\mathrm{R} 35 \mathrm{X} / \mathrm{R} 35 \mathrm{X}} \quad \mathrm{Atm}^{+/+} \mathrm{Atm}^{\text {R35X/R35X }}$ $\mathrm{Aptx}^{+/+} \quad \mathrm{Aptx}^{-/-} \quad \mathrm{Aptx}^{+/+} \mathrm{Aptx}^{-/-}$
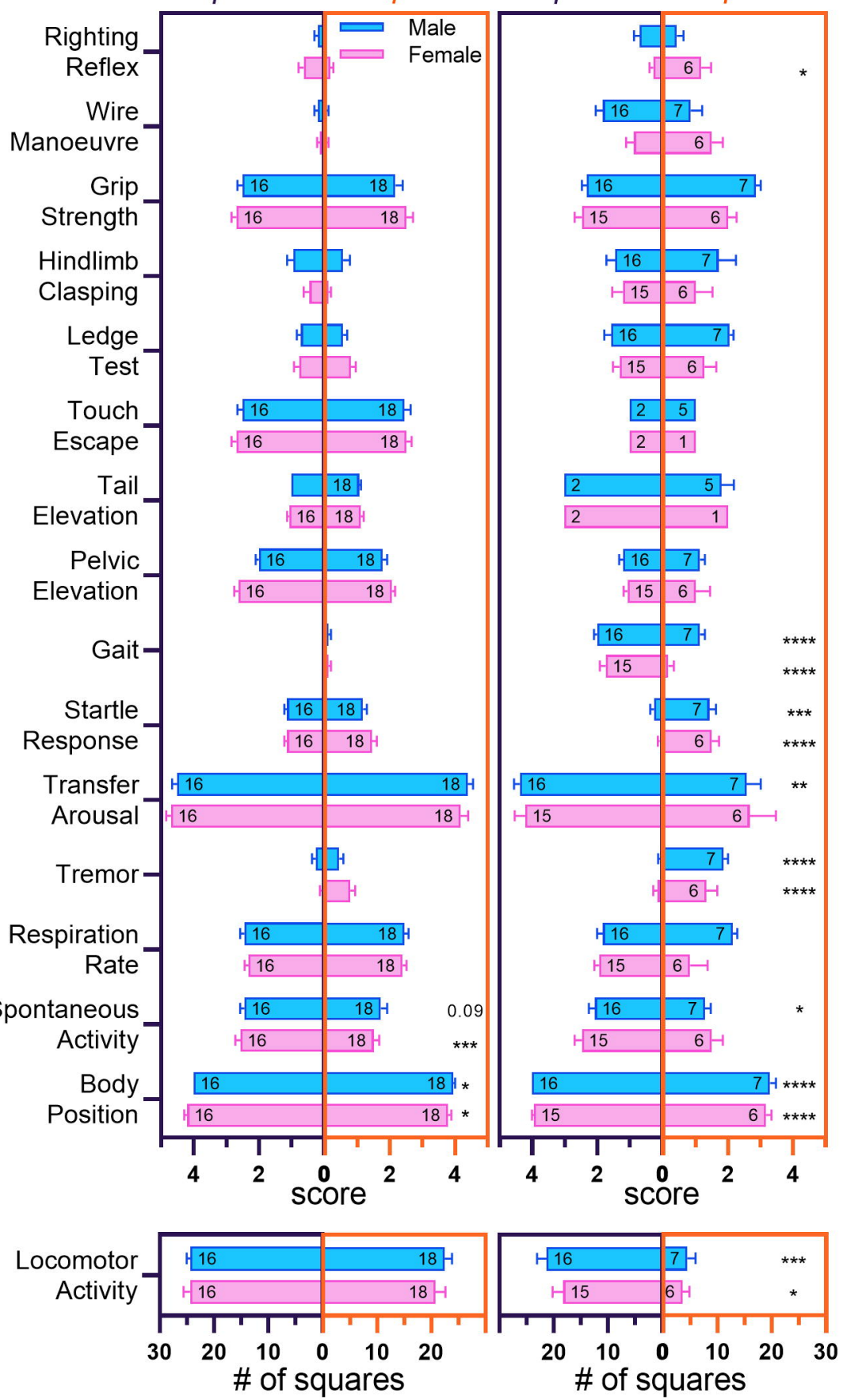

Postnatal (P8) Righting Reflex

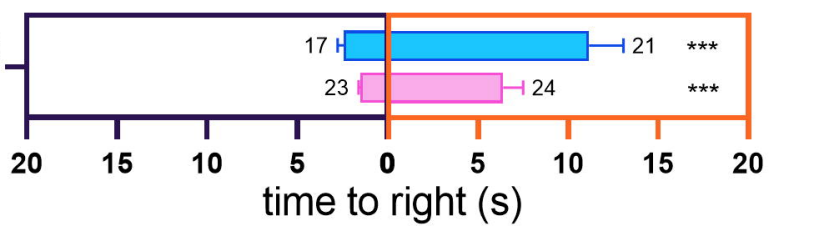


Fig. 4

A

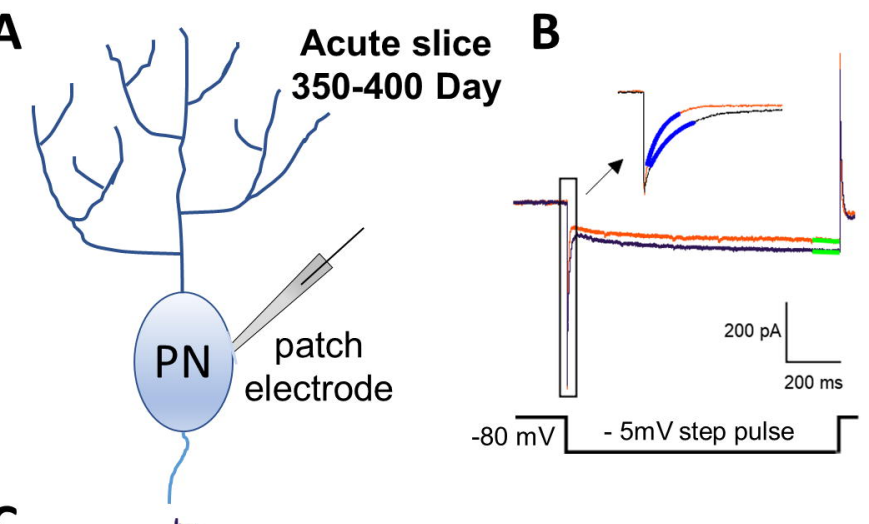

C

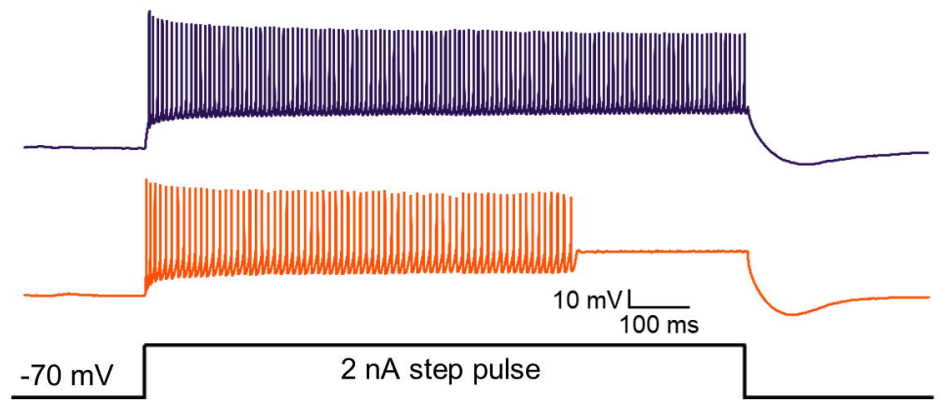

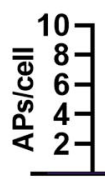

E

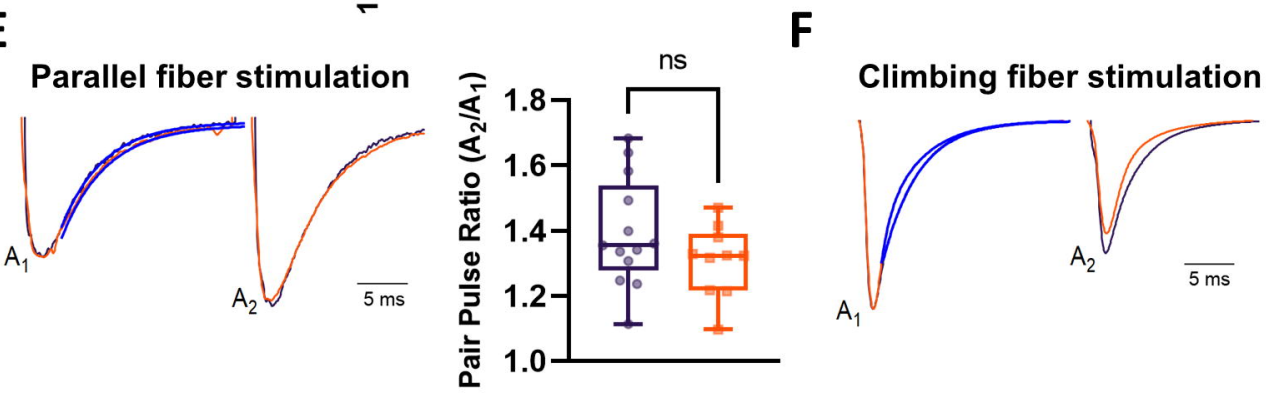

$\mathrm{Atm}^{+/+} ; \mathrm{Aptx}^{+/+} \quad-\mathrm{Atm}^{\mathrm{R} 35 \mathrm{X} / \mathrm{R} 35 \mathrm{X}} ; \mathrm{Aptx}^{-/-}$ Membrane properties
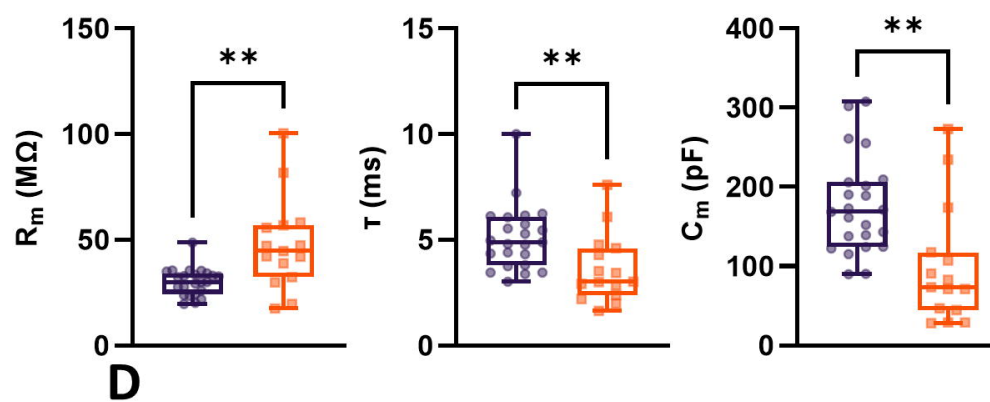

\section{mEPSC}

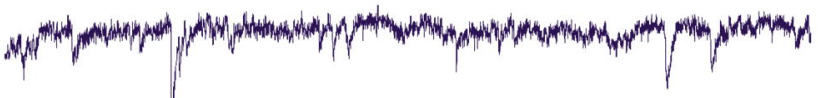

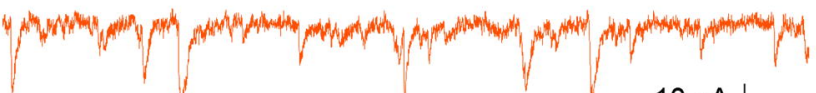

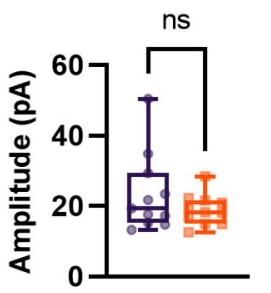

$10 \mathrm{pA} \mathrm{L}$ $100 \mathrm{~ms}$
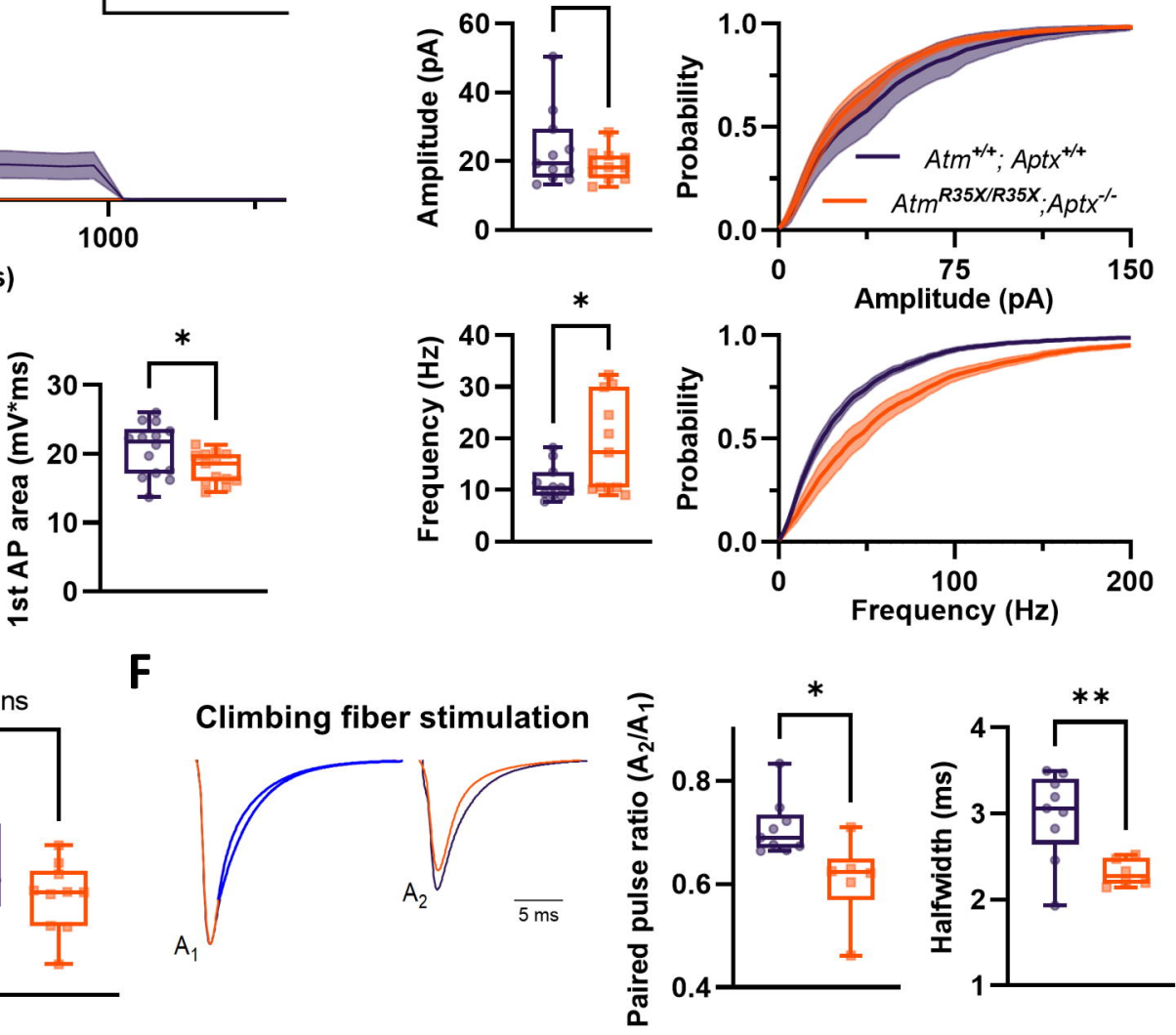
Fig. 5

A

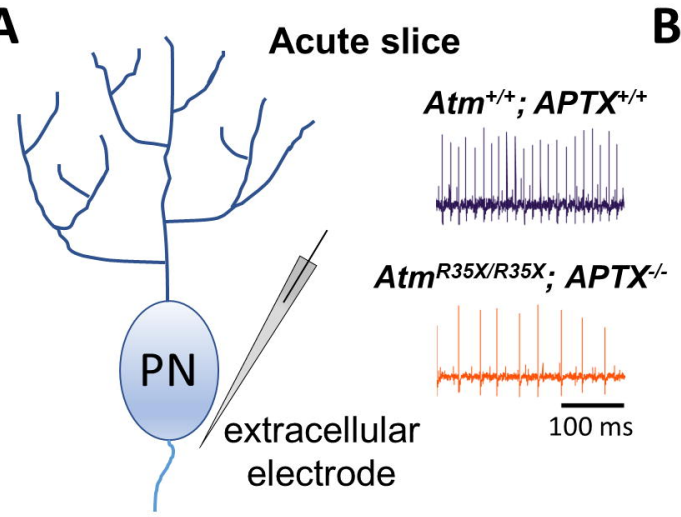

C

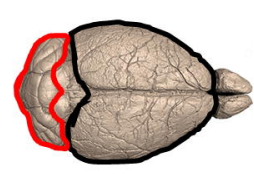

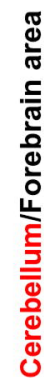

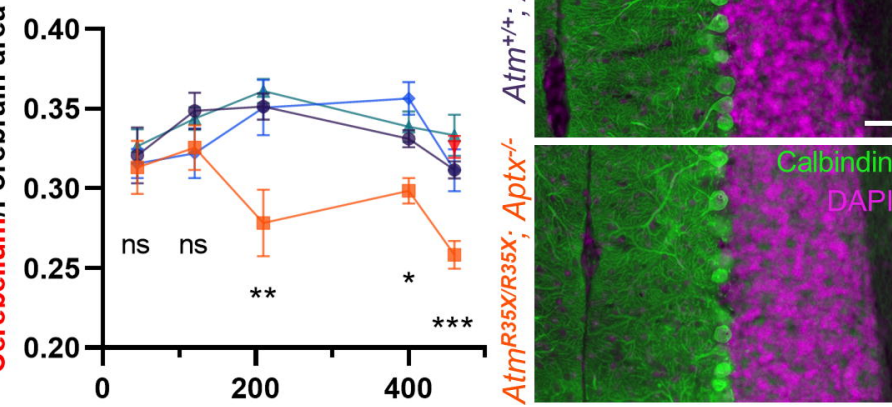

Days old

B $-\mathrm{Atm}^{+/+} ; \mathrm{Aptx}^{+/+} \rightarrow \mathrm{Atm}^{\mathrm{R} 35 \mathrm{X} / \mathrm{R} 35 \mathrm{X}} ; \mathrm{AptX}^{+/+} \rightarrow \mathrm{Atm}^{+/+} ; \mathrm{Aptx}^{-/-}$ $\rightarrow A t m^{R 35 X /+} ; A p t x^{-/-} \quad-\quad A t m^{R 35 X / R 35 X} ; A^{-1 /-}$

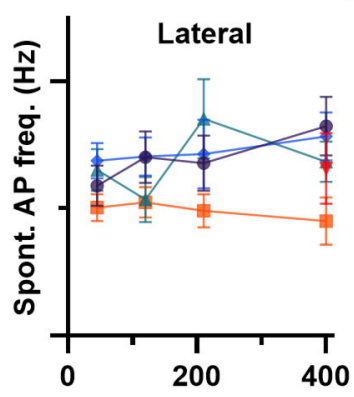

Days old

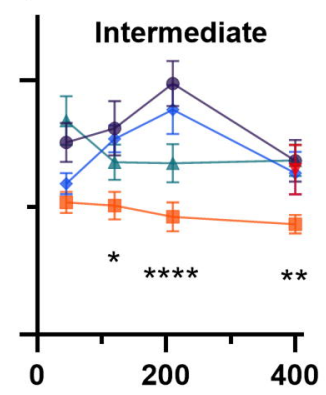

Days old
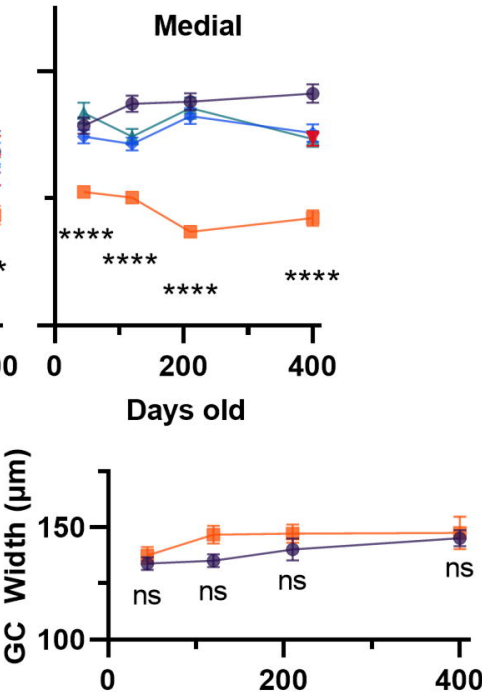

Days old

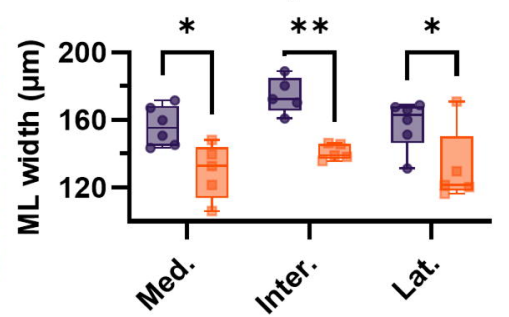

400 days old

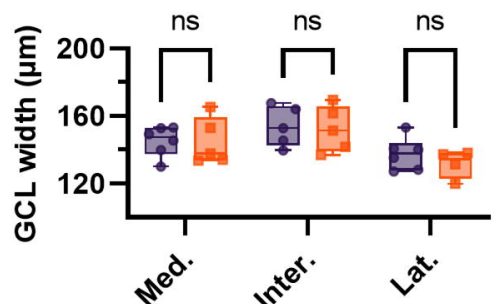

400 days old 
Fig. 6

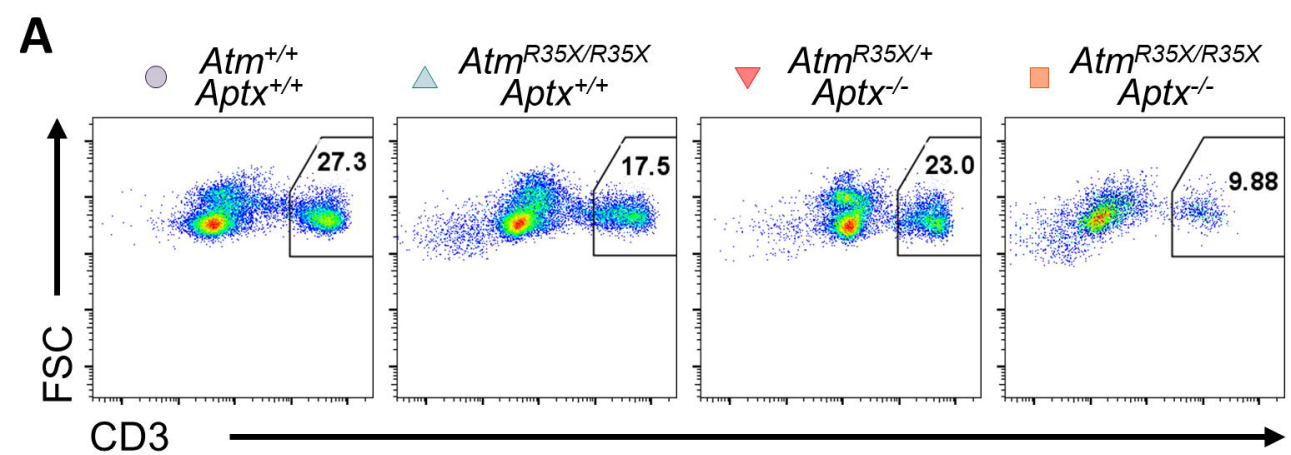

B

Gated on $\mathrm{CD}^{+}$

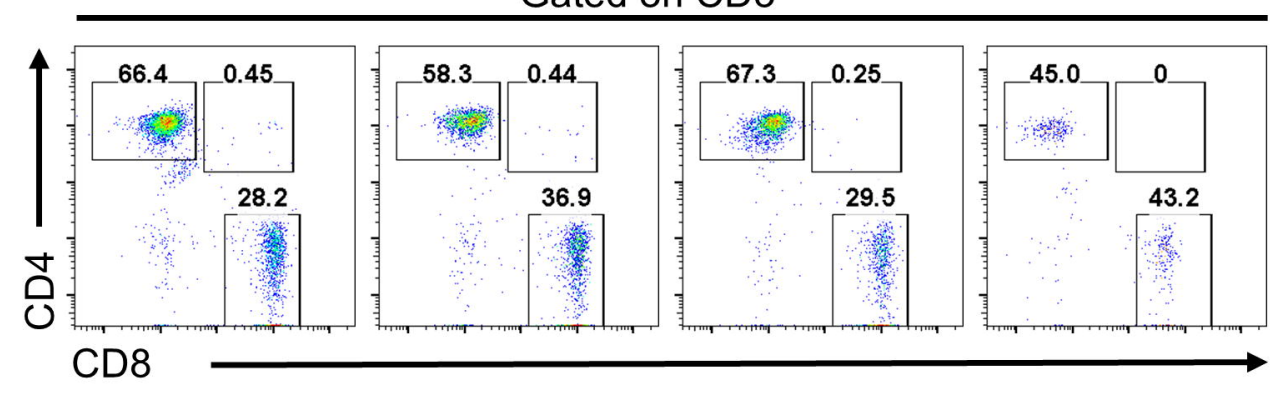

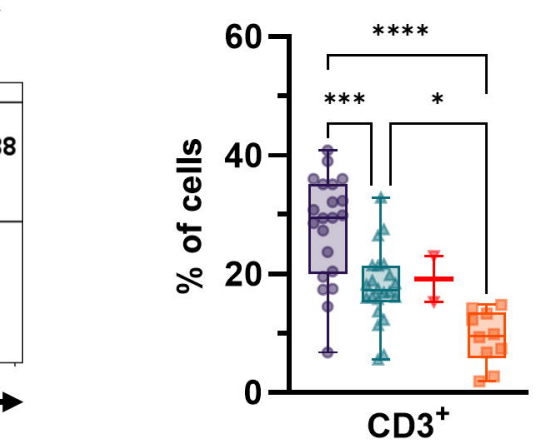
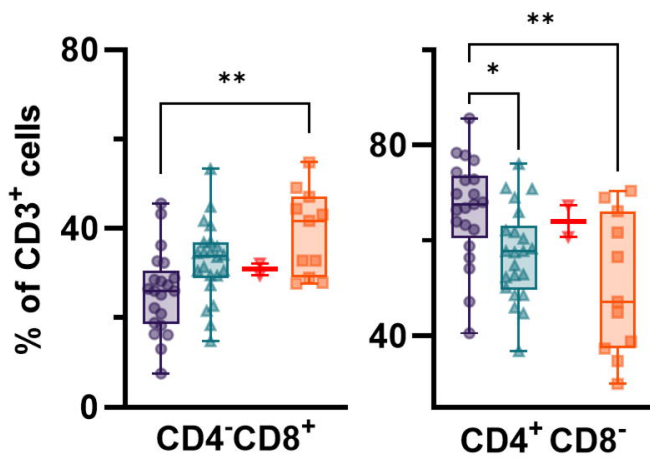
Fig. 7

A

Gated on CD4- CD8-

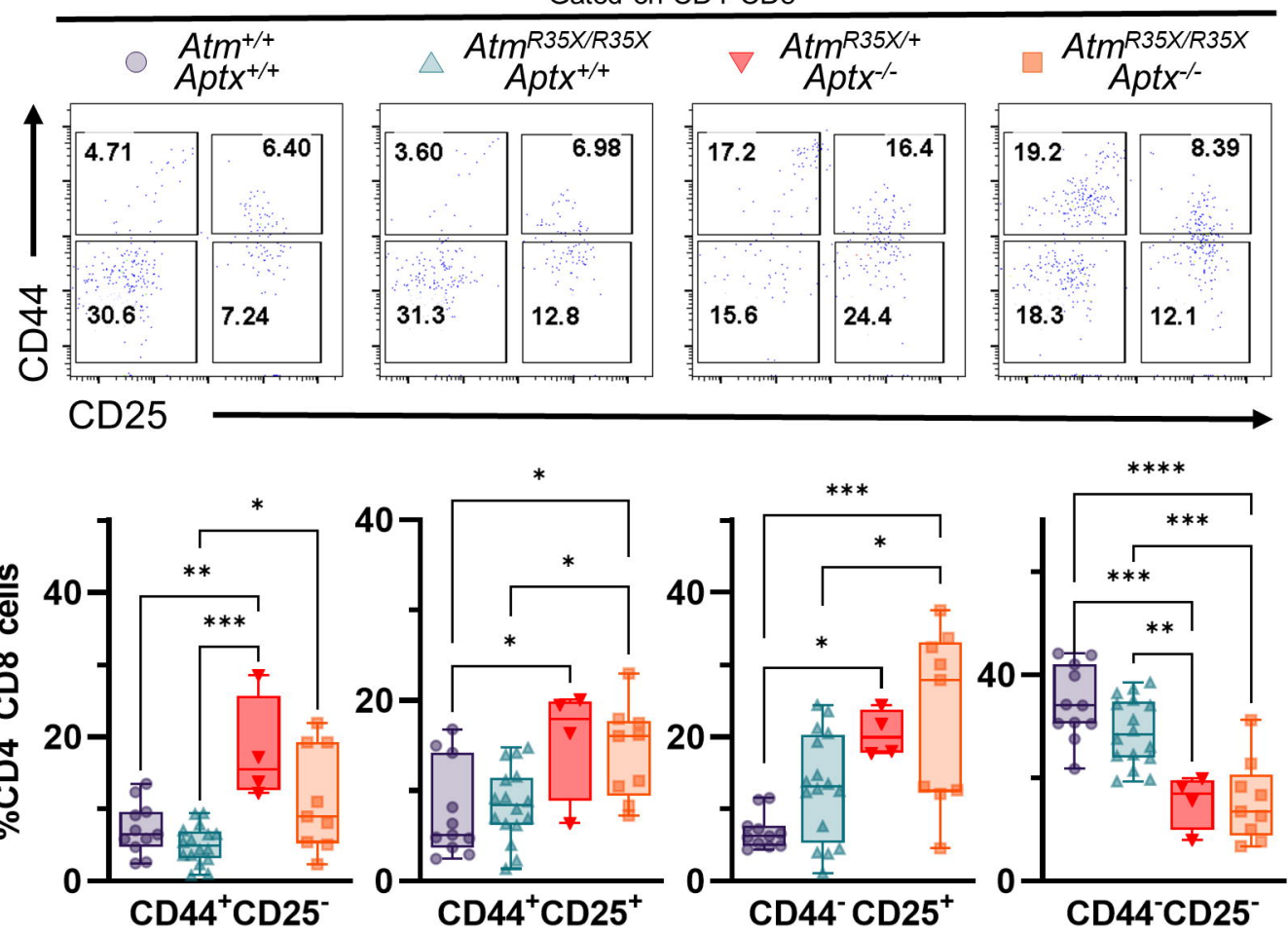

B
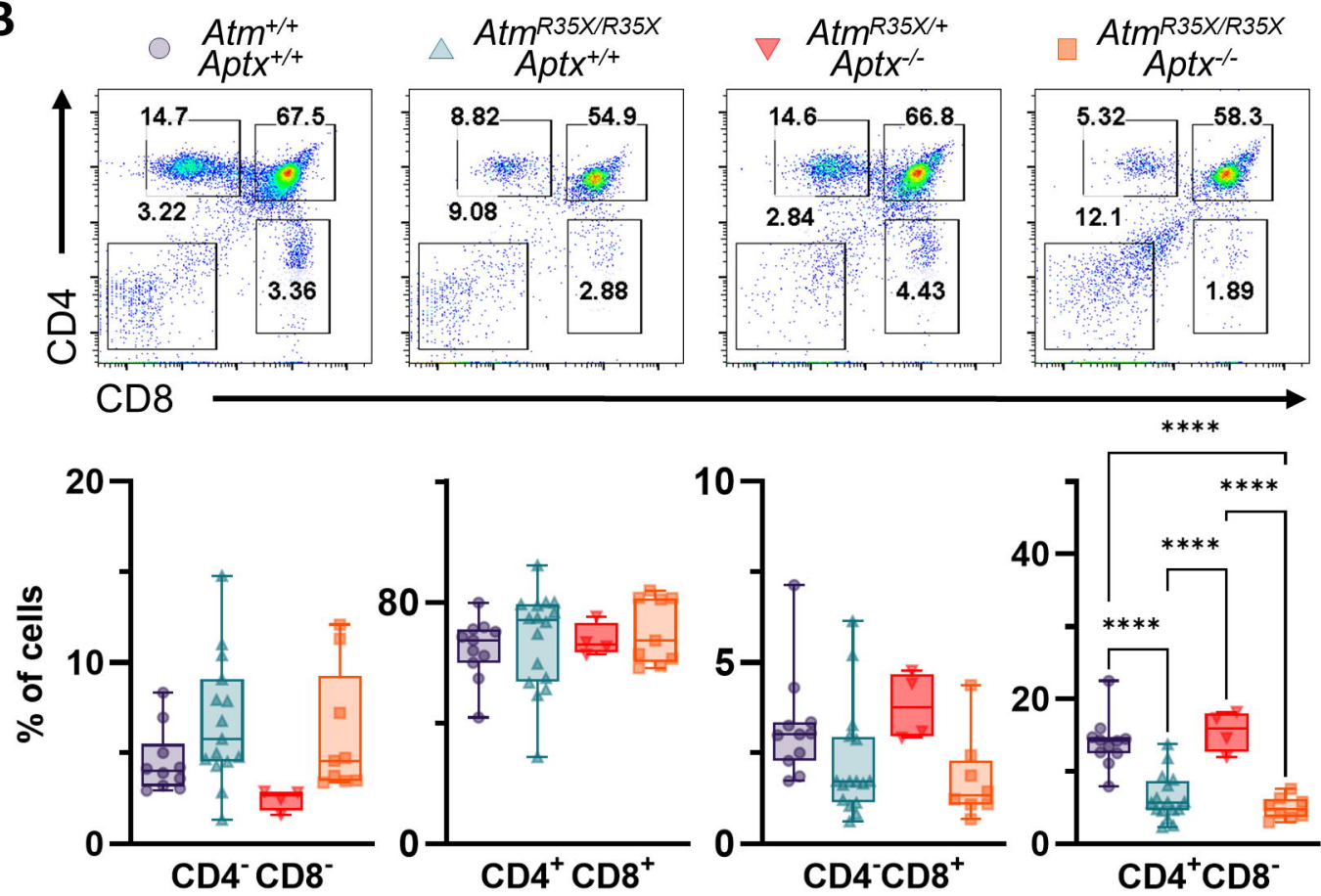
Fig. 8

Spleen
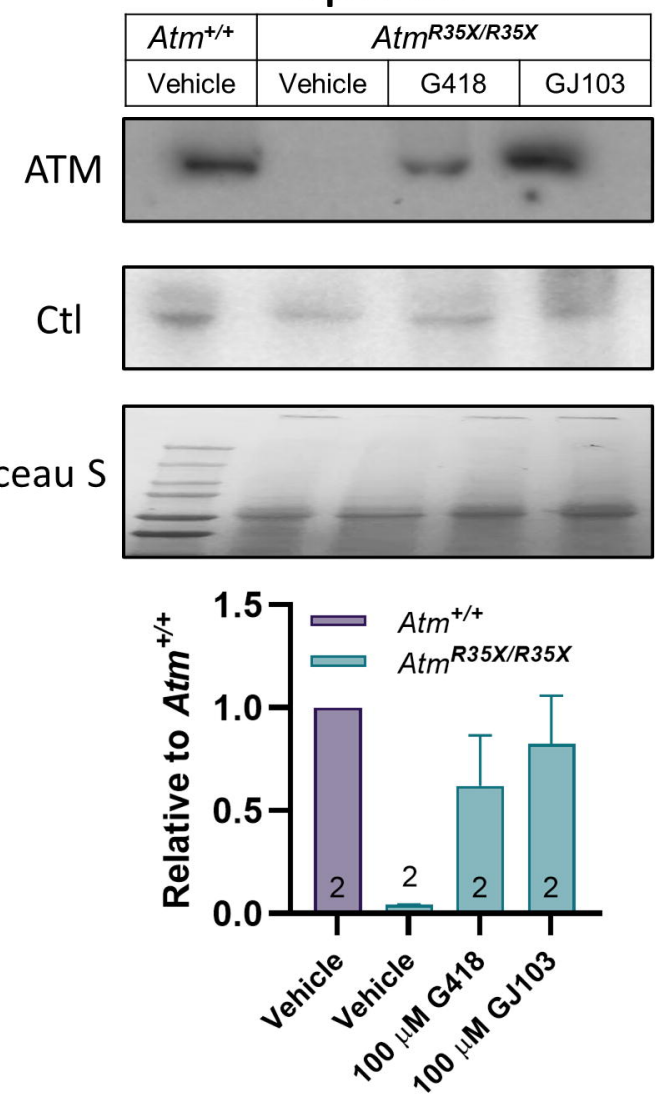

Cerebellum

\begin{tabular}{|l|c|c|c|}
\hline Atm $^{+/+}$ & \multicolumn{3}{|c|}{ Atm $^{R 35 X / R 35 X}$} \\
\hline Vehicle & Vehicle & G418 & GJ103 \\
\hline
\end{tabular}
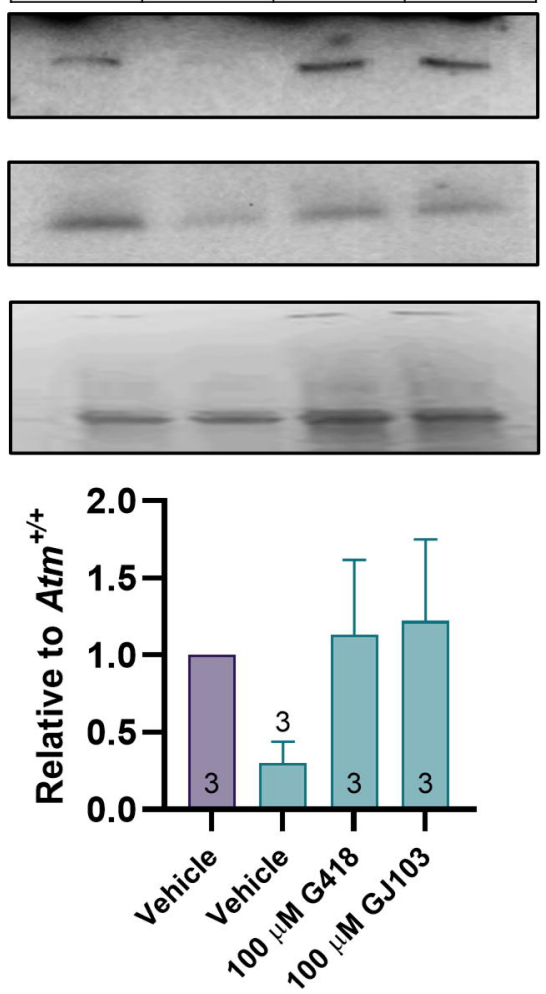

Spleen
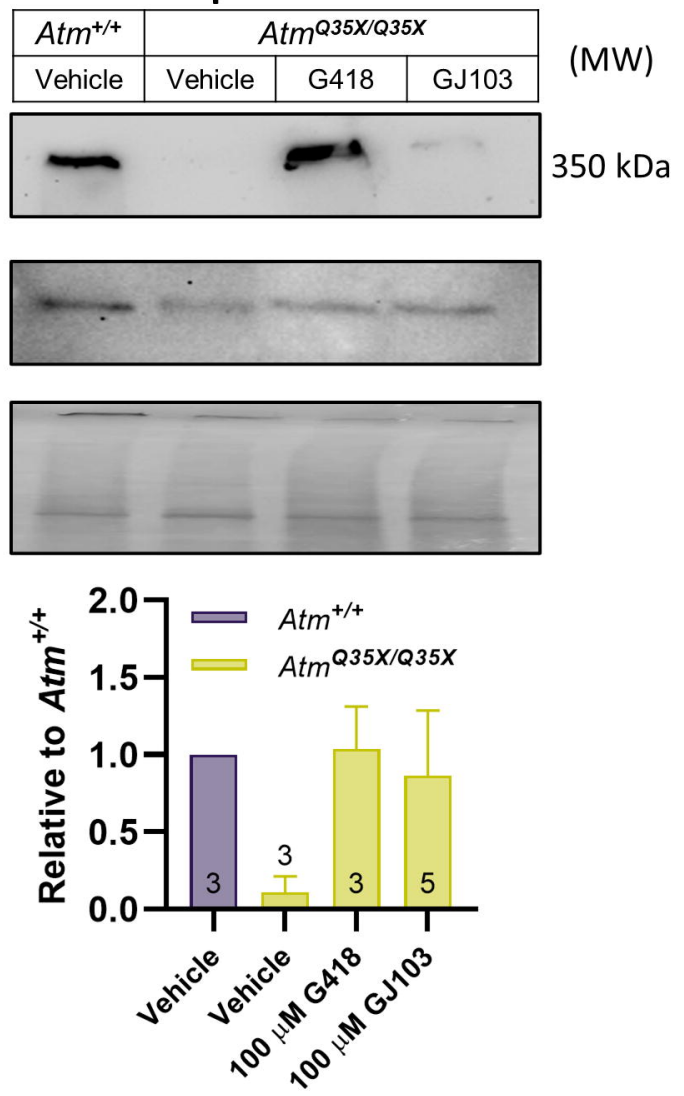